WSRC-TR-93-085

\title{
FLOWTRAN-TF User Guide (U)
}

\author{
G. P. Flach, S. Y. Lee \& S. E. Aleman
}

Westinghouse Savannah River Company

Savannah River Site

Aiken, SC 29808 


\section{DISCLAIMER}

This report was prepared by Westinghouse Savannah River Company (WSRC) for the United States Department of Energy under Contract No. DE-AC09-89SR18035 and is an account of work performed under that contract. Neither the United States Department of Energy, nor WSRC, nor any of their employees makes any warranty, expressed or implied, or assumes any legal liability or responsibility for accuracy, completeness, or usefulness, of any information, apparatus, or product or process disclosed herein or represents that its use will not infringe privately owned rights. Reference herein to any specific commercial product, process, or service by trademark, name, manufacturer or otherwise does not necessarily constitute or imply endorsement, recommendation, or favoring of same by WSRC or by the United States Government or any agency thereof. The views and opinions of the authors expressed herein do not necessarily state or reflect those of the United States Government or any agency thereof. 
WSRC-TR-93-085

FLOWTRAN-TF User Guide (U)

G. P. Flach, S. Y. Lee \& S. E. Aleman

Publication Date: February, 1993

Westinghouse Savannah River Company

Savannah River Site

Aiken, SC 29808 
TASK NUMBER: 89-021-1

DOCUMENT TITLE: FLOWTRAN-TF User Guide (U)

DOCUMENT NUMBER: WSRC-TR-93-085

REVISION NUMBER: 0 


\section{Acknowledgements}

The FLOWTRAN-TF code development effort was initiated in early 1989. Several members of the Code Development Group have contributed to FLOWTRAN-TF development as summarized alphabetically below:

Contributor

Sebastian Aleman

Roger Cooper

Greg Flach

Larry Hamm

Andrea Kielpinski

Larry Koffman

Si Young Lee

Andy Shadday

Frank Smith

\section{Principal Contributions}

Axial wall drag, neutronic power distribution, splines, code architecture, documentation, coding, graphics, testing

Coding, graphics

Program leadership, interfacial drag, axial wall drag, phase transition logic, fluid finite-differencing and solution methods, equations of state, documentation, coding, testing, benchmarking

Program concept, initiation and leadership, all aspects of physical model development and computational implementation, interfacial heat and mass transfer, code architecture, coding, testing, benchmarking

Interfacial heat and mass transfer coefficients, flow regime map, documentation

Documentation

Channel inlet void distribution, CCFL correlation, inter-subchannel mixing, interfacial heat and mass transfer coefficients, rib void model, equations of state, documentation, coding, testing, benchmarking

Azimuthal wall drag, documentation, testing

Solid heat conduction, neutronic power distribution, wall heat transfer, interfacial heat and mass transfer, fluid finite differencing and solution methods, code architecture and $\mathrm{I} / \mathrm{O}$, documentation, coding, testing, benchmarking

The developers are grateful to the many technical reviewers of FLOWTRAN-TF. These include Ken Moore, Garry Gose, Ken Katsma and M. Paulsen of Computer Simulation \& Analysis, Inc. and Steve Hensel and Jeff Jerrell of WSRC. The helpful suggestions of the DOE Independent Review Panel (DIRP) are also appreciated.

The developers also appreciate the support of the DOE, former WSRC Nuclear Engineering Section manager Ken Huffman and present manager Al Garrett, and former Code Development Group managers Larry Hamm and Bill Horton and current manager Dave Crowley. 
This page intentionally left blank 


\section{Table of Contents}

GENERAL CODE CAPABILITIES AND INPUT OPTIONS .........................

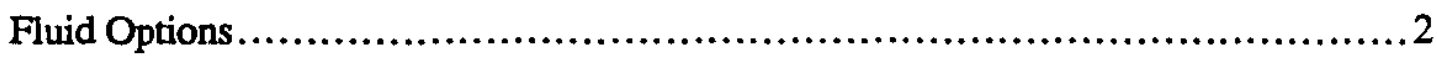

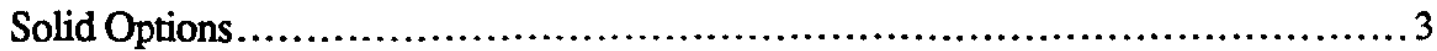

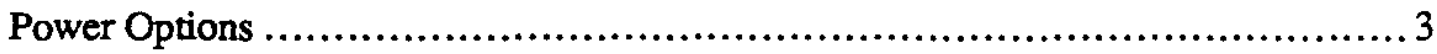

Numerical Considerations ....................................................... 4

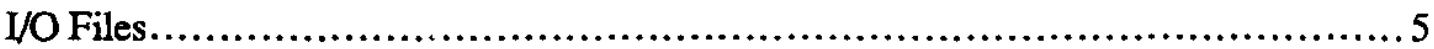

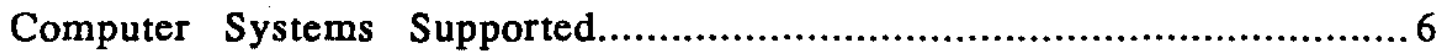

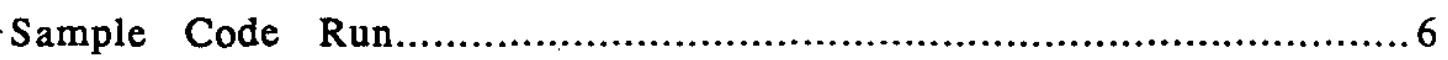

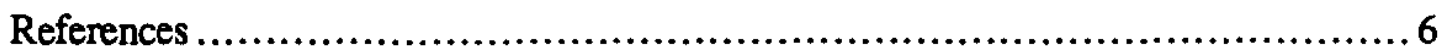

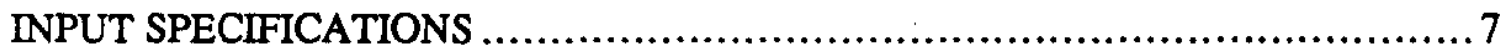

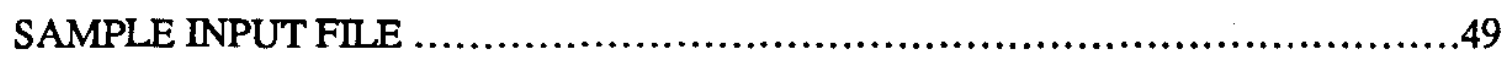

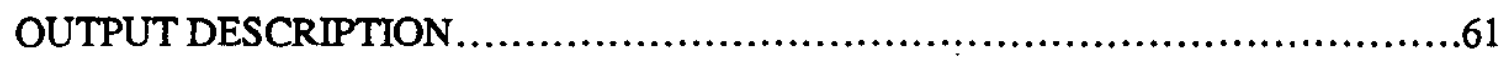

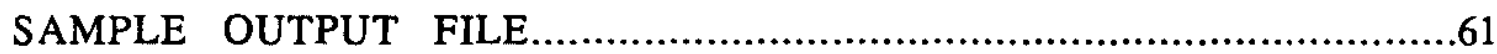


This page intentionally left blank 
Detailed instructions and guidelines to aid users in constructing and interpreting FLOWTRAN-TF input and output files are given in this report for version 1.2 of the source code. The user is assumed to be familiar with the FLOWTRAN-TF Software Design report, SRS fuel assembly hardware, and two-phase flow. The FLOWTRAN-TF code proprietor is responsible for defining formal training requirements and user qualifications. FLOWTRAN-TF reference documents include

- FLOWTRAN-TF Code Development Technical and QA Plan, Rev. 0 (Flach, 1991)

- FLOWTRAN-TF Software Requirements Specification, Rev. 1 (Flach, 1993a)

- FLOWTRAN-TF Software Test Plan, Rev. 1 (Flach, 1993b)

- "FLOWTRAN-TF Software Design (U)", WSRC-TR-92-532 (Aleman et al., 1993a)

- "FLOWTRAN-TF Software Testing (U)", WSRC-TR-93-084 (Aleman et al., 1993b)

- "FLOWTRAN-TF v1.2 Source Code (U)", WSRC-TR-93-086 (Aleman et al., 1993c)

This User Guide satisfies the requirements of Quality Assurance Procedure QAP IV-4, Rev. 0 "Software Design and Implementation" in the 1Q34 manual.

The User Guide is divided into three parts. First, general code capabilities and input options are summarized. Then, detailed instructions for creating and interpreting code input files are given next. Also, a sample input deck and corresponding output files are listed for reference and illustration. Variable and subroutine names as well as input values are denoted by the Courier typeface in general.

\section{General Code Capabilities and Input Options}

FLOWTRAN-TF is a two-phase thermal-hydraulics code of similar technology to existing commercial reactor codes such as RELAP and TRAC but customized for Savannah River Site applications. Briefly, the main features and capabilities of FLOWTRAN-TF are

- Detailed Mk22 fuel assembly ribbed annular geometry

- Conjugate heat transfer

- Detailed neutronic power distribution

- Three-dimensional heat conduction in Mk22 fuel and target tubes

- Two-dimensional coolant flow in channels (axial, azimuthal)

- Single-phase and/or two-phase fluid (gas, liquid and/or gas-liquid)

- Two-component (air, water) 
- Constitutive models applicable to low pressure air-water downflow in ribbed annular channels.

The user is referred to the FLOWTRAN-TF Software Design report and Software Requirements Specifications for more information on the intended applications of FLOWTRAN-TF and the software design. The FLOWTRAN-TF Software Design and Software Testing reports define the accuracy and limitations of the code.

The code may be used to simulate solid components, fluid coolant flow and solid-fluid heat transfer, or fluid flow only (adiabatic flow channels). Pure component water or twocomponent air-water flows may be modeled. A variety of materials may be chosen for the solid tubes separating flow channels. FLOWTRAN-TF is fundamentally a transient analysis tool. However, the code is capable of detecting steady-state conditions during a transient calculation. Steady-state results can be easily generated by using the false transient option of the code, also. Fluid and solid conditions at the end of calculation may be saved in a restart file. The restart file may be binary, which saves the exact values, or ASCII, which allows the restart file to used across computer systems. Calculations may start from user specified initial conditions or from a previously saved restart file. The user may choose between fixed power calculations or iterative power calculations. For iterative power calculations, FLOWTRAN-TF searches automatically for the power which satisfies user specified thermal-hydraulic criteria. Sensitivity analyses involving important code parameters may be performed through input. Time and spatially varying quantities are specified through either linear or cubic splines giving the user great flexibility. FLOWTRAN-TF is maintained on VAX, CRAY and IBM 6000 computer systems.

\section{Fluid Options}

The fluid computational mesh capabilities are fully discussed in the FLOWTRAN-TF Software Design report. The user has sufficient flexibility in specifying the coolant channel geometry to model existing fuel assemblies and experimental rigs. The code is basically capable of handling thermal-hydraulic problems in a cylindrical channel geometry. The fluid mesh is comprised of Top, Middle and Bottom sections. The Top and Bottom sections are one-dimensional ( $\mathrm{z}$ coordinate). The Middle section most generally contains multiple flow channels, each with axial and azimuthal discretization $(z, \theta$ coordinates respectively). As special cases, the Middle section may be a single, one-dimensional channel, multiple one-dimensional channels, or a single two-dimensional channel, among others. The convention for the positive directions in the $\mathbf{x - z}$ coordinate system is clockwise azimuthally and downward axially. Cell lengths, flow areas, hydraulic parameters may generally vary arbitrarily throughout the mesh. Notable exceptions are the axial cell lengths in the Middle section. Here the azimuthal cells of all channels must share a common axial discretization scheme (which is not necessarily uniform).

Axial cell numbers in the Top and Bottom sections start with 1 and end with $n z t$ and $n z b$, respectively. The user should be aware that two different numbering schemes are used for the Middle section axial cells. The Middle section computational mesh contains 2 extra rows of axial cells, called 'fictitious' cells, which overlap the last cell of the Top section and first cell of the Bottom section. For $\mathrm{nz}$ non-overlapping cells in the Middle section, the internal cell numbering starts with 1 in the upper row of fictitious cells and ends with $\mathrm{nz}+2$ in the lower row of fictitious cells. Error messages and warnings use this internal numbering system. However, the output to units 11 and 20 designates the first nonoverlapping cell by 1 and the last non-overlapping cell by $n z$. That is, the output shifts the axial cell numbers by 1 . 
Several boundary condition options are available as discussed in the FLOWTRAN-TF Software Design report. The basic boundary conditions at the input and outlet are prescribed pressure, void fraction, gas temperature, liquid temperature and air mass fraction. Alternatively, the user may prescribe gas and/or liquid flowrates at the inlet. Initial conditions are basically set by interpolating between the initial boundary conditions for a fresh start, or by using the conditions previously saved in a restart file. For the fresh start, axial velocities are set by a user defined flowrates and azimuthal velocities in the Middle section are set to be zero initially.

Interfacial mass transfer in the bulk fluid and/or at the wall may be turned off through userspecified flags.

All fluid input parameters may be entered in SI dimensional units $\left(\mathrm{m}, \mathrm{m}^{2}, \mathrm{~m}^{3}, \mathrm{~Pa}, \mathrm{~m}^{3} / \mathrm{s}\right.$, ${ }^{\circ} \mathrm{C}$ ) or 'SRS' units (in, in ${ }^{2}$, in ${ }^{3}$, psia, gpm , ${ }^{\circ} \mathrm{C}$ ). The output dimensional units correspond with the chosen input units.

\section{Solid Options}

The solid mesh is comprised of nested tubes creating the annular flow channels of the fluid mesh. The solid cylinders may be discretized axially, radially and azimuthally for a full three-dimensional heat conduction calculation. Special cases include radial, radial-axial and radial-azimuthal calculations however. The fundamental calculation is a transient one. If steady-state conditions are desired, the approach to steady-state can be accelerated by artificially reducing the heat capacity of the solid. The following materials may be chosen from: Uranium, Aluminum, 304L Stainless Steel, Lithium-Aluminum Alloy, UraniumAluminum Alloy, 6063 Aluminum, Macor, Inconel 600 and Flame Sprayed Oxide.

Four wall heat transfer options are available. Options 1 and 2 are complete boiling curves based on the Mikic and Chen correlations, respectively. For options -1 and and 0 only non-boiling forced convection correlations are used regardless of wall temperature. The Sieder-Tate correlation is selected by 0 and the SRS correlation by -1 . The non-boiling forced convection only options are useful for $T_{w a l l} \leq T_{\text {sat }}$ calculations because they typically speed-up the calculation without affecting the final converged power.

\section{Power Options}

The user may choose between detailed neutronic power input applicable to a reactor fuel assembly or abbreviated input adequate for describing an experimental rig. The code is capable of iterating for the pre-incident power which satisfies one or more user selected thermal-hydraulic acceptance criteria. The criteria options are

- Bulk fluid temperature below local saturation temperature $\left(\mathrm{T}_{\text {fluid }} \leq \mathrm{T}_{\mathrm{sat}}\right)$

- Maximum instantaneous metal surface temperature below local fluid saturation temperature (instantaneous $\mathrm{T}_{\text {wall }} \leq \mathrm{T}_{\text {sal }}$ )

- Maximum running time averaged metal surface temperature below local fluid saturation temperature (average $T_{\text {wall }} \leq T_{\text {sal }}$ )

- Counter-current flow limitation correlation not exceeded. 


\section{Numerical Considerations}

During each time advancement, three iterations are performed. At the highest level is the NEWTON iteration which determines converged values for the new time step pressure, void fraction, gas temperature, liquid temperature and air mass fraction. The INNER iteration within the NEWTON iteration determines pressure updates after the fluid equation set has been reduced to a pressure-only problem. Also within the NEWTON iteration is the GAMMA I iteration for bulk fluid interfacial heat and mass transfer rates.

For 2-D fluid calculations in the Middle section the recommended INNER iteration scheme is the alternating axial-azimuthal scheme with coarse mesh rebalance given by ischem = 3 , irebal $=1$ and $\mathrm{ncmr}=1$.

Convergence tolerances and maximum numbers of iteration are specified by the user as discussed in detail below. The user should be aware that the convergence tolerances for the INNER and GAMMAI calculations should be smaller than those for the NEWTON iteration; that is, the NEWTON iteration requires input information more accurate than its requested accuracy. Suggested values are given for each parameter. If highly accurate transient results are desired, the user may want to repeat the computation with smaller values for these quantities to ensure that the convergence criteria are sufficiently small.

The maximum change in the interfacial steam mole fraction and air mass fraction iterates in the GAMMAI and NEWTON iterations is 0.04 . During phase transitions these parameters may change from approximately 0 to 1 or vice versa during a single time-step. Therefore, the maximum number of GAMMAI and NEWTON iterations must exceed 25. A value of 50 is suggested for both.

Phase transitions challenge FLOWTRAN-TF's ability to iterate to a correct solution. For example, in transitioning from single-phase liquid to two-phase flow the air mass fraction goes from 0 to near 1 and the gas temperature goes from the saturation temperature to approximately the fluid temperature as the void fraction goes from 0 to 0.001 . In this sensitive region the NEWTON iteration convergence tolerances may need to be relaxed on $X_{a}$ and $T_{\mathrm{g}}$ to achieve a successful simulation.

Also, since the large changes in $\mathrm{X}_{\mathrm{a}}$ and $\mathrm{T}_{\mathrm{g}}$ cannot be handled by the basic Newton iteration method, FLOWTRAN-TF limits the amount of change of the iterates to prevent a divergent iteration. This 'damped' Newton method is robust and yields a converged solution virtually all the time. However, the method is known to fail occasionally. If problems are encountered in transitioning from single-phase flow to two-phase flow or vice versa, the user should consider whether a 'seed' void fraction of 0.001 or more can be added to the single-phase portion of the simulation without significantly affecting the relevant physics. Then the simulation is two-phase throughout and difficult phase transitions are avoided.

Many FLOWTRAN-TF applications involve sufficiently low liquid flowrates that the liquid forms a pool in the bottom portion of the channel which more or less blocks air throughput. The upper portion of the channel is highly voided. The gas velocity typically oscillates between positive and negative values with an average value near zero. During FLOWTRAN-TF development involving such cases, non-physical values of air mass fraction and sometimes gas temperature were observed on either side of a cell face with a gas velocity switching between positive and negative values between each time step. One cell would have an air mass fraction of 1.000 and the other cell would have a low air mass fraction. Under isothermal room temperature conditions the air mass fraction should be slightly less than one, instead. 
The non-physical values observed are an inherent result of the explicit donoring scheme used by FLOWTRAN-TF. Gas phase properties at cell faces are defined to be the properties of the adjacent cell from which the gas flows at the old time level. The explicit donoring scheme is appropriate if the gas velocity does not change direction between time steps. For occasional velocity reversals, no difficulties are encountered. If the velocity reverses for every time step the explicit donoring scheme is not appropriate as the Figure 1 illustrates. Figure 1 shows a two cell sealed container with a two-phase air-water mixture present. The gas velocity is shown to reverse from time step to time step. The air mass fractions are initialized to different values. Mass transfer between the liquid and gas phases of water is neglected for the moment. For time step $n+1$ the lower cell air mass fraction stays the same because the incoming flow and the lower cell both have the same $X_{\mathrm{a}}$. The upper cell air mass fraction decreases because the outgoing $X_{a}$ is greater than the upper cell $X_{\mathrm{a}}$. For the $n+2$ time step, the upper cell remains unchanged while $X_{a}$ increases in the lower cell. As the process continues, the air mass fractions diverge unbounded with nonphysical results as the outcome.
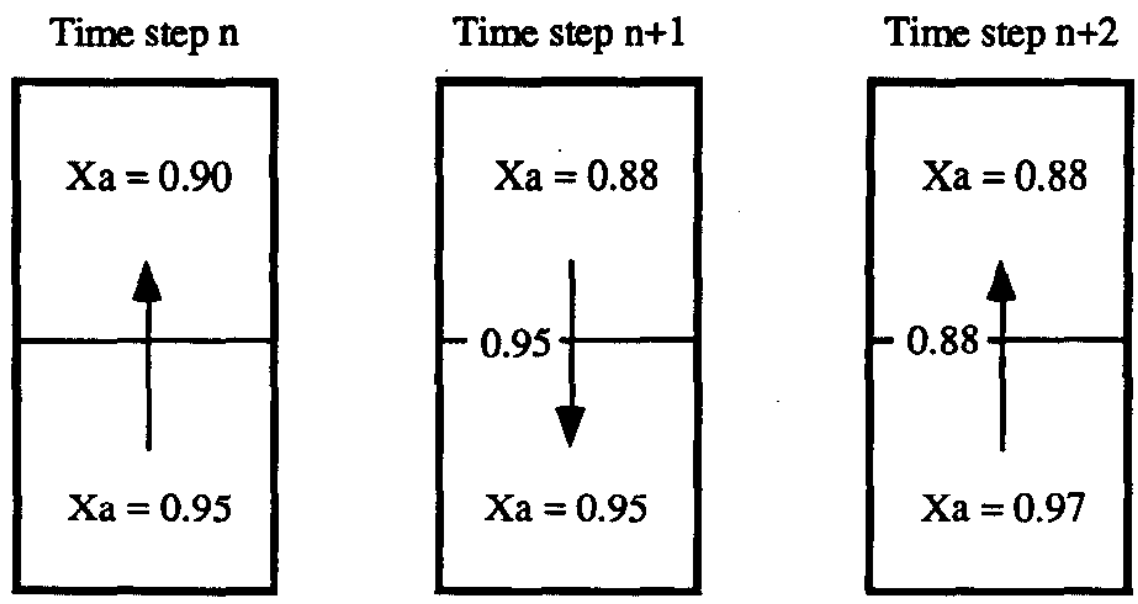

Figure 1

Illustration of continuous velocity reversals leading to non-physical results.

Interfacial mass transfer between the liquid and gas phases counteracts the above process. In Figure 1, water vapor will condense in the upper cell and liquid will vaporize in the lower cell tending to bring the air mass fractions back to equilibrium values. Unfortunately, in the annular flow regime the default interfacial mass transfer rates are too small to overcome the process shown in Figure 1. One remedy is to increase the interfacial mass transfer rate by setting $x k g i$ to say 100.0 (see Input Specifications). The gas temperature may also diverge on either side of an oscillating gas velocity. One remedy is to increase the interfacial gas side heat transfer rate by setting xhgi to say 10.0 (see Input Specifications).

The time step is usually limited by the numerical stability constraint or the solution accuracy control logic of subroutine ACCCHK. If a very small solution accuracy tolerance (tol parameter) is specified the computational effort will increase due to small time steps.

\section{I/O Files}

FORTRAN unit numbers for the various data files are assigned by FLOWTRAN-TF to be 
5 primary input file

7 modified primary input file stripped of comments, etc. (scratch file)

8 output binary dump file for post-plotting results

9 input restart file

10 output restart file

11 primary output

20 secondary output

The files associated with units 5,11 and 20 are ASCII formatted. The unit 8 file is binary. The files for units 9 and 10 may be binary or ASCII depending on the option selected. The unit 7 file is a scratch file not accessible to the user. All input data for unit 5 are read in free format. Restart dumps are written and read by unformatted read and write statements.

\section{Computer Systems Supported}

The source code is stored under the VAX CMS system. Configured source and executable versions of the code are maintained under SCMS on the VAX and CRAY computer systems and under NES CMS on the NES IBM 6000 workstations. See the FLOWTRAN-TF code proprietor, the SCMS custodian, and/or the NES CMS custodian for specific information about access controls.

\section{Sample Code Run}

The input deck used to perform VOID Rig benchmarking results for -1 psig plenum pressure, 12" tank level, and $8 \mathrm{gpm}$, and corresponding output, are given below to illustrate typical FLOWTRAN-TF input and output files. The application is fully described in the FLOWTRAN-TF Software Testing report.

\section{References}

Aleman, et al., 1993a, "FLOWTRAN-TF Software Design (U)", WSRC-TR-92-532.

Aleman, et al., 1993b, "FLOWTRAN-TF Software Testing (U)", WSRC-TR-93-084

Aleman, et al., 1993c, "FLOWTRAN-TF v1.2 Source Code (U)", WSRC-TR-93-086.

Flach, G. P., 1991, FLOWTRAN-TF Code Development Technical and QA Plan, Rev. 0, 8/1/91, QA task number 89-021-1.

Flach, G. P., 1993a, FLOWTRAN-TF Software Requirements Specification, Rev. 1, 1/14/93, QA task number 89-021-1.

Flach, G. P., 1993b, FLOWTRAN-TF Software Test Plan, Rev. 1, 1/29/93, QA task number 89-021-1. 


\section{Input Specifications}

A detailed guide to input deck creation and interpretation is given in this section. All data input is free format.

The required input described below may be augmented with additional descriptive comments by making use of the '!' character. All exclamation points and trailing characters are considered by FLOWTRAN-TF to be extraneous comments and are ignored.

The ' $\$$ ' and ' $\&$ ' characters also take on special meanings and are used to abbreviate the input. In many instances repetitive lines of input are required. Rather than explicitly specifying each line, the repeating line may be identified with a dollar sign and the number of occurrences of the line placed after the numerical input. If a group of lines repeats, the first line is identified with ' $\$ \#$ ' and the additional lines are marked with a ' $\&$ '.

For example

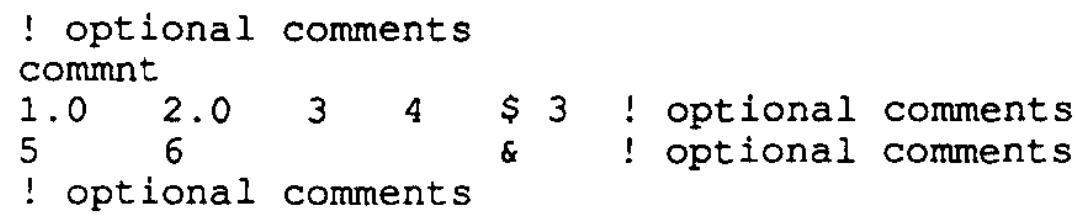

is equivalent to

$\begin{array}{llll}\text { commnt } & & \\ 1.0 & 2.0 & 3 & 4 \\ 5 & 6 & & \\ 1.0 & 2.0 & 3 & 4 \\ 5 & 6 & & \\ 1.0 & 2.0 & 3 & 4 \\ 5 & 6 & & \end{array}$

The remainder of this section specifies in detail the input information required by FLOWTRAN-TF. The user is assumed to be familiar with the FLOWTRAN-TF Software Design report. The sample input deck given in the next section is provided for example. The FLOWTRAN-TF source listing (WSRC-TR-93-086) may be used for further clarification of physical models or input requirements as needed.

\section{Section 1}

Input file title

The first section of the input file is a single comment line read by subroutine INOPTS giving a title or other descriptive information about the input. Section 1 has the form

commint

where

commnt $\equiv$ Input file title 


\section{Section 2}

\section{Run time, time step limits, print time intervals}

The second section starts with a comment line followed by a second line containing the run time, time step limits and print time intervals. Section 2 is read by subroutine INOPTS and takes the form

Commint
runsec dtmin dtmax dtpeld dtpsid dtepwr dtpdmp

where

$$
\begin{aligned}
& \text { commnt } \equiv \text { Section label } \\
& \text { runsec } \equiv \text { End time of calculation (s) } \\
& d t \min \equiv \text { Minimum permitted time step (s). A value of } 10^{-5} \text { or smaller is suggested } \\
& d t \max \equiv \text { Maximum permitted time step (s). A value of approximately } 0.5 \text { is } \\
& \text { suggested. } \\
& d t p f l d \equiv \text { Print time interval for fluid output (s) } \\
& d t p s I d \equiv \text { Print time interval for solid output (s) } \\
& d t p p w r \equiv \text { Print time interval for power output (s) } \\
& d t p d m p \equiv \text { Print time interval for binary data output (s) }
\end{aligned}
$$

\section{Section 3 Boundary condition, units, restart and print flags}

The section starts with a comment line followed by a second line containing several boundary condition, dimensional units, restart and print option parameters. Section 3 is read by subroutine INOPTS and takes the form

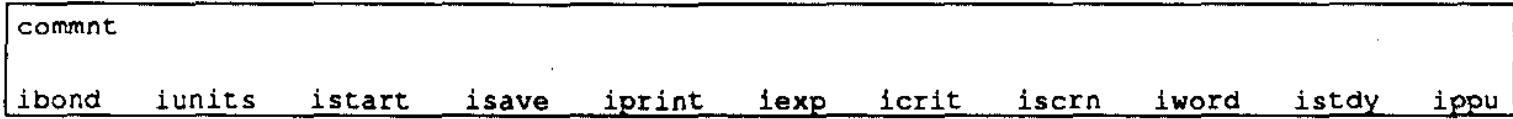

where

$$
\begin{aligned}
\text { commnt } \equiv & \text { Section label } \\
\text { ibond } \equiv & \text { Inlet boundary condition option number. Options are } \\
& 1 \text { for prescribed pressure } \\
& 2 \text { for prescribed liquid volumetric flowrate } \\
& 3 \text { for prescribed gas volumetric flowrate } \\
& 4 \text { for prescribed liquid and gas volumetric flowrates } \\
\text { iunits } \equiv & \text { Units selector for fluid input (only). Options are } \\
& \left.1 \text { for SI units (m, } \mathrm{m}^{2}, \mathrm{~m}^{3}, \mathrm{~Pa}, \mathrm{~m}^{3} / \mathrm{s},{ }^{\circ} \mathrm{C}\right) \\
& \left.2 \text { for SRS units (in, in } \mathrm{in}^{2}, \mathrm{in}^{3}, \mathrm{psia}, \mathrm{gpm},{ }^{\circ} \mathrm{C}\right)
\end{aligned}
$$


istart $\equiv$ Initialization from restart file flag. Options are

0 for initial conditions set by this input file with tsec initialized to 0

1 for initial conditions set by a binary restart file with $t \mathrm{sec}$ initialized to the value of runsec in the restart file

2 for initial conditions set by a binary restart file with t sec initialized to 0

3 for initial conditions set by a binary restart file with tsec initialized to tcrmax in this input file

-1 for initial conditions set by a ASCII restart file with tsec initialized to the value of runsec in the restart file -2 for initial conditions set by a $A S C I I$ restart file with tsec initialized to 0

-3 for initial conditions set by a ASCII restart file with tsec initialized to tcrmax in this input file

is ave $\equiv$ Restart file creation flag. Options are

0 for no restart file containing conditions at runsec saved

1 for a binary restart file containing conditions at runsec saved with tsec equal to runsec (unchanged)

2 for a binary restart file containing conditions at runsec saved with t sec set to 0

3 for a binary restart file containing conditions at runsec saved with t sec set to tcrmax

-1 for a ASCII restart file containing conditions at runsec saved with $t$ sec equal to runsec (unchanged)

-2 for a $A S C I I$ restart file containing conditions at runsec saved with $\mathrm{t} \sec$ set to $O$

-3 for a $A S C I I$ restart file containing conditions at runsec saved with t sec set to tcrmax

iprint $\equiv$ Fluid print flag. Options are

1 for short print (pressure, void fraction, temperatures and velocities)

2 for long print (above plus interfacial heat and mass transfer information, densities and enthalpies, flowrates, and superficial velocities)

3 for medium print (pressure, void, temperatures, phasic and superficial velocities, and volumetric flowrates) 


\author{
iexp $\equiv$ Power input flag. Options are \\ 0 for full power input \\ 1 for abbreviated 'experimental rig' power input \\ icrit $\equiv$ Criteria print flag. Options are \\ 0 for no printing of power iteration criteria messages \\ 1 for printing of power iteration criteria messages \\ iscrn $\equiv$ Screen print flag. Options are \\ 0 for no print of time step summary information to screen \\ 1 for short print of time step information to screen \\ 2 for long print of time step information to screen (not recommended in \\ general) \\ i word $\equiv$ Word length flag used for binary dumps. Options are \\ 1 for 1 byte per word (VAX) \\ 2 for 8 bytes per word (CRAY, IBM 6000) \\ istdy $\equiv$ Steady-state flag. Options are \\ 0 for a transient calculation starting from the initial value of $t s e c$ and \\ ending at runsec \\ 1 for a transient calculation starting from the initial value of $t \mathrm{sec}$ and \\ ending when steady-state conditions are reached, nst dy is exceeded, or \\ t $\sec =$ runsec, whichever occurs first. See tolss parameter below. \\ 2 for a steady-state calculation ( $t$ sec is not advanced) using the \\ boundary conditions at the initial value of $t \mathrm{sec}$. Calculations end when \\ steady-state conditions are reached or nst dy is exceeded, whichever \\ occurs first. runsec must be greater than the initial value of $t$ sec. See \\ tolss parameter below. \\ 3 for a steady-state calculation as with option 2 automatically followed by \\ a transient calculation as with option 0 . See tolss parameter below. \\ ippu $\equiv$ Plenum pressure update flag. Options are \\ 0 for no update \\ 1 for update always \\ 2 for update only when the plenum void fraction is less than alphs \\ defined below.
}

The section starts with a comment line followed by a second line containing a variety of parameters as specified below. Section 4 is read by subroutine INOPTS and takes the form 
commnt

ilg pref factor vminz vminx tol tolss nstdy tsupw htdamp cidamp xdelt xturb xao

where

$$
\text { commnt } \equiv \text { Section label }
$$

ilq $\equiv$ Liquid component flag. Options are

1 for light water $\left(\mathrm{H}_{2} \mathrm{O}\right)$

2 for heavy water $\left(\mathrm{D}_{2} \mathrm{O}\right)$

pref $\equiv$ Reference pressure used in conjunction with the relative tolerance for INNER pressure iterations, eps in, to determine the absolute tolerance. (Default is $101325 \mathrm{~Pa}$ or $14.696 \mathrm{psia}$ )

factor $\equiv$ Liquid compressibility factor. fact or is a multiplier to $\partial \rho_{\mathrm{f}} / \partial \mathrm{P}$ in the liquid equation of state model. See comments below

vminz $\equiv$ Minimum axial velocity for full donoring. The units of vminz are $\mathrm{m} / \mathrm{s}$ regardless of the value of iunits. (Typical selection is 0.0 to 0.05 $\mathrm{m} / \mathrm{s})$

vminx $\equiv$ Minimum azimuthal velocity for full donoring. The units of vminx are $\mathrm{m} / \mathrm{s}$ regardless of the value of iunits. (Typical selection is 0.0 to $0.05 \mathrm{~m} / \mathrm{s}$ )

tol $\equiv$ Tolerance for change between time steps used to control calculation accuracy. TIMSTP controls $\Delta t$ such that tol is not exceeded anywhere in the mesh by the

- relative change in pressure, $\left|\mathrm{P}^{\mathrm{n}+1}-\mathrm{P}^{\mathrm{n}}\right| \mathrm{P}^{\mathrm{n}}$

- absolute change in void fraction $\left|\alpha^{n+1}-\alpha^{n}\right|$

- relative change in gas temperature, $1 T_{g}^{n+1}-T_{g}{ }^{n} 1 / T_{g}{ }^{n}$

- relative change in liquid temperature, $\mid T_{f}^{n+1}-T_{f}^{n} 1 / T_{f}^{n}$

- absolute change in air mass fraction, $\left|X_{a^{n+1}}-X_{a^{n}}\right|$

tolss $\equiv$ Tolerance on the rate of change of mixture extensive enthalpy, $\mathrm{dH}_{\mathrm{mix}} / \mathrm{dt}$, for defining when steady-state conditions have been reached $\left(\mathrm{J} / \mathrm{m}^{3} \mathrm{~s}\right)$ (istdy $=1,2$ or 3 )

nstdy $\equiv$ Maximum number of time steps allowed during an attempt to reach steady-state conditions (ist dy $=1,2$ or 3 )

t supw $\equiv$ Wall temperature bias in power iteration criteria $\# 2$ and $\# 3\left(\Delta \mathrm{T}_{\text {sup }}\right)$

htdamp $\equiv$ Solid-fluid wall heat transfer damping factor used as follows

$$
q_{w k}^{n+1} \leftarrow(h t d a m p) q_{w k}^{n+1}+(1-h t d a m p) q_{w k}^{n}
$$


cidamp $\equiv$ Interfacial drag and heat/mass transfer rate coefficient damping parameter. The magnitude is the value of the time constant $\tau$ used as described below. The sign selects between two damping schemes. An exponential decay factor is first computed as

$$
\gamma^{n}=2^{-\frac{\Delta t^{n}}{\tau}}
$$

where $\tau \equiv$ lcidampl. If cidamp is positive then the interfacial drag coefficient is computed using the 'averager' option as

$$
C_{i}^{n} \leftarrow \gamma^{n} C_{i}^{n-1}+\left(1-\gamma^{n}\right) C_{i}^{n}
$$

If cidamp is negative then the 'limiter' option is used:

$$
C_{i}^{n} \leftarrow \max \left[\min \left(C_{i}^{n}, \frac{C_{i}^{n-1}}{\gamma^{n}}\right), C_{i}^{n-1} \gamma^{n}\right] .
$$

Analogous operations apply to the interfacial heat and mass transfer rate coefficients. Small cidamp gives large weight to the new time step value (small time constant $=$ fast response)

$x$ de lt $\equiv$ Multiplier to $\Delta t$ in solid calculations for istdy $\geq 1$. xdelt greater than 1 has the effect of decreasing heat capacity of the solid and thus speeding progress towards a steady-state solution. (xdelt does not affect steadystate results)

$x t u r b \equiv$ Multiplier to the inter-subchannel turbulent mixing terms. Can be used for sensitivity studies or to turn mixing off $(x t u r b=0)$. Default value is 1.0 .

xaO $\equiv$ Reference air mass fraction in $\Gamma_{\mathrm{a}}$ model. Must be set to zero.

Single-phase liquid calculations are frequently difficult to initiate with a prescribed liquid flowrate boundary condition because water is nearly incompressible. With this boundary condition, large pressure changes typically occur in the first time-step in making pressures consistent with the imposed flowrate.

Large pressure changes also occur whenever the prescribed flowrate forcing function is not continuous through the first derivative. In fact, an infinite inlet pressure change is required to make any discontinuous change in flowrate of an incompressible fluid as can be seen from Newton's second law of motion. If the slope $\mathrm{dQ}_{\mathrm{f}} / \mathrm{dt}$ is discontinuous, then inlet pressure is a discontinuous for an incompressible fluid. Water is compressible but only slightly.

Increasing the liquid compressibility will reduce the changes in pressure in both cases discussed above. This may be done by changing pref from the default of 1.0 to say 10.0 or 100.0 . 
The section starts with a comment line followed by a second line containing boiling curve and interfacial heat and mass transfer parameters. Section 5 is read by subroutine INOPTS and takes the form

lboil 1chf matgas persat lgami lgamw

where

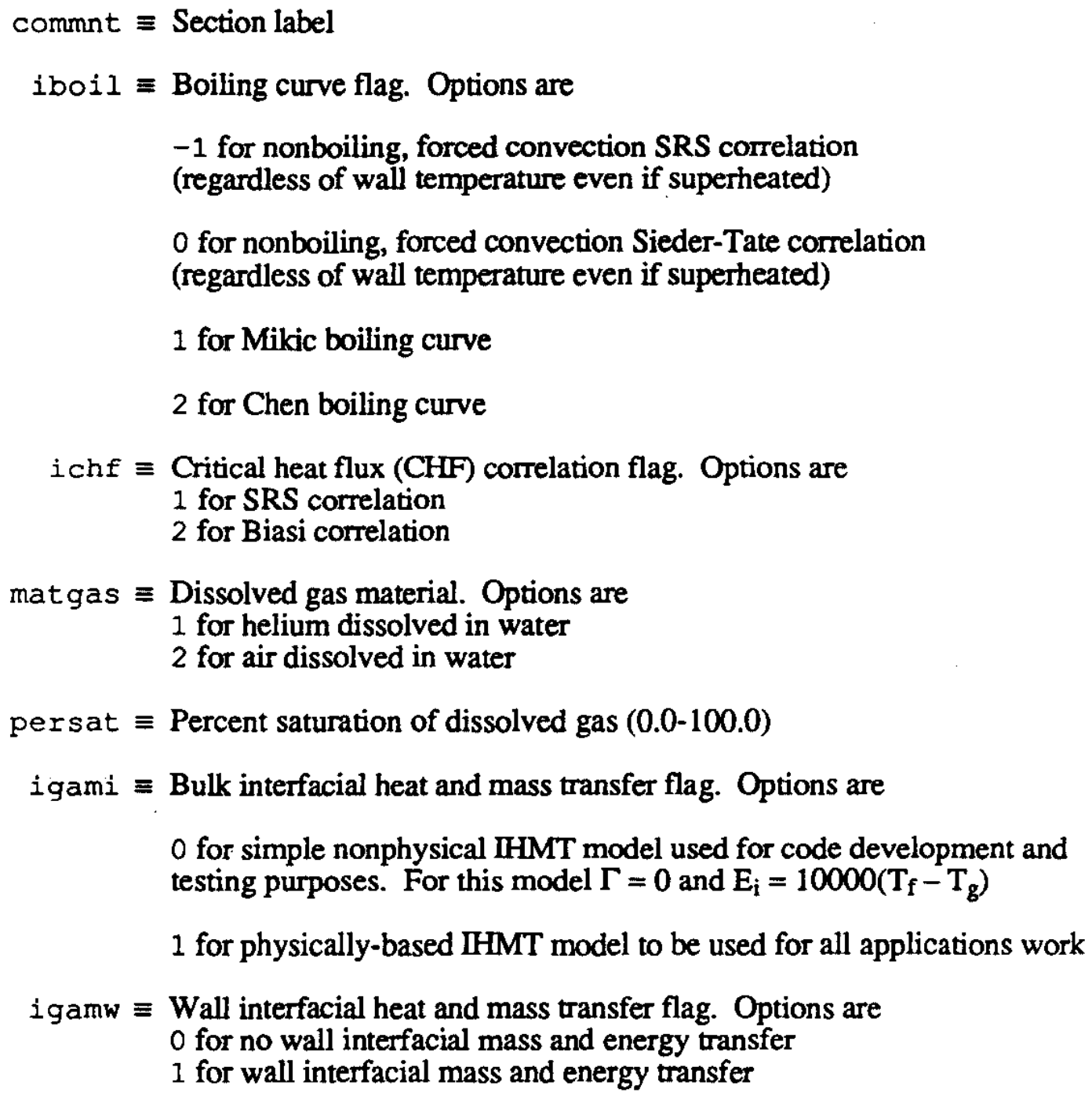

iboil options -1 and 0 are useful for $T_{\text {wall }}=T_{\text {sat }}$ power iterations for which there is no boiling when $T_{\text {wall }}=T_{\text {sat. }}$. Frequently during power iterations, an iterate will significantly exceed the $T_{\text {wall }}=T_{\text {sat }}$ power and calculations will slow down due to a ACCCHK restriction on time-step size or other factor. Choosing iboil $=-1$ or 0 prevents boiling and small time-steps without affecting the results when $T_{\text {wall }}=T_{\text {sal }}$. 
The section starts with a comment line followed by a second line containing parameters for the solid heat conduction calculations. Section 6 is read by subroutine INOPTS and takes the form

\begin{tabular}{lll} 
commnt \\
isolid iaxial ws noms tsolid tsrfac \\
\hline
\end{tabular}

where

$$
\begin{aligned}
& \text { commnt } \equiv \text { Section label } \\
& \text { isolid } \equiv \text { Solid calculations flag. Options are } \\
& 0 \text { for no solid calculations and no wall heat transfer to fluid } \\
& \text { iaxial } \equiv \text { Axial heat conduction flag. Options are } \\
& 0 \text { for no axial heat conduction } \\
& 1 \text { for axial heat conduction }
\end{aligned}
$$$$
1 \text { for solid calculations and wall heat transfer to fluid }
$$

ws $\equiv$ Weighting factor between $\mathrm{n}$ and $\mathrm{n}+1$ time quantities in spatial differenced terms. ws s must be between 0.0 and 1.0 . Example selections are

The section starts with a comment line followed by 3 lines containing iteration control parameters for the INNER, GAMMAI and NEWTON iterations, respectively. Section 7 is read by subroutine INOPTS and takes the form

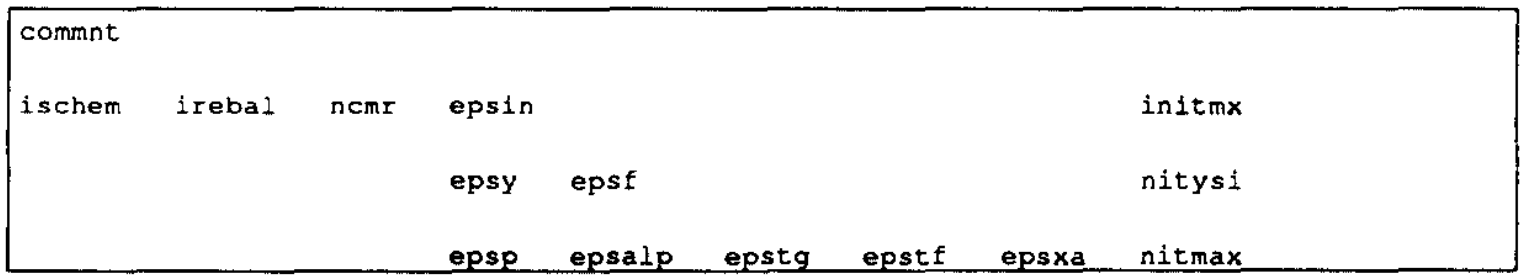

where

$$
\text { commnt } \equiv \text { Section label }
$$


ischem $\equiv$ Solution strategy fiag for INNER pressure-only problem. Options are 1 for axial tridiagonal scheme

2 for azimuthal tridiagonal scheme

3 for alternating axial and azimuthal tridiagonal schemes

irebal $\equiv$ Coarse mesh rebalance flag. Options are

0 for no coarse mesh rebalance

1 for a coarse mesh rebalance on the first overall iteration pass only

2 for a coarse mesh rebalance on each overall iteration pass

ncmr $\equiv$ Number of coarse mesh rebalances per pass when irebal $=1$ or 2

epsin $\equiv$ INNER iteration convergence tolerance for relative pressure change. The reference pressure is pref specified in section 4 above. (For pref $=1$ atm default is about $10^{-4}$ )

initmx $\equiv$ Maximum number of INNER iterations allowed. (Default is 50)

epsy $\equiv$ GAMMAI iteration convergence tolerance for relative change in interface steam mole fraction, $y_{\text {si. }}$ GAMMAI constrains the resulting absolute tolerance, epsy*ys $i$, to be greater than or equal to $10^{-6}$, however. (Default is $10^{-4}$ )

epsf $\equiv$ GAMMAI iteration convergence tolerance for

$$
F\left(y_{s i}\right)=\Gamma\left(1-y_{s i}+\phi \Delta y_{s}\right)-K_{g} \Delta y_{s}
$$

(Default is 0.1 )

nitysi $\equiv$ Maximum number of GAMMAI iterations. (Default is 50)

epsp $\equiv$ NEWTON iteration convergence tolerance for absolute pressure change (Pa). (Default is about 100.0)

epsalp $\equiv$ NEWTON iteration convergence tolerance for absolute void fraction change. (Default is about 0.005 )

epstg $\equiv$ NEWTON iteration convergence tolerance for absolute gas temperature change $\left({ }^{\circ} \mathrm{C}\right)$. (Default is 0.05 )

epstf $\equiv$ NEWTON iteration convergence tolerance for absolute liquid temperature change $\left({ }^{\circ} \mathrm{C}\right.$ ). (Default is about 0.05 )

epsxa $\equiv$ NEWTON iteration convergence tolerance for absolute air mass fraction change. (Default is about 0.005 )

nitmax $\equiv$ Initmaxl is the maximum number of NEWTON iterations. If nitmax is positive and In itmaxl iterations are reached then the computations proceed to the next time using $m=n i t m a x$ iteration values. For negative nitmax and $m=n i t \max$, the time step is aborted and reattempted with reduced $\Delta \mathrm{t}$.. (Default is 50 ) 
For 2-D fluid calculations in the Middle section the recommended INNER iteration scheme is the alternating axial-azimuthal scheme with coarse mesh rebalance given by ischem = 3 , irebal $=1$ and $\mathrm{ncmr}=1$.

INNER iterations cease when the eps in criterion is satisfied or in itmx is exceeded. GAMMAI iterations cease when the epsy criterion is satisfied and $F\left(y_{s i}\right)<$ eps $f$ or nitysi is exceeded. NEWTON iterations cease when the epsp, epsalp, epstg, epst $f$ and epsxa criteria are all satisfied or nitmax is exceeded.

The user should be aware that the convergence tolerances for the INNER and GAMMAI calculations should be smaller than those for the NEWTON iteration; that is, the NEWTON iteration requires input information more accurate than its requested accuracy. The maximum change in the interfacial steam mole fraction and air mass fraction iterates in the GAMMAI and NEWTON iterations is 0.04 . During phase transitions these parameters may change from approximately 0 to 1 or vice versa during a single time-step. Therefore, the maximum number of GAMMAI and NEWTON iterations must exceed 25 . A value of 50 is suggested for both.

\section{Section 8}

Number of spline profiles and data points

The section starts with a comment line followed by a line specifying the number of spline data groups (ndata), the maximum number of radial points in power shapes, and the number of time snapshots for axial power profiles. The next ndata lines contain the number of data points per data set and the number of data sets per group. Section 8 is read by subroutine INOPTS and takes the form

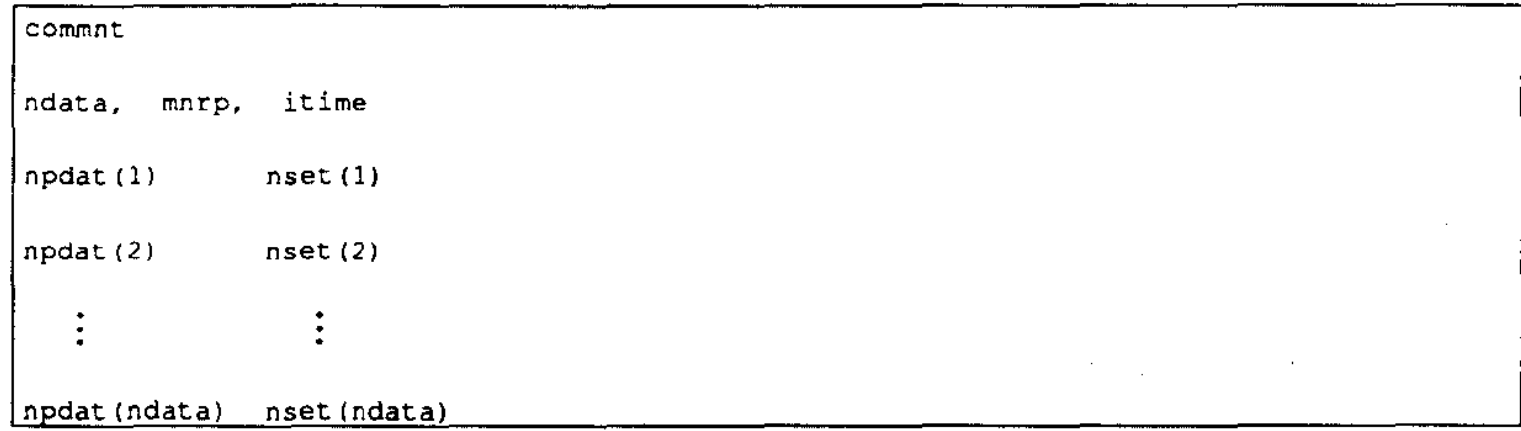

where

$$
\begin{aligned}
\text { commnt } & \equiv \text { Section label } \\
\text { ndata } & \equiv \text { Number of data groups } \\
\text { mnrp } & \equiv \text { Maximum number of radial points in power shapes } \\
\text { it } i m e & \equiv \text { Number of time snapshots for axial power profiles } \\
\text { npdat }(i) & \equiv \text { Number of data points per data set } \\
\text { nset }(i) & \equiv \text { Number of data sets per group }
\end{aligned}
$$


As an illustration, consider the 7 data pairs $(x, y),(x, z),(a, b),(a, c),(a, d)$, and $(a, e)$ grouped in the last section of the input file as shown below:

$\begin{array}{lllll}\mathrm{x}_{1} & \mathrm{y}_{1} & \mathrm{z}_{1} & & \\ \mathrm{x}_{2} & \mathrm{y}_{2} & \mathrm{z}_{2} & & \\ \mathrm{x}_{3} & \mathrm{y}_{3} & \mathrm{z}_{3} & & \\ \mathrm{x}_{4} & \mathrm{y}_{4} & \mathrm{z}_{4} & & \\ & & & & \\ \mathrm{a}_{1} & \mathrm{~b}_{1} & \mathrm{c}_{1} & \mathrm{~d}_{1} & \mathrm{e}_{1} \\ \mathrm{a}_{2} & \mathrm{~b}_{2} & \mathrm{c}_{2} & \mathrm{~d}_{2} & \mathrm{e}_{2} \\ \mathrm{a}_{3} & \mathrm{~b}_{3} & \mathrm{c}_{3} & \mathrm{~d}_{3} & \mathrm{e}_{3}\end{array}$

For this example, ndata $=2, \operatorname{npdat}(1)=4, \operatorname{nset}(1)=2, \operatorname{npdat}(2)=3$ and nset $(2)=4$.

\section{Section 9}

Geometric dimensions

The section starts with a comment line followed by a line specifying the geometric dimensions of the solid and fluid meshes. Section 9 is read by subroutine INOPTS and takes the form

nchn nxmax ncyln na nrmax nzt nz nzb

where

$$
\begin{aligned}
\text { commnt } & \equiv \text { Section label } \\
n c h n & \equiv \text { Number of flow channels in the Middle section of the fluid mesh } \\
n x \max & \equiv \text { Maximum number of fluid azimuthal cells per channel }(\geq 1) \\
n c y l n & \equiv \text { Number of solid cylinders }(\geq 1) \\
n a & \equiv \text { Number of solid azimuthal cells }(\geq 1) \\
n r \max & \equiv \text { Maximum number of solid radial cells }(\geq 3) \\
n z t & \equiv \text { Number of Top section axial fluid cells }(\geq 2) \\
n z & \equiv \text { Number of Middle section axial cell layers }(\geq 3) \\
n z b & \equiv \text { Number of Bottom section axial fluid cells }(\geq 2)
\end{aligned}
$$

The section starts with a comment line followed by a line specifying active core parameters. Section 10 is read by subroutine INOPTS and takes the form 


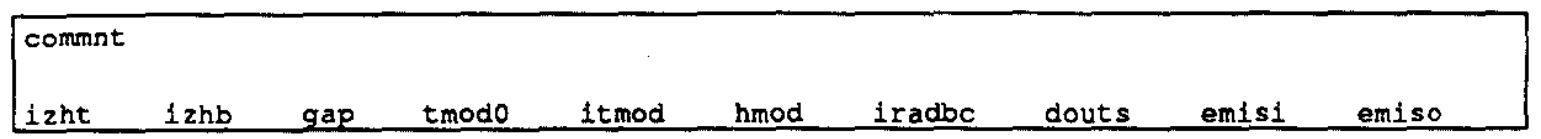

where

$$
\begin{aligned}
& \text { commnt } \equiv \text { Section label } \\
& \text { izht } \equiv \text { Number of first heated cell in Middle section }(1 \leq \text { izht } \leq \mathrm{nz}) \\
& \text { gap } \equiv \text { Gap distance from active core to tank bottom } \\
& \text { tmodo } \equiv \text { Multiplier to moderator spline function. The printed output assumes that }
\end{aligned}
$$$$
i z h b \equiv \text { Number of last heated cell in Middle section ( } i z h t \leq i z h b \leq n z)
$$
the spline function (selected by itmod) starts with 1.0 making tmodo

itmod $\equiv$ Number of the data set from which the spline function defining moderator

hmod $\equiv$ Moderator heat transfer coefficient $\left(\mathrm{W} / \mathrm{m}^{2} \mathrm{~K}\right.$ or BTU/hr $\mathrm{ft}^{2}$ o $\mathrm{F}$ depending

1 for radiation heat transfer between the outer surface of the outer solid tube and another annular tube of diameter douts, emissivity emi so and

Convection heat transfer from the outer surface of the outer solid tube only occurs over the wetted portion of the tube as defined by tank level. Radiative heat transfer, if selected by ir $\mathrm{adbc}=1$, occurs only over the dry portion of the outer tube. See section 2.5.1 of FLOWTRAN-TF Software Design report for more detailed information.

\section{Section 11}

Power iteration input

The section starts with a comment line followed by a line specifying power iteration parameters. Section 11 is read by subroutine INOPTS and takes the form 
where

$$
\begin{aligned}
& \text { commnt } \equiv \text { Section label } \\
& \text { asypwr } \equiv \begin{array}{l}
\text { Multiplier to the spline function(s) defining the transient power response } \\
(\mathbf{k W})
\end{array} \\
& \text { maxpi } \equiv \text { Maximum number of power iterations (Recommended as } 10 \text { or less) } \\
& \text { tolpow } \equiv \text { Convergence tolerance for power } \\
& \text { ncrit } \equiv \text { Total number of power iteration criteria (Must specify } 4)
\end{aligned}
$$

The printed output assumes the power spline function starts with 1.0 making power the initial power level but this is not a requirement. Also, power may take on any positive, zero or negative value.

\section{Section 12}

Sensitivity parameters

The section starts with a comment line followed by a line generally specifying numerous parameters enabling the user to perform sensitivity calculations through input. Section 12 is read by subroutine INOPTS and takes the form

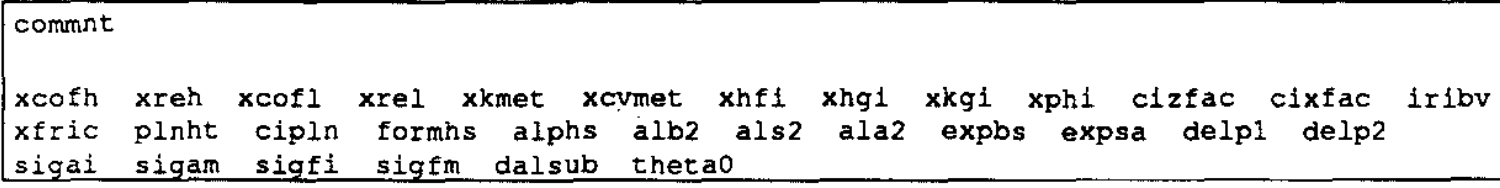

where

$$
\begin{aligned}
& \text { commnt } \equiv \text { Section label } \\
& \mathrm{xcofh} \equiv \text { Multiplier to the leading coefficient in the dispersed regime forced }
\end{aligned}
$$
convection heat transfer correlation given by equation (2.5.1-4a) in the FLOWTRAN-TF Software Design report. Appears in subroutines SRLHTC and MIKIC.

$\mathrm{xreh} \equiv$ Multiplier to the Reynolds number exponent in the dispersed regime forced convection heat transfer correlation given by equation (2.5.1-4a) in the FLOWTRAN-TF Software Design report. Appears in subroutines SRLHTC and MIKIC.

$x \operatorname{cof} 1 \equiv$ Multiplier to the leading coefficient in the annular regime forced convection heat transfer correlation given by equation $(2.5 .1-5 \mathrm{a})$ in the FLOWTRAN-TF Software Design report. Appears in subroutines SRLHTC and MIKIC.

xrel $\equiv$ Multiplier to the Reynolds number exponent in the annular regime forced convection heat transfer correlation given by equation (2.5.1-5a) in the FLOWTRAN-TF Software Design report. Appears in subroutines SRLHTC and MIKIC. 
xkmet $\equiv$ Multiplier to the solid thermal conductivity

xcvmet $\equiv$ Multiplier to the solid heat capacity

$x h f \equiv$ Multiplier to the fluid-side interfacial heat transfer rate coefficient

$x h g i \equiv$ Multiplier to the gas-side interfacial heat transfer rate coefficient

$\mathrm{xkgi} \equiv$ Multiplier to the gas-side interfacial mass transfer rate coefficient

$x p h i \equiv$ Multiplier to the $\phi$ parameter associated with the Ackermann mass transfer rate correction

cizfac $\equiv$ Axial interfacial drag coefficient multiplier or value, depending on sign. If cizfac is positive, cizfac is a multiplier to the axial interfacial drag coefficient. If cizfac is negative, cizfac is the axial interfacial drag coefficient $\left((\mathrm{Pa} / \mathrm{m}) *(\mathrm{~m} / \mathrm{s})^{-2}\right.$ regardless of iunits value $)$.

cixfac $\equiv$ Azimuthal interfacial drag coefficient multiplier or value, depending on sign. If cixfac is positive, cixfac is the azimuthal interfacial drag coefficient $\left((\mathrm{Pa} / \mathrm{m})^{*}(\mathrm{~m} / \mathrm{s})^{-2}\right.$ regardless of iunits value $)$. If cixfac is negative, cixfac is a multiplier to the azimuthal interfacial drag coefficient. Default value is $+10^{9}$.

Note that cizfac and cixfac use opposite sign conventions. The default for both is a positive value however.

iribv $\equiv$ Rib void fraction correlation flag. Options are

0 for rib void fraction equal to cell average void fraction

1 for rib void fraction defined by equation (2.5.7-5) in the . FLOWTRAN-TF Software Design report.

$\mathrm{xfric} \equiv$ Multiplier to the frictional component of axial wall drag.

plnht $\equiv$ Channel vertical height $\mathbf{H}$ in the horizontal, stratified flow model at the junction between the Plenum and Top section. See section 3.6 of the FLOWTRAN-TF Software Design report for more information.

cipln $\equiv$ Interfacial drag coefficient $C_{i, s t r a t}^{z}$ in the horizontal, stratified flow model $\left((\mathrm{Pa} / \mathrm{m}) *(\mathrm{~m} / \mathrm{s})^{-2}\right.$ regardless of iunits value $)$

formh $s \equiv$ Form loss coefficient $\mathrm{K}_{\text {strat }}^{\mathbf{z}}$ in the horizontal, stratified flow model

alphs $\equiv$ Magnitude is the void fraction $\alpha_{\text {strat }}$ in the horizontal, stratified flow model which defines the breakpoint between dispersed and separated flow. The sign determines which of two approximations of the void gradient term is used. For alphs positive, the finite difference approximation 


$$
\frac{\partial \alpha}{\partial z} \rightarrow \frac{\left(\alpha_{t 1}-\alpha_{p l}\right) A_{c z, 1 / 2}}{V_{z, 1 / 2}}
$$

is used. For alphs negative,

$$
\frac{\partial \alpha}{\partial z} \rightarrow \frac{\left(1-\alpha_{\mathrm{pl}}\right) \mathbf{A}_{\mathrm{cz}, 1 / 2}}{\mathrm{~V}_{\mathrm{z}, 1 / 2}}
$$

is used whenever $\alpha_{11}>\alpha_{\mathrm{pl}}$. See the FLOWTRAN-TF Software Design report for a discussion of these choices.

a lb2 $\equiv$ Flow regime map parameter $\alpha_{b}{ }^{* *}$. (Default value is 0.25 )

als2 $\equiv$ Flow regime map parameter $\alpha_{\delta}^{* *}$. (Default value is 0.52 )

ala2 $\equiv$ Flow regime map parameter $\alpha_{a}^{* *}$. (Default value is 0.75 )

expbs $\equiv$ Flow regime map parameter $n_{b s}$. (Default value is 4.0 )

expsa $\equiv$ Flow regime map parameter $\mathrm{n}_{\text {sa. }}$. (Default value is 4.0 )

delp1 $\equiv$ Mk22 channel inlet void distribution parameter. $\Delta \mathrm{P}<$ delpl is classified as an adverse pressure gradient. The units of de $\mathrm{Pp} 1$ are $\mathrm{Pa}$ regardless of iunits value. (Default value is $\mathbf{0} \mathrm{Pa}$ )

delp2 $\equiv$ Mk22 channel inlet void distribution parameter. $\Delta \mathrm{P}>$ de $1 \mathrm{p} 2$ is classified as a favorable pressure gradient. The units of de $\mathrm{P} 1$ are $\mathrm{Pa}$ regardless of iunits value. (Default value is $200 \mathrm{~Pa}$ )

sigai $\equiv$ Mk22 channel inlet void distribution sensitivity parameter augmenting the adverse-inner channel correlation given by equation (2.5.6-13) in the

FLOWTRAN-TF Software Design report as

$$
\alpha_{\mathrm{i}}^{\mathrm{adv}}=\text { r.h.s. of equation }(2.5 .6-13)+4 \alpha(1-\alpha) \sigma_{\mathrm{ai}}
$$

where $\sigma_{\mathrm{ai}} \equiv$ sigai. Default value is 0 .

sigam $\equiv$ Mk22 channel inlet void distribution sensitivity parameter augmenting the adverse-middle channel correlation given by equation (2.5.6-14) in the

FLOWTRAN-TF Software Design report as

$$
\alpha_{m}^{\mathrm{adv}}=\text { r.h.s. of equation }(2.5 .6-14)+4 \alpha(1-\alpha) \sigma_{\mathrm{am}}
$$

where $\sigma_{\mathrm{am}} \equiv$ sigam. Default value is 0 .

sigfi $\equiv$ Mk22 channel inlet void distribution sensitivity parameter augmenting the favorable-inner channel correlation given by equation $(2.5 .6-15)$ in the FLOWTRAN-TF Software Design report as

$$
\alpha_{\mathrm{i}}^{\mathrm{fav}}=\text { r.h.s. of equation }(2.5 .6-15)+4 \alpha(1-\alpha) \sigma_{\mathrm{fi}}
$$


where $\sigma_{\mathrm{fi}} \equiv$ sigfi. Default value is 0 .

sigfm $\equiv$ Mk22 channel inlet void distribution sensitivity parameter augmenting the favorable-middle channel correlation given by equation (2.5.6-16) in the FLOWTRAN-TF Software Design report as

$$
\alpha_{m}^{\mathrm{fav}}=\text { r.h.s. of equation }(2.5 .6-16)+4 \alpha(1-\alpha) \sigma_{\mathrm{fm}}
$$

where $\sigma_{\mathrm{fm}} \equiv \mathrm{sigfm}$. Default value is 0 .

dalsub $\equiv$ Middle section subchannel inlet void maldistribution magnitude. The Middle section subchannel inlet void fractions are modified as

$$
\alpha_{\mathrm{ix}, \mathrm{ic}} \leftarrow \alpha_{\mathrm{ix}, \mathrm{ic}}+\Delta \alpha \cos \left(\theta-\theta_{0}\right)
$$

where $\Delta \alpha$ is da I sub, $\theta$ is the orientation of the subchannel cell center, and $\theta_{0}$ is defined below. Default value is 0 .

theta $0 \equiv$ Middle section subchannel inlet void maldistribution orientation in degrees. Peak void (lowest liquid flow) occurs at $\theta=\theta_{0}$. Azimuthal cell face number 1 in channel 1 is $0^{\circ}$.

\section{Section 13}

Plenum boundary cell geometry

The section starts with a comment line followed by a line specifying the Plenum cell volume and cell center area. Section 13 is read by subroutine GEOFLD and takes the form

commnt

volpl acpl

where

$$
\begin{aligned}
\text { commnt } & \equiv \text { Section label } \\
\text { volpl } & \equiv \text { Volume of Plenum boundary cell } \\
\text { acpl } & \equiv \text { Cell center area of Plenum boundary cell }
\end{aligned}
$$


Section 14

Top section cell geometry and hydraulic parameters

Section 14 is read by subroutine GEOFLD and takes on one of four forms depending on the values of iuform:

For iuform $=1$ and then 1

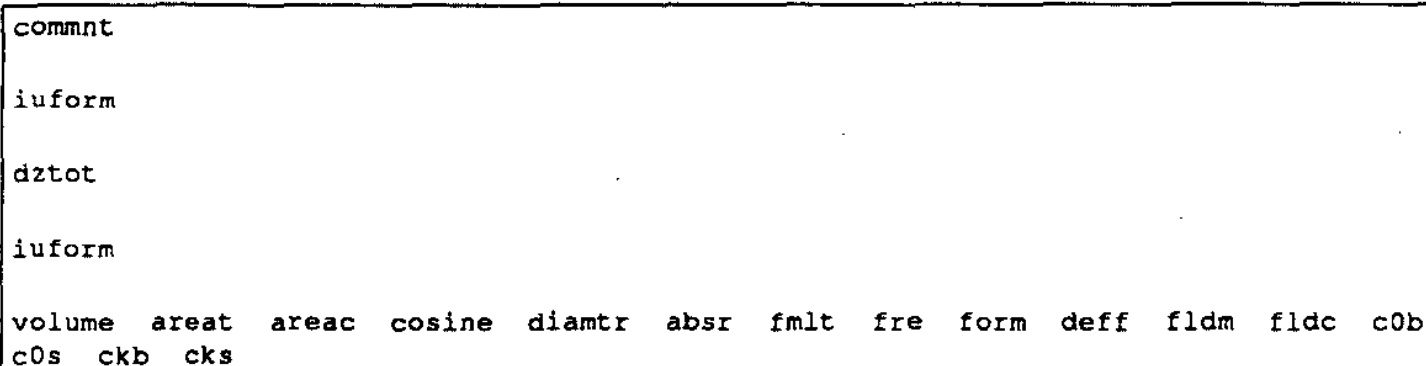

For $i$ uform $=2$ and then 1

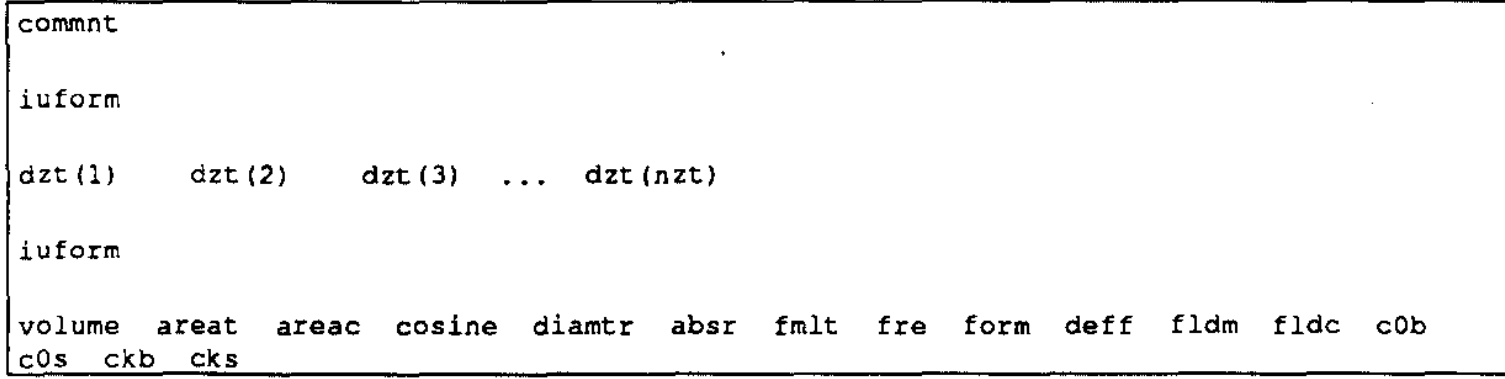

For iuform $=1$ and then 2

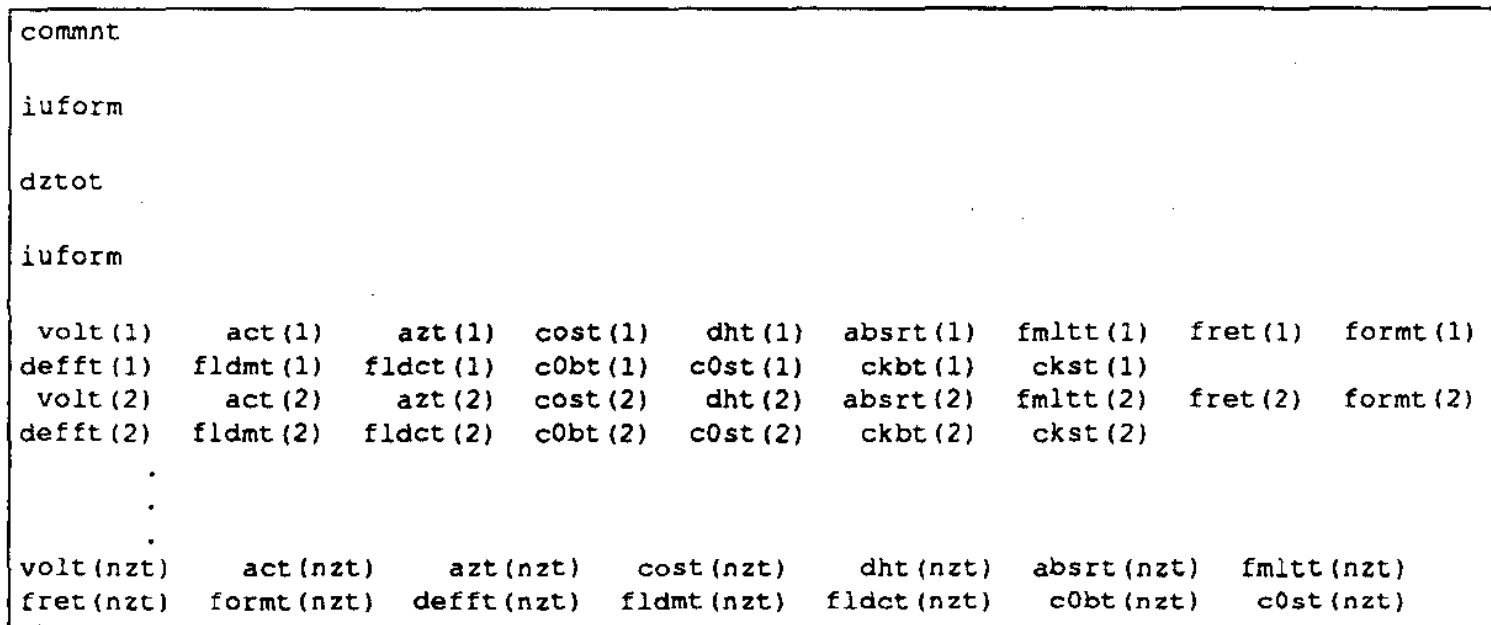


For iuform $=2$ and then 2

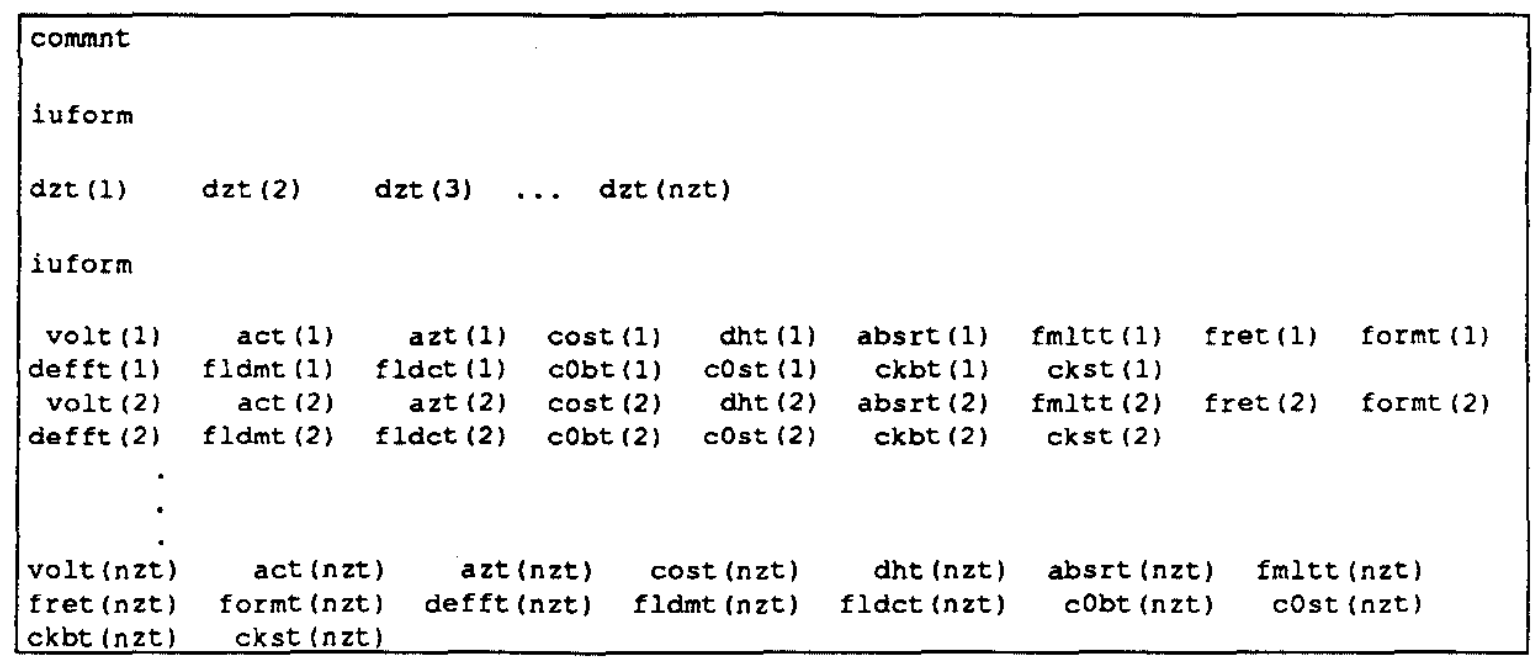

where

$$
\begin{aligned}
& \text { commnt } \equiv \text { Section label } \\
& \text { iuform } \equiv \text { Uniformity flag. Options are } \\
& \begin{array}{r}
\text { for uniform cell parameters } \\
2 \text { for individually specified cell parameters }
\end{array} \\
& \operatorname{dztot} \equiv \text { Total length of Top section } \\
& \operatorname{dzt}(j z) \equiv \text { Length of cell } j z, \Delta z \\
& \operatorname{volume/volt~}(j z) \equiv \text { Cell volume, } V_{c} \\
& \text { areat } / \operatorname{act}(j z) \equiv \text { Face area, } A_{c z} \\
& \text { areac/azt }(j z) \equiv \text { Cell area, } A_{z z}
\end{aligned}
$$

$\operatorname{cosine} / \operatorname{cost}(j z) \equiv$ Face direction $\operatorname{cosine}, \cos \theta$. Specify +1.0 for a gravitational vector aligned with the positive $\mathrm{z}$ direction.

diamtr/dht $(j z) \equiv$ Face hydraulic diameter, $D_{h}$

absr/absrt $(j z) \equiv$ Face absolute wall roughness, $\varepsilon$

fmlt $/ f m l t t(j z) \equiv$ Face frictional drag multiplier

fre/fret $(j z) \equiv$ Face hydraulic diameter correction factor, $K_{h}$.

form/formt $(j z) \equiv$ Face form loss coefficient, $K^{\mathbf{z}}$

$\operatorname{def} f / \operatorname{defft}(j z) \equiv$ Face characteristic dimension for the slug flow regime, $D_{c}$

$f l d m / f l d m t(j z) \equiv$ Face parameter $m$ in CCFL correlation 


\section{$f l d c / f l d c t(j z) \equiv$ Face parameter $C$ in CCFL correlation}

$\mathrm{cOb} / \mathrm{CObt}(j \mathrm{z}) \equiv$ Face distribution coefficient for the bubbly regime, $\mathrm{C}_{0 b}$

$\cos / \operatorname{cost}(j z) \equiv$ Face distribution coefficient for the slug regime, $\mathrm{C}_{0 s}$

$\mathrm{ckb} / \mathrm{ckbt}(j \mathrm{z}) \equiv$ Face drift velocity correlation coefficient for the bubbly regime, $\mathbf{K}_{\mathbf{b}}$

cks/ckst $(j z) \equiv$ Face drift velocity correlation coefficient for the slug regime, $K_{s}$

Note that wall frictional drag may be turned-off by specifying fmlt/fmltt $(j z)=0$.

\section{Section 15}

Section 15 is read by subroutine GEOFLD and takes on one of two forms depending on the value of iuform:

For iuform $=1$

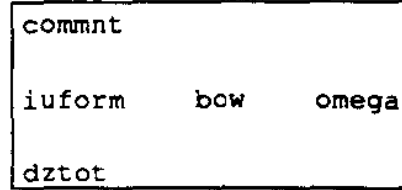

For iuform $=2$

$\begin{array}{lll}\text { commint } & \\ \text { iuform bow omega } \\ d z(1) \quad d z(2) & d z(3) & \ldots \quad d z(n z+1)\end{array}$

where

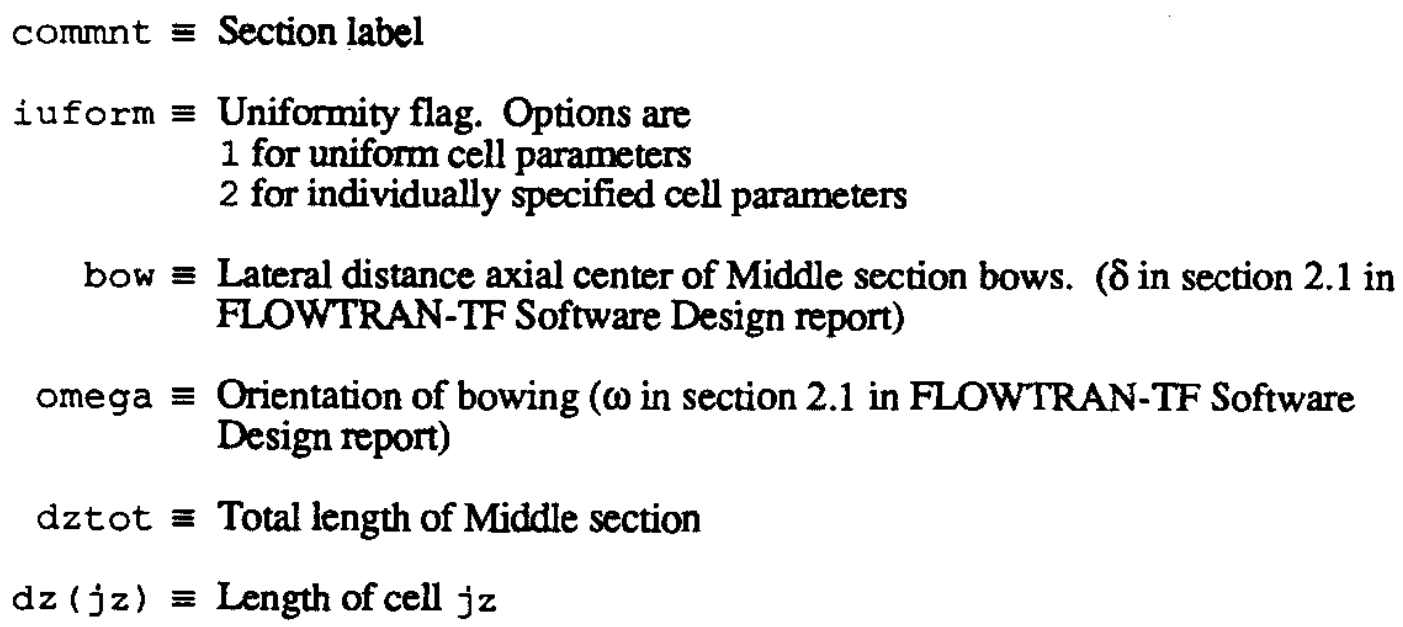


Section 16 is read by subroutine GEOFLD and takes on the form:

comnnt
nsub di do

where

$$
\begin{aligned}
\text { commnt } & \equiv \text { Section label } \\
\text { nsub } & \equiv \text { Number of subchannels } \\
d i & \equiv \text { Inner diameter of channel } \\
\text { do } & \equiv \text { Outer diameter of channel }
\end{aligned}
$$

\section{Section 17 Channel 1 azimuthal cell geometry and hydraulic parameters}

Section 17 is read by subroutine GEOFLD and takes on one of three forms:

\begin{tabular}{|c|c|c|c|c|}
\hline commint & & & & \\
\hline iuform & & & & \\
\hline $\operatorname{acx}(2,1,1)$ & $\operatorname{axx}(2,1,1)$ & $\cos x(2,1,1)$ & $\operatorname{dh} x(2,1,1)$ & $\operatorname{absr} \times(2,1,1)$ \\
\hline$f m l t x(2,1,2)$ & $f \operatorname{rex}(2,1,1)$ & $\operatorname{form} \times(2,1,1)$ & & \\
\hline $\begin{array}{r}\operatorname{acx}(2,2,1) \\
f \operatorname{lt} x(2,2,1)\end{array}$ & $\operatorname{axx}(2,2,1)$ & $\begin{array}{r}\cos \times(2,2,1) \\
\operatorname{form}(2,2,1)\end{array}$ & $\operatorname{dh} x(2,2,1)$ & $\operatorname{absr} x(2,2,1)$ \\
\hline $\operatorname{acx}(2,3,1)$ & $\operatorname{ax} \times(2,3,1)$ & $\cos x(2,3,1)$ & $\operatorname{dh} \times(2,3,1)$ & $\operatorname{absr} \times(2,3,1)$ \\
\hline$f \operatorname{mlt} x(2,3,1)$ & $f \operatorname{rex}(2,3,1)$ & $\operatorname{formx}(2,3,1)$ & & \\
\hline $\operatorname{acx}(2,4,1)$ & $\operatorname{ax} \times(2,4,1)$ & $\cos \times(2,4,1)$ & $\operatorname{dh} \times(2,4,1)$ & $\operatorname{absr} \times(2,4,1)$ \\
\hline$f \mathrm{mlt} \times(2,4,1)$ & $\operatorname{frex}(2,4,1)$ & $\operatorname{formx}(2,4,1)$ & & \\
\hline
\end{tabular}

For $i$ f form $=1$ (axial and azimuthal uniformity)

commnt
iuform
gapl gap2 cosine diamtr abs 2 fmlt fre form

For iuform $=2$ (axial uniformity) 
For iuform $=3$

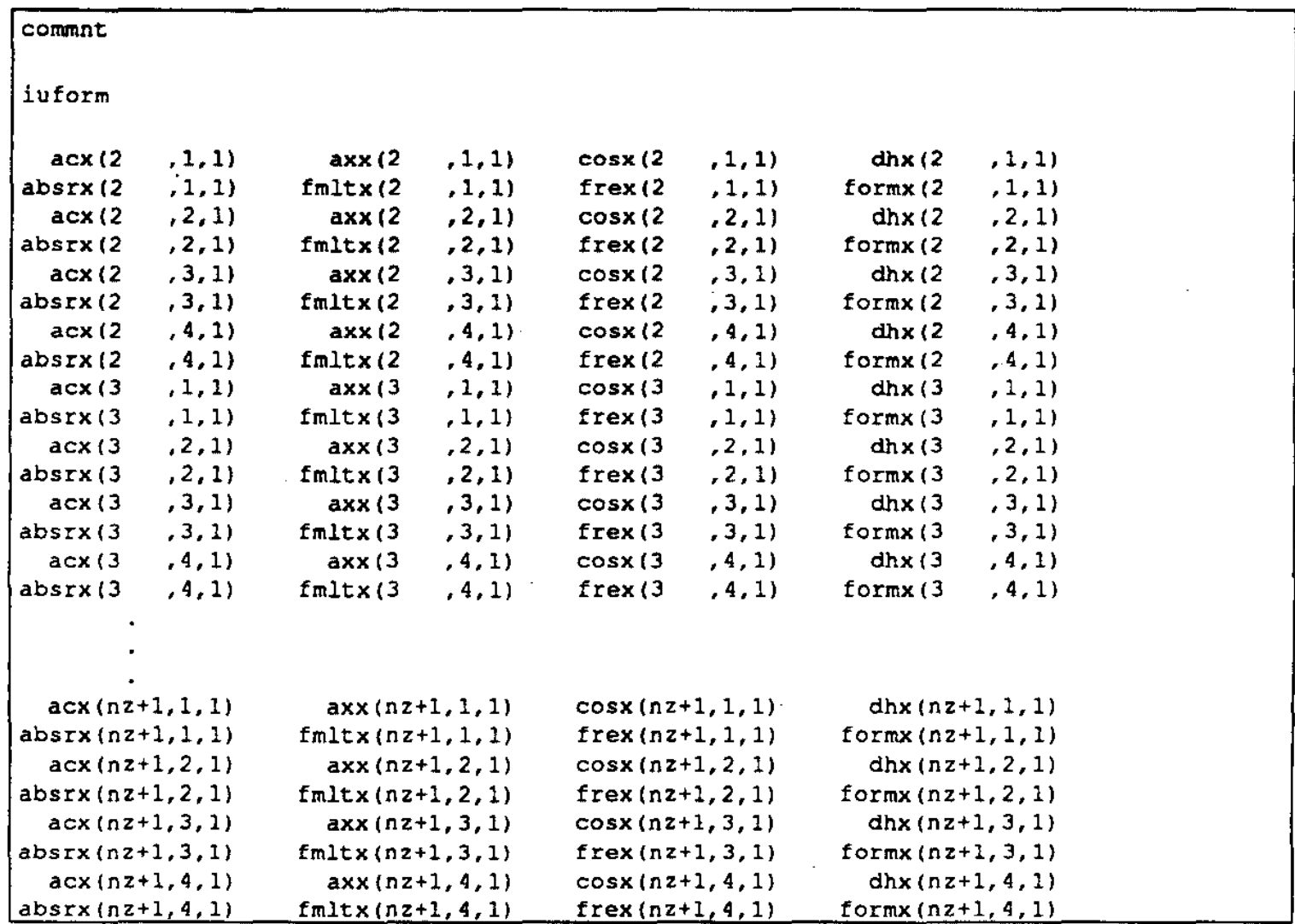

where

$$
\begin{aligned}
\text { commnt } \equiv & \text { Section label } \\
\text { iu form } \equiv & \text { Uniformity flag. Options are } \\
& 1 \text { for axially and azimuthally uniform cell parameters } \\
& 3 \text { for axially uniform cell parameters }
\end{aligned}
$$

gap1/acx $(j z, i x, i c) \equiv$ Face radial gap (Rib gap). See comment below gap2/axx $(j z, i x, i c) \equiv$ Cell radial gap (Channel gap). See comment below $\cos i n e / \cos x(j z, i x, i c) \equiv$ Face direction cosine. Specify 0.0 for a gravitational vector aligned with the positive $\mathrm{z}$ direction.

$\operatorname{diamt} r / \operatorname{dhx}(j z, i x, i c) \equiv$ Face hydraulic diameter

$a b s r / a b s r x(j z, i x, i c) \equiv$ Face absolute wall roughness

fmlt $/ \operatorname{fmltx}(j z, i x, i c) \equiv$ Face frictional drag multiplier

fre/frex $(j z, i x, i c) \equiv$ Face hydraulic diameter correction factor, $K_{h}$. 


\section{form/formx $(j z, i x, i c)=$ Face form loss coefficient}

For convenience, the rib and channel gaps are read temporarily into the acx and axx arrays. The code converts these to areas based on the cell lengths $\mathrm{dz}(j \mathrm{z})$.

\section{Section 18}

\section{Channel 1 axial cell geometry and hydraulic parameters}

Section 18 is read by subroutine GEOFLD and takes on one of three forms:

For iuform $=1$ (axial and azimuthal uniformity)

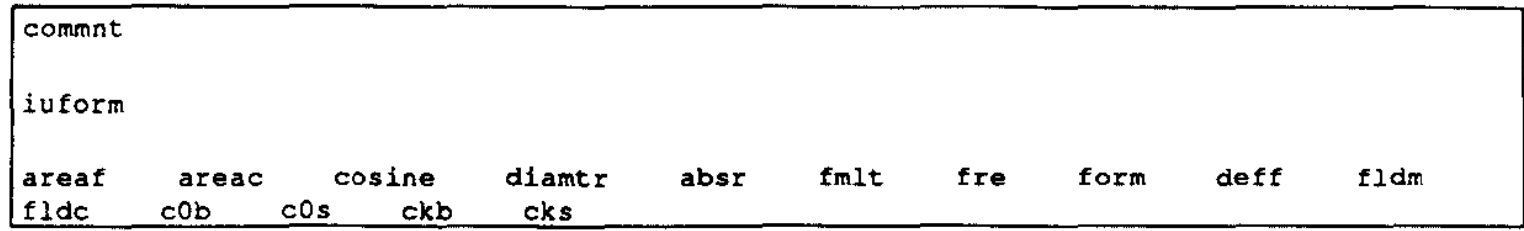

For i uform $=2$ (axial uniformity)

\begin{tabular}{|c|c|c|c|c|c|c|c|}
\hline commnt & & & & & & & \\
\hline iuform & & & & & & & \\
\hline $\operatorname{acz}(2$ & $.1,11$ & $\operatorname{azz}(2$ & $, 1,1)$ & $\cos z 12$ & $, 1,1)$ & $\operatorname{dhz}(2$ & $, 1,1)$ \\
\hline $\operatorname{absrz} 12$ & $.1,1)$ & fmltz 12 & $.1,1)$ & frez 12 & $.2,11$ & formz $(2$ & $, 1,1)$ \\
\hline $\operatorname{deffz}(2$ & $, 1,11$ & fldmz (2 & $, 1,1)$ & $f l d c z(2$ & $, 1,1)$ & & \\
\hline $\operatorname{cobz} 12$ & $, 1,1)$ & $\cos z 12$ & $.1,1)$ & $c k b z(2$ & $, 1,1)$ & $\operatorname{cksz}(2$ & $.1,1)$ \\
\hline $\operatorname{acz}(2$ & $.2,1)$ & $a z z 12$ & $, 2,1)$ & $\cos z 12$ & $, 2,1)$ & $\operatorname{dhz}(2$ & $, 2,1)$ \\
\hline$a b \leq x \geq 12$ & $, 2,11$ & $f m l t z 12$ & $, 2,1)$ & frez $(2$ & $, 2,1)$ & formz 12 & $, 2,1)$ \\
\hline $\operatorname{def} \mathrm{fz}(2$ & $.2,1)$ & $\mathrm{f} 1 \mathrm{dm} z(2$ & $.2,1)$ & fldcz $(2$ & $, 2,1)$ & & \\
\hline $\mathrm{cObz}(2$ & $, 2,1)$ & $\cos z(2$ & $, 2,1)$ & ckbz (2 & $, 2,1)$ & $\operatorname{cksz} 12$ & $, 2,1)$ \\
\hline $\operatorname{acz} 12$ & $, 3,1)$ & $\operatorname{azz}(2$ & $, 3,1)$ & $\cos z(2$ & $, 3,11$ & $\operatorname{dhz}(2$ & $, 3,1)$ \\
\hline absrz 12 & $.3,1)$ & fmltz 2 & $.3,1)$ & $\operatorname{Erez}(2$ & $.3,1)$ & formz 12 & $, 3,1)$ \\
\hline $\operatorname{de} f f z(2$ & $, 3,1)$ & $f \operatorname{ldm} z(2$ & $, 3,1)$ & fldcz $(2$ & $, 3,1)$ & & \\
\hline $\operatorname{cobz} 12$ & $.3,11$ & $\cos z(2$ & $.3,1)$ & $\mathrm{ckbz}(2$ & $, 3,11$ & $c k s z 12$ & $, 3,1)$ \\
\hline $\operatorname{acz}(2$ & $.4,11$ & $\operatorname{azz}(2$ & $, 4,1)$ & $\cos z(2$ & $, 4,1)$ & $\operatorname{dh} z(2$ & $, 4,1)$ \\
\hline abssz 12 & $, 4,1)$ & fmltz 12 & $.4,11$ & frez $(2$ & $, 4,11$ & formz 12 & $, 4,11$ \\
\hline $\operatorname{def} f z<2$ & $, 4,11$ & fldmz ( 2 & $, 4,1)$ & fldez $\{2$ & $, 4,1)$ & & \\
\hline $\mathrm{cOb}_{2} 12$ & $, 4,1\}$ & $\cos 212$ & $, 4,1)$ & $c k b z 12$ & $, 4,1)$ & cksz 12 & $, 4,1)$ \\
\hline
\end{tabular}


For iuform $=3$

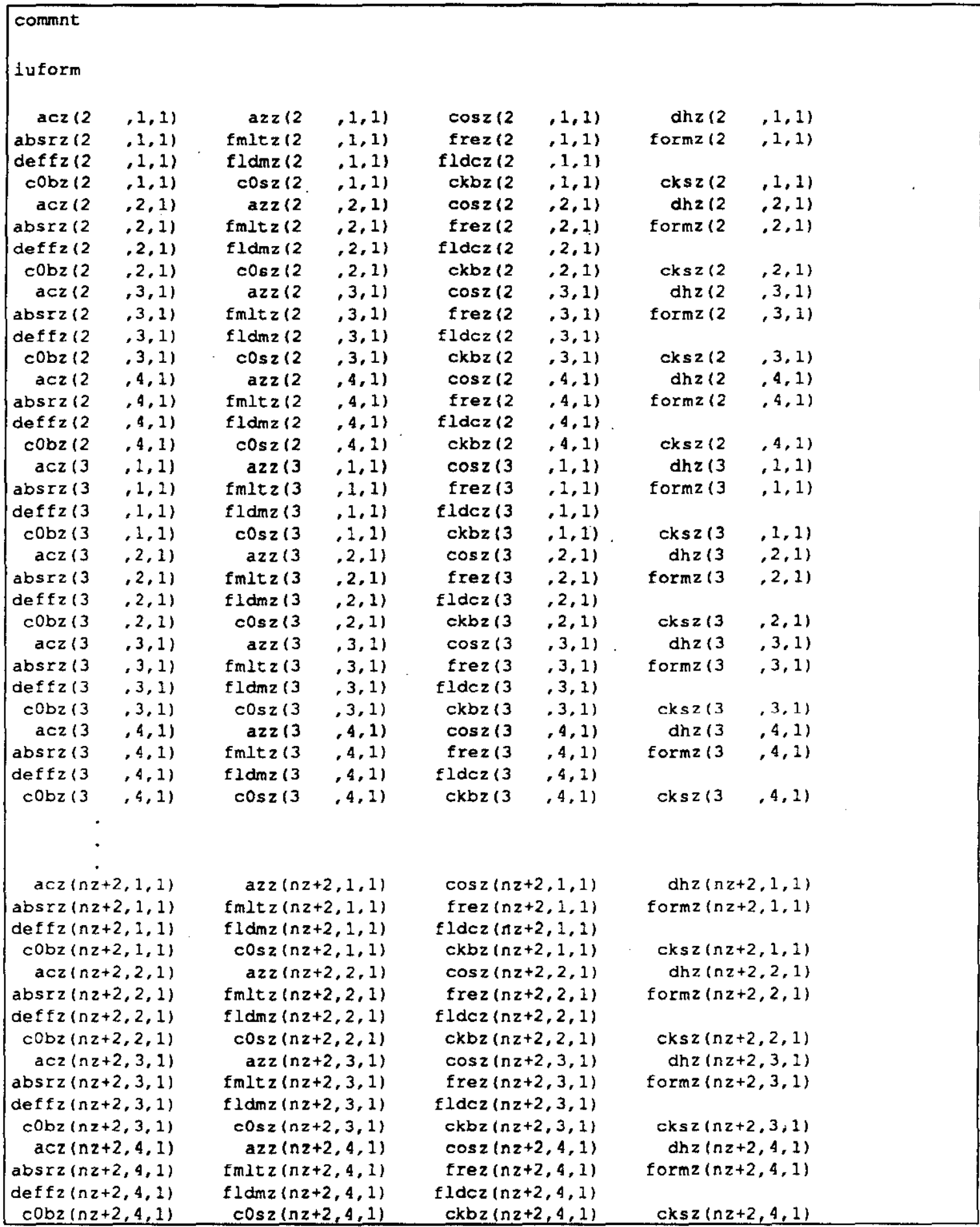

where 


$$
\begin{aligned}
& \text { iuform } \equiv \text { Uniformity flag. Options are } \\
& 1 \text { for axially and azimuthally uniform cell parameters } \\
& 2 \text { for axially uniform cell parameters } \\
& 3 \text { for individually specified cell parameters } \\
& \text { areaf/acz }(j z, i x, i c) \equiv \text { Face area } \\
& \text { areac/azz }(j z, i x, i c) \equiv \text { Cell area } \\
& \cos i n e / \cos z(j z, i x, i c) \equiv \text { Face direction cosine. Specify }+1.0 \text { for a } \\
& \text { gravitational vector aligned with the positive } z \\
& \text { direction. } \\
& \text { diamt } r / d h z(j z, i x, i c) \equiv \text { Face hydraulic diameter } \\
& a b s r / a b s r z(j z, i x, i c) \equiv \text { Face absolute wall roughness } \\
& \text { fmlt fmltz }(j z, i x, i c) \equiv \text { Face frictional drag multiplier } \\
& f r e / f r e z(j z, i x, i c) \equiv \text { Face hydraulic diameter correction factor, } K_{h} \text {. } \\
& \text { form/formz }(j z, i x, i c) \equiv \text { Face form loss coefficient } \\
& \operatorname{def} f / \operatorname{deffz}(j z, i x, i c) \equiv \text { Face characteristic dimension for the slug flow regime } \\
& f l d m / f l d m z(j z, i x, i c) \equiv \text { Face parameter } m \text { in CCFL correlation } \\
& f l d c / f l d c z(j z, i x, i c) \equiv \text { Face parameter } C \text { in CCFL correlation } \\
& \mathrm{cOb} / \mathrm{CObz}(j z, i x, i c) \equiv \text { Face distribution coefficient for the bubbly regime } \\
& \cos / \cos z(j z, i x, i c) \equiv \text { Face distribution coefficient for the slug regime } \\
& c k b / c k b z(j z, i x, i c) \equiv \text { Face drift velocity correlation coefficient for the bubbly } \\
& \text { regime } \\
& c k s / c k s z(j z, i x, i c) \equiv \text { Face drift velocity correlation coefficient for the slug } \\
& \text { regime }
\end{aligned}
$$

The number of cells in the Middle section is $n z$ (numbered internally from 2 to $n z+1$ ) while the number of faces is $n z+1$ (numbered internally from 2 to $n z+2$ ). Input is read for $j z=2$ to $n z+2$. The value read for $a z z(n z+2$, ix, 1$)$ is extraneous and not used by the code.

\section{Sections $18+1$ through $18+3($ nchn -1$)$}

Sections 16,17 and 18 are repeated for each additional channel in the Middle section. 
Section 19+3(nchn - 1) Bottom section cell geom. and hydr. parameters

Section $19+3$ (nchn -1 ) is read by subroutine GEOFLD and takes on one of four forms depending on the values of iuform:

For iuform $=1$ and then 1

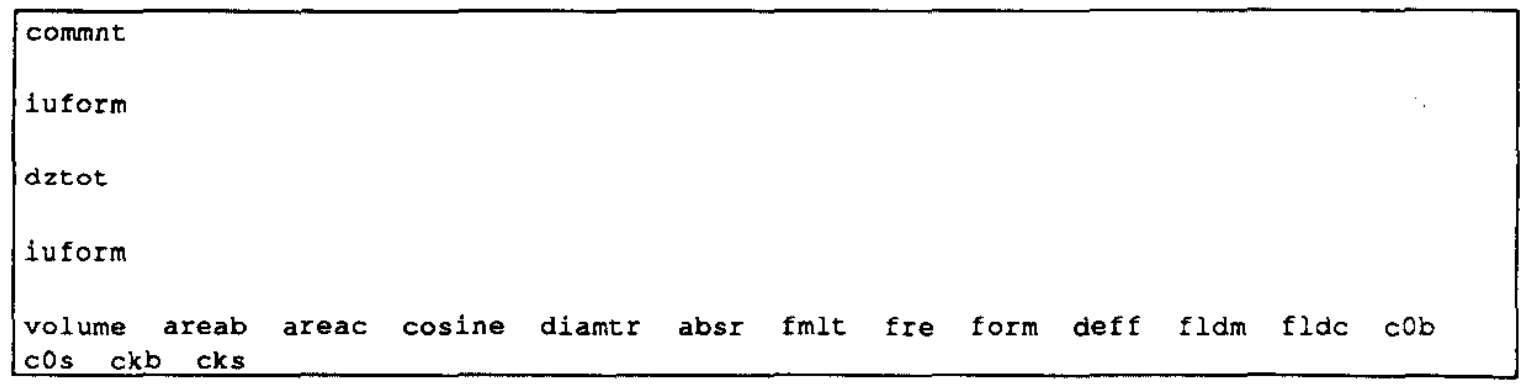

For iuform $=2$ and then 1

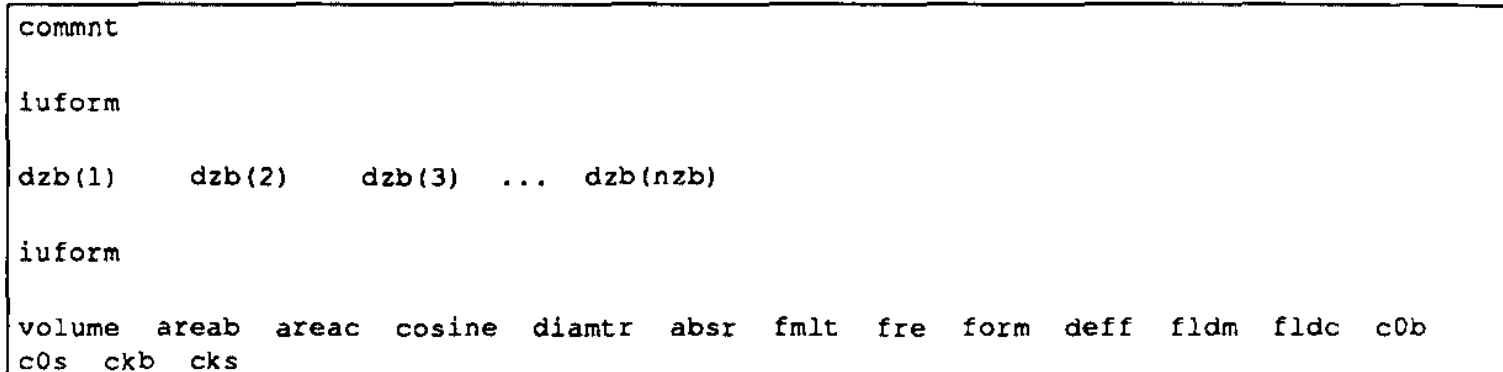

For $i$ uform $=1$ and then 2

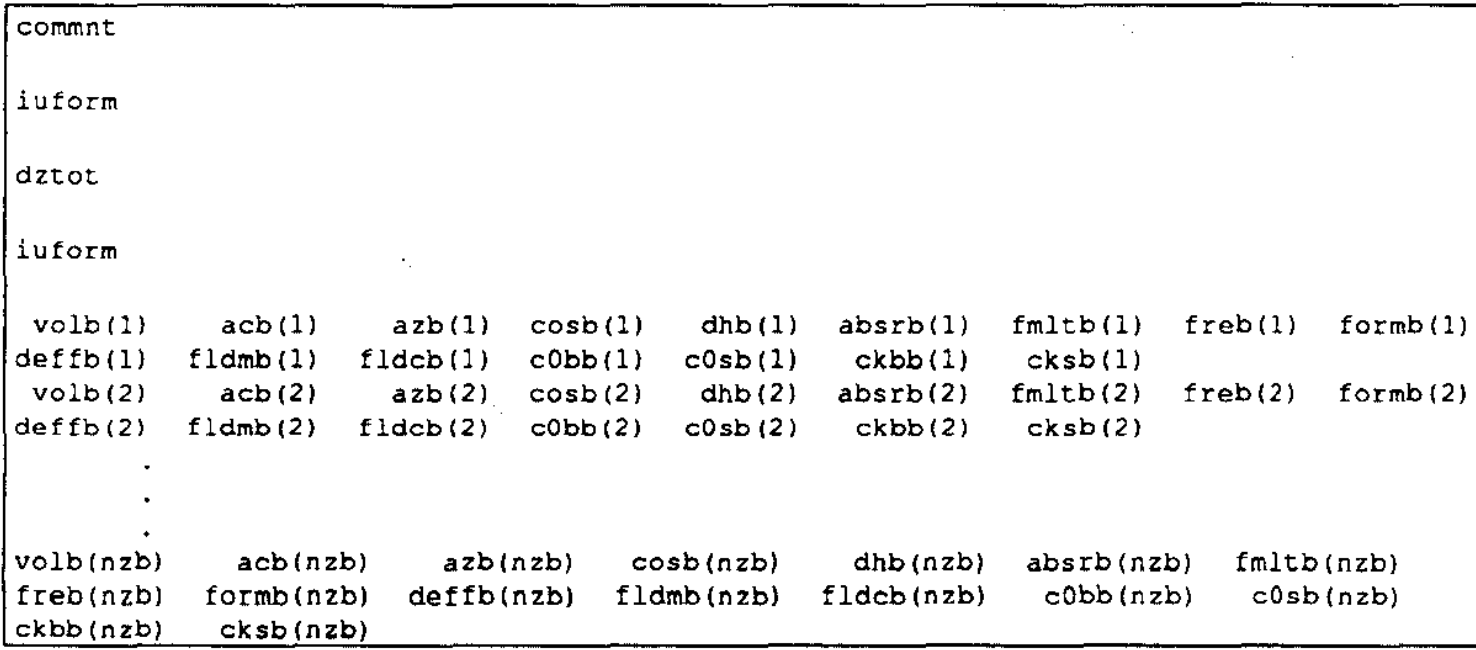


For 1 uform $=2$ and then 2

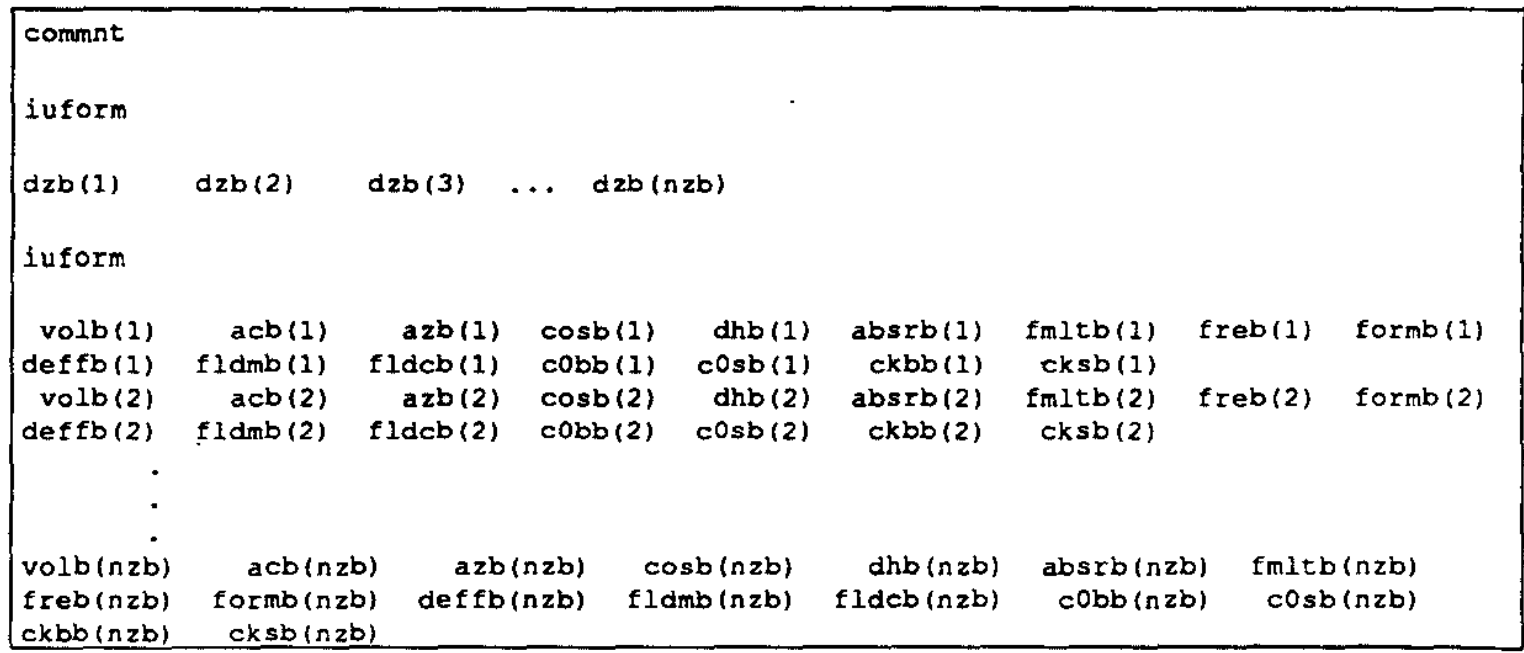

where

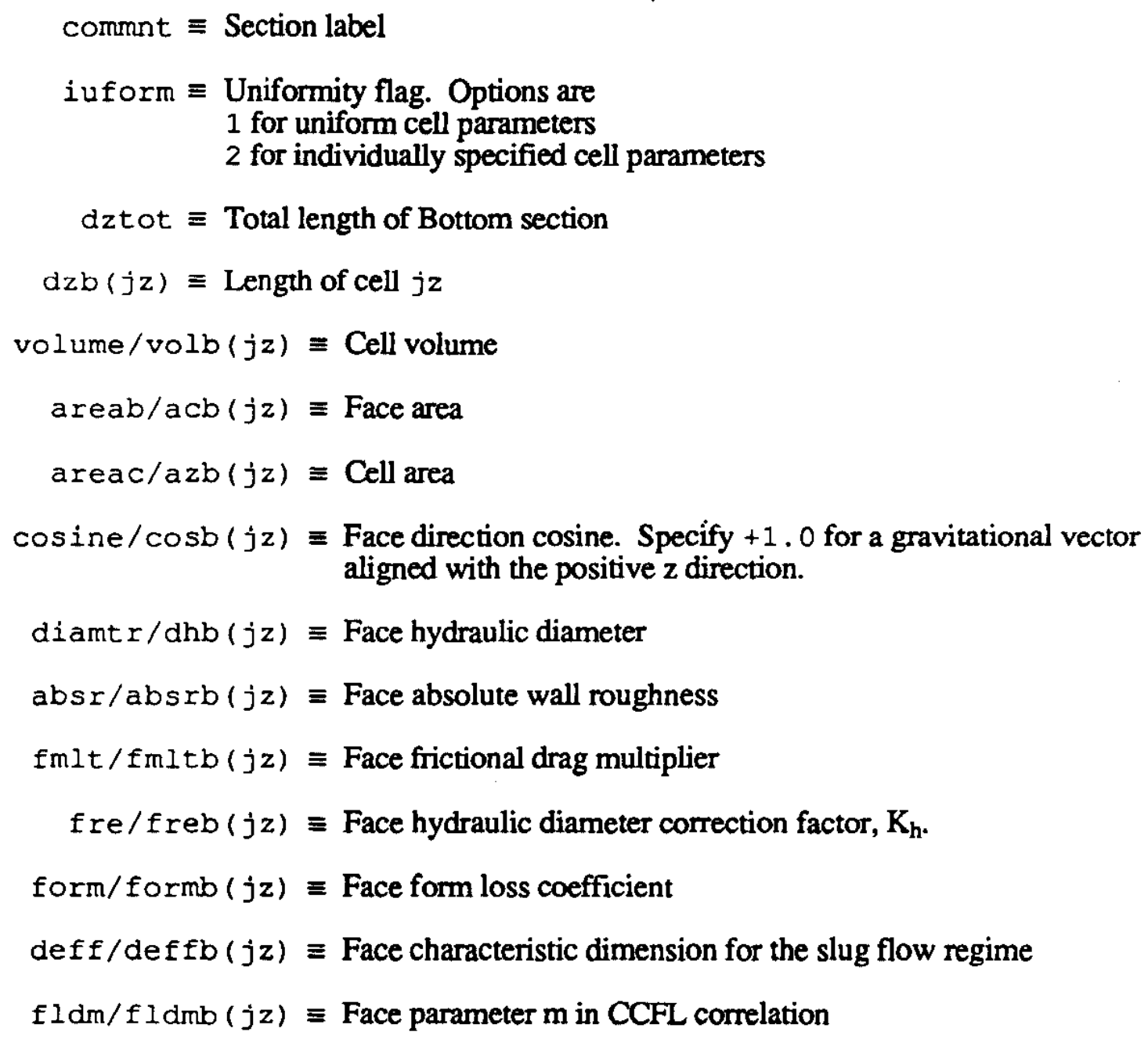
aligned with the positive $\mathrm{z}$ direction.

diamtr/dhb $(j z) \equiv$ Face hydraulic diameter

$a b s r / a b s r b(j z) \equiv$ Face absolute wall roughness

fmlt $/ f m I t b(j z) \equiv$ Face frictional drag multiplier

$\mathrm{fre} / \mathrm{freb}(j z) \equiv$ Face hydraulic diameter correction factor, $\mathbf{K}_{\mathrm{h}}$.

form/formb $(j z) \equiv$ Face form loss coefficient

$\operatorname{def} f / \operatorname{deffb}(j z) \equiv$ Face characteristic dimension for the slug flow regime

$f I d m / f I d m b(j z) \equiv$ Face parameter $m$ in CCFL correlation 


\section{$f l d c / f l d c b(j z) \equiv$ Face parameter $C$ in CCFL correlation}

$\mathrm{cOb} / \mathrm{cObb}(j z) \equiv$ Face distribution coefficient for the bubbly regime

$\mathrm{c} 0 \mathrm{~s} / \mathrm{cosb}(j z) \equiv$ Face distribution coefficient for the slug regime

$\mathrm{ckb} / \mathrm{ckbb}(\mathrm{jz}) \equiv$ Face drift velocity correlation coefficient for the bubbly regime

$\mathrm{cks} / \mathrm{cksb}(j z) \equiv$ Face drift velocity correlation coefficient for the slug regime

\section{$\overline{\text { Section } 20+3 \text { (nchn }-1) \quad \text { Tank Bottom boundary cell geometry }}$}

The section starts with a comment line followed by a line specifying the Tank Bottom cell volume and cell center area. Section $20+3(\mathrm{nchn}-1)$ is read by subroutine GEOFLD and takes the form

commnt
voltb actb

where

$$
\begin{aligned}
\text { commnt } & \equiv \text { Section label } \\
\text { volpl } & \equiv \text { Volume of Tank Bottom boundary cell } \\
\text { acpl } & \equiv \text { Cell center area of Tank Bottom boundary cell }
\end{aligned}
$$

$\overline{\text { Section } 21+3 \text { (nchn }-1)}$

Section $21+3($ nchn -1 ) is read by subroutine GEOSLD and takes the form

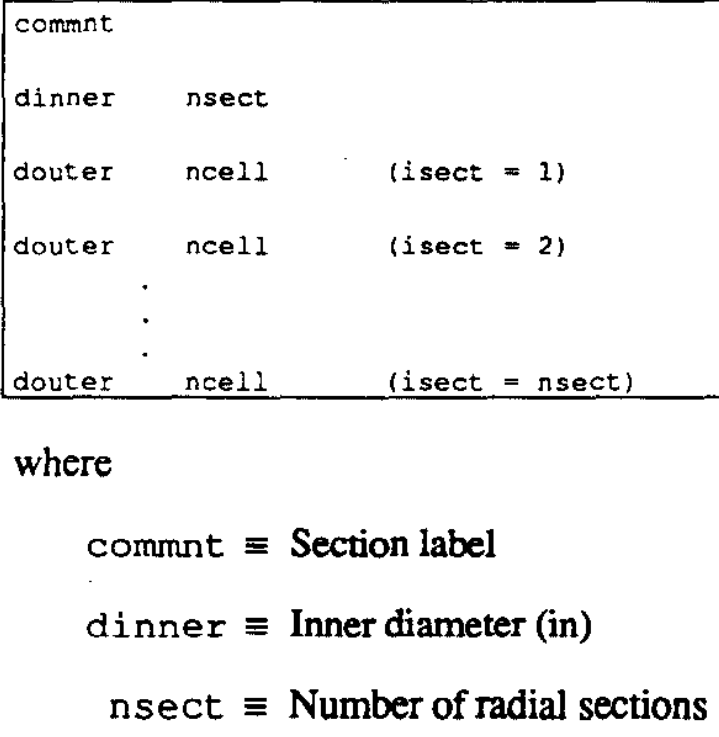

where

$$
\begin{aligned}
\text { commnt } & \equiv \text { Section label } \\
\text { dinner } & \equiv \text { Inner diameter (in) } \\
\text { nsect } & \equiv \text { Number of radial sections }
\end{aligned}
$$


douter $\equiv$ Outer diameter of section (in)

nce $11 \equiv$ Number of radial cells in section

Section 22+3(nchn - 1)

Solid cylinder 1 rib characteristics

Section $22+3($ nchn -1$)$ is read by subroutine GEOSLD and takes the form

commnt

where

commnt $\equiv$ Section label

$$
\begin{aligned}
\operatorname{iorib}(i c y l n) \equiv & \text { Rib presence flag. Options are } \\
& 0 \text { for no ribs } \\
& 1 \text { for ribs on outer surface of solid cylinder } \\
& -1 \text { for ribs on inner surface of solid cylinder } \\
\operatorname{ribl}(i c y l n) \equiv & \text { Rib length (in) } \\
\operatorname{ribt}(i c y l n) \equiv & \text { Rib half thickness (in) }
\end{aligned}
$$

Section $23+3(n c h n-1)$

Solid cylinder 1 material composition

Section $23+3(n c h n-1)$ is read by subroutine GEOSLD and takes the form

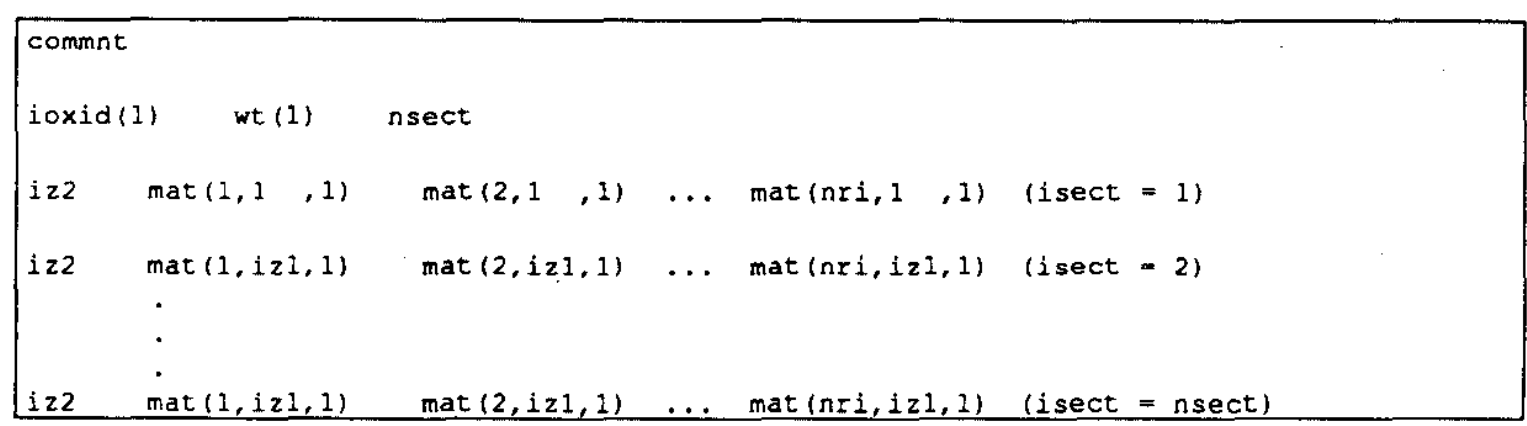

where

$$
\begin{aligned}
\text { commnt } & \equiv \text { Section label } \\
\text { ioxid }(i c y l n) & \equiv \text { Not used. Specify } 0 \\
w t(i c y l n) & \equiv \text { Weight percent of U or Li in U-Al or Li-Al alloy } \\
n s e c t ~ & \equiv \text { Number of axial material sections } \\
i z 2 & \equiv \text { Number of last axial layer in each material section }
\end{aligned}
$$


iz1 $\equiv$ Number of first axial layer in material section

\section{$n r i \equiv$ Total number of radial cells}

mat $(i r, i z 1, i c y l n) \equiv$ Material identification flag. Options are

1 for Uranium

2 for Aluminum

3 for 304L Stainless Steel

4 for Lithium -Aluminum Alloy

5 for Uranium-Aluminum Alloy

6 for 6063 Aluminum

7 for Macor

8 for Inconel 600

9 for Flame Sprayed Oxide

Axial layers iz, where $i z 2$-previous line $<i z \leq i z 2$-current line, are assigned the material identification number given on the $i z 2$ line. The last $i z 2$ must agree with $n z$ specified above.

Sections $23+1+3(n c h n-1)$ through $23+3(n c y) n-1)+3(n c h n-1)$

Sections 21, 22 and 23 are repeated for each additional solid cylinder in the Middle section.

\section{Section $\overline{24+3(n c h n-1)+3(n c y) n-1)}$ Surface criteria checking fiags}

Section $24+3($ nchn -1$)+3($ ncy $1 n-1)$ is read by subroutine GEOSLD and takes the form

commnt

ichks (1) ichks(2) ... ichks (nsurf)

where

commnt $\equiv$ Section label

ichks (isurf) $\equiv$ Power iteration criteria checking flag for surface number

isurf. Options are

0 for no criteria checking

1 for criteria checking

nsurf $\equiv$ Number of solid surfaces $($ ncyln + nchn +1$)$ 
Section $25+3(n c h n-3)+3(n c y l n-1)$ Plenum boundary conditions

Section $25+3($ nchn -1$)+3($ ncyln -1$)$ is read by subroutine INBOND and takes the form

\begin{tabular}{|rc|} 
commnt & \\
commnt & \\
pplo & $1 p p 1$ \\
alpplo & ialpl \\
$t f p 10$ & $1 t f p 1$ \\
$t g p 10$ & $1 t g p 1$ \\
xaplo & ixapl \\
\hline
\end{tabular}

where

$$
\begin{aligned}
& \text { commnt } \equiv \text { Section label } \\
& \text { (e.g. "BOUNDARY CONDITION INPUT SECTION") } \\
& \text { commnt } \equiv \text { Section label (e.g. "PLENUM") } \\
& \text { ppl0 } \equiv \text { Pressure spline function multiplier } \\
& \text { ippl } \equiv \text { Pressure spline function number } \\
& \text { a } 1 \text { pp } 10 \equiv \text { Void fraction spline function multiplier } \\
& \text { ialpl } \equiv \text { Void fraction spline function number } \\
& \text { tfplO } \equiv \text { Liquid temperature spline function multiplier } \\
& \text { itfpl } \equiv \text { Liquid temperature spline function number } \\
& \text { tgplo } \equiv \text { Gas temperature spline function multiplier } \\
& \text { itgpl } \equiv \text { Gas temperature spline function number } \\
& \text { xap10 } \equiv \text { Air mass fraction spline function multiplier } \\
& \text { ixapl } \equiv \text { Air mass fraction spline function number }
\end{aligned}
$$


Section $26+3($ nchn -1$)+3($ ncyln -1$)$

Tank Bottom boundary conditions

Section $26+3($ nehn -1$)+3($ ncyln -1$)$ is read by subroutine INBOND and takes the form

\begin{tabular}{|rc|}
\hline commnt & \\
ptbo & iptb \\
alptbo & laltb \\
tftbo & itftb \\
tgtbo & itgtb \\
xatbo & ixatb \\
\hline
\end{tabular}

where

$$
\begin{aligned}
& \text { commnt } \equiv \text { Section label (e.g. "TANK BOTTOM") } \\
& \text { ptbo } \equiv \text { Pressure spline function multiplier } \\
& \text { iptb } \equiv \text { Pressure spline function number } \\
& \text { alptbo } \equiv \text { Void fraction spline function multiplier } \\
& \text { ia } t \mathrm{tb} \equiv \text { Void fraction spline function number } \\
& \text { tftbo } \equiv \text { Liquid temperature spline function multiplier } \\
& \text { itftb } \equiv \text { Liquid temperature spline function number } \\
& \text { tgtbo } \equiv \text { Gas temperature spline function multiplier } \\
& \text { itgtb } \equiv \text { Gas temperature spline function number } \\
& \text { xatbo }=\text { Air mass fraction spline function multiplier } \\
& \text { ixatb } \equiv \text { Air mass fraction spline function number }
\end{aligned}
$$

Section $27+3($ nchn -1$)+3($ ncy $1 n-1)$

Inlet flowrates

Section $27+3(n c h n-1)+3($ ncy $1 n-1)$ is read by subroutine INBOND and takes the form

commnt
gfino iqfin
ggino iggin

where

$$
\text { commnt } \equiv \text { Section label }
$$


qfino $\equiv$ Multiplier to inlet liquid volumetric flowrate spline function iqf in $\equiv$ Inlet liquid volumetric flowrate spline function number qgino $\equiv$ Multiplier to inlet gas volumetric flowrate spline function iqgin $\equiv$ Inlet gas volumetric flowrate spline function number

Section $28+3(n c h n-1)+3($ ncyln -1$)$

Initial inlet flowsplits

Section $28+3($ nchn -1$)+3($ ncyln -1$)$ is read by subroutine INBOND and takes the form commnt

$f \operatorname{splt}(1) \quad f \operatorname{splt}(2) \quad \ldots \quad f \operatorname{splt}(\mathrm{nch} n)$

where

$$
\text { commnt } \equiv \text { Section label }
$$

fsplt $(i c) \equiv$ Flow split for channel ic. fsplt (ic) is normalized according to

$$
\text { fsplt(ic) } \leftarrow \frac{\text { fsplt(ic) }}{\sum \text { fsplt(ic) }}
$$

so fsplt (ic) may be specified as a fraction or percentage.

Section $29+3($ nchn -1$)+3$ (ncy $1 n-1)$

Tank level

Section $29+3(n c h n-1)+3(n c y) n-1)$ is read by subroutine INBOND and takes the form

commnt

tnklvo itnkiv

where

commnt $\equiv$ Section label

tnk 1 vo $\equiv$ Multiplier to tank level spline function

itnklv $\equiv$ Tank level spline function number 
Section $30+3(\operatorname{nch} n-1)+3($ ncy $1 n-1)$

Criteria checking flags

Section $30+3($ nchn -1$)+3($ ncyln -1$)$ is read by subroutine INBOND and takes the form

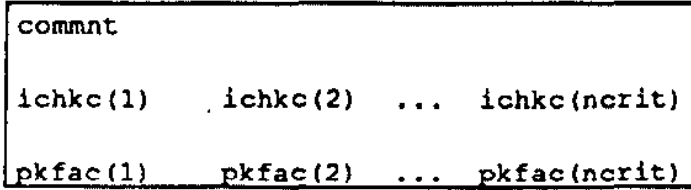

where

$$
\text { commnt } \equiv \text { Section label }
$$

$i c h k c(i c) \equiv$ Checking flag for criterion number $i c$. Options are 0 for no checking of criterion ic

1 for checking of criterion ic

pkfac (ic) $\equiv \phi_{1}$ in section 3.10 of the FLOWTRAN-TF Software Design report if $i c=1$

$\Delta \mathrm{T}_{\text {sup }}$ in section 3.10 of the FLOWTRAN-TF Software Design report if $i c=2$ or 3

$\phi_{4}$ in section 3.10 of the FLOWTRAN-TF Software Design report if ic $=4$

Section 31+3(nchn -1$)+3($ ncyln -1$)$

Criteria checking time

Section $31+3($ nchn -1$)+3($ ncy $l n-1)$ is read by subroutine INBOND and takes the form

commint

tcrmax

where

commnt $\equiv$ Section label

tcrmax $\equiv$ Time to begin criteria checking 
Section $31+(1-i \exp )+3(n c h n-1)+3(n c y l n-1) \quad$ Assembly exposure ...

Section $31+(1-1$ exp $)+3($ nchn -1$)+3($ ncyln -1$)$ is read by subroutine INPOWR only if $i \exp =O$ (otherwise omit this section) and takes the form

commnt

expose delmod deldry

where

$$
\begin{aligned}
& \text { commnt } \equiv \text { Section label } \\
& \text { expose } \equiv \text { Assembly exposure in MWD or \% U-235 bum-up } \\
& \text { delmod } \equiv \text { Fraction of deposited power from moderated decay heat } \\
& \text { deldry } \equiv \text { Fraction of deposited power from dry.decay heat }
\end{aligned}
$$

\section{Section $32+(1-i \exp )+3(n c h n-1)+3($ ncyln -1$)$ \\ Fission power - tube region power fractions}

Section $32+(1-$ iexp $)+3(n c h n-1)+3(n c y) n-1)$ is read by subroutine INDPWR and takes the form

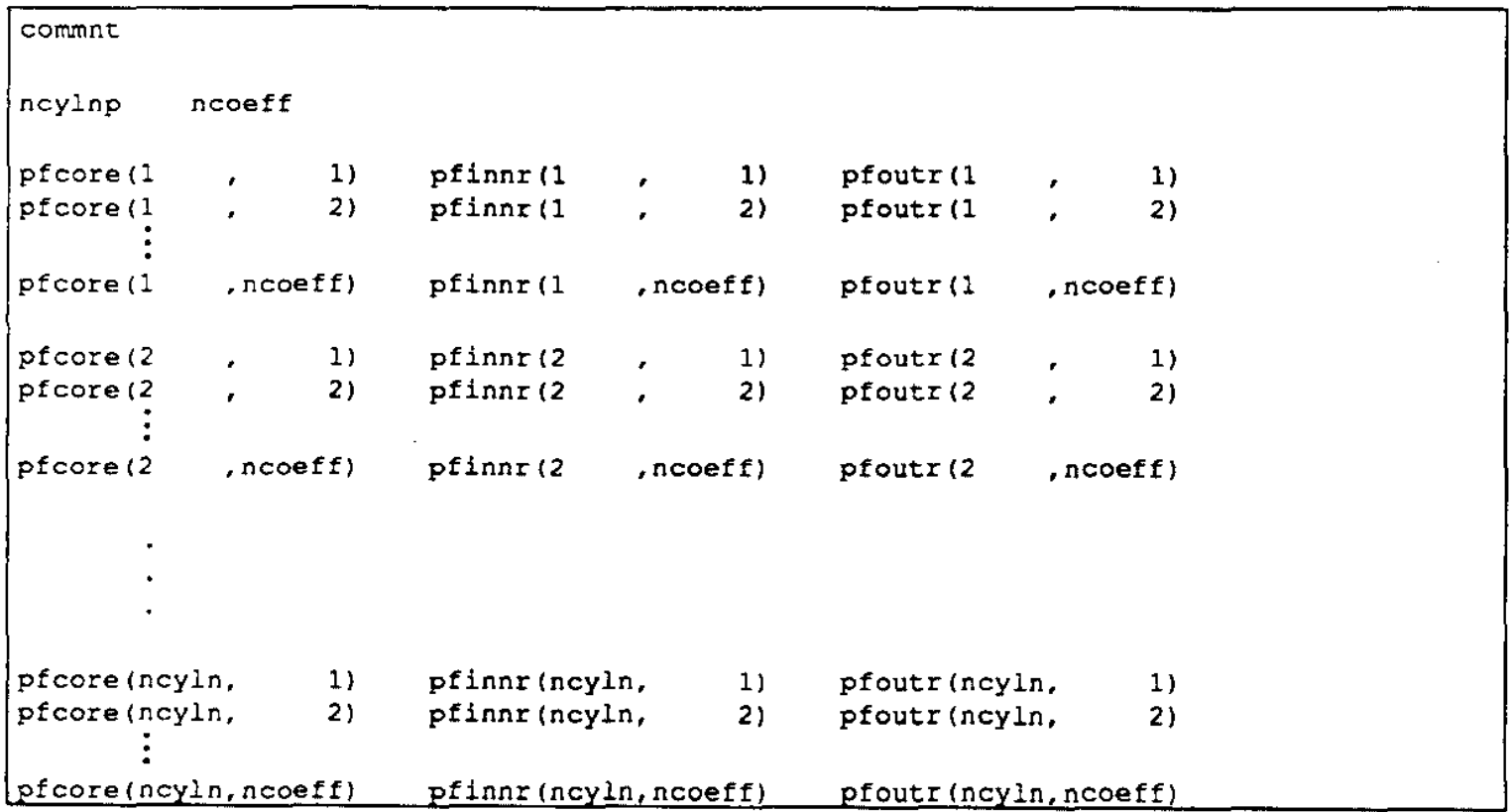

where

$$
\begin{aligned}
& \text { commnt } \equiv \text { Section label } \\
& \text { ncy lnp } \equiv \begin{array}{l}
\text { Number of cylinders (must be same as ncy ln specified } \\
\text { above) }
\end{array}
\end{aligned}
$$


ncoeff $\equiv$ Number of polynomial coefficients in each power fraction pfcore (icyln, ncf) $\equiv$ ncf th $c o e f f i c i e n t$ for power fraction polynomial in exposure for core region of cylinder icyln

pfinns (icyln, ncf) $\equiv n$ nf $^{\text {th }}$ coefficient for power fraction polynomial in exposure for inner clad region of cylinder icy in

pfoutr (icyln, ncf) $\equiv$ ncf th $c$ cofficient for power fraction polynomial in exposure for outer clad region of cylinder icyln

See section 3.2 of the FLOWTRAN-TF Software Design report for more information.

Section $33+(1-1$ exp $)+3$ (nchn -1$)+3($ neyln -1$)$

Fission power - radial power shapes

Section $33+(1-1$ exp $)+3(n c h n-1)+3($ ncy $1 n-1)$ is read by subroutine INDPWR and takes the form

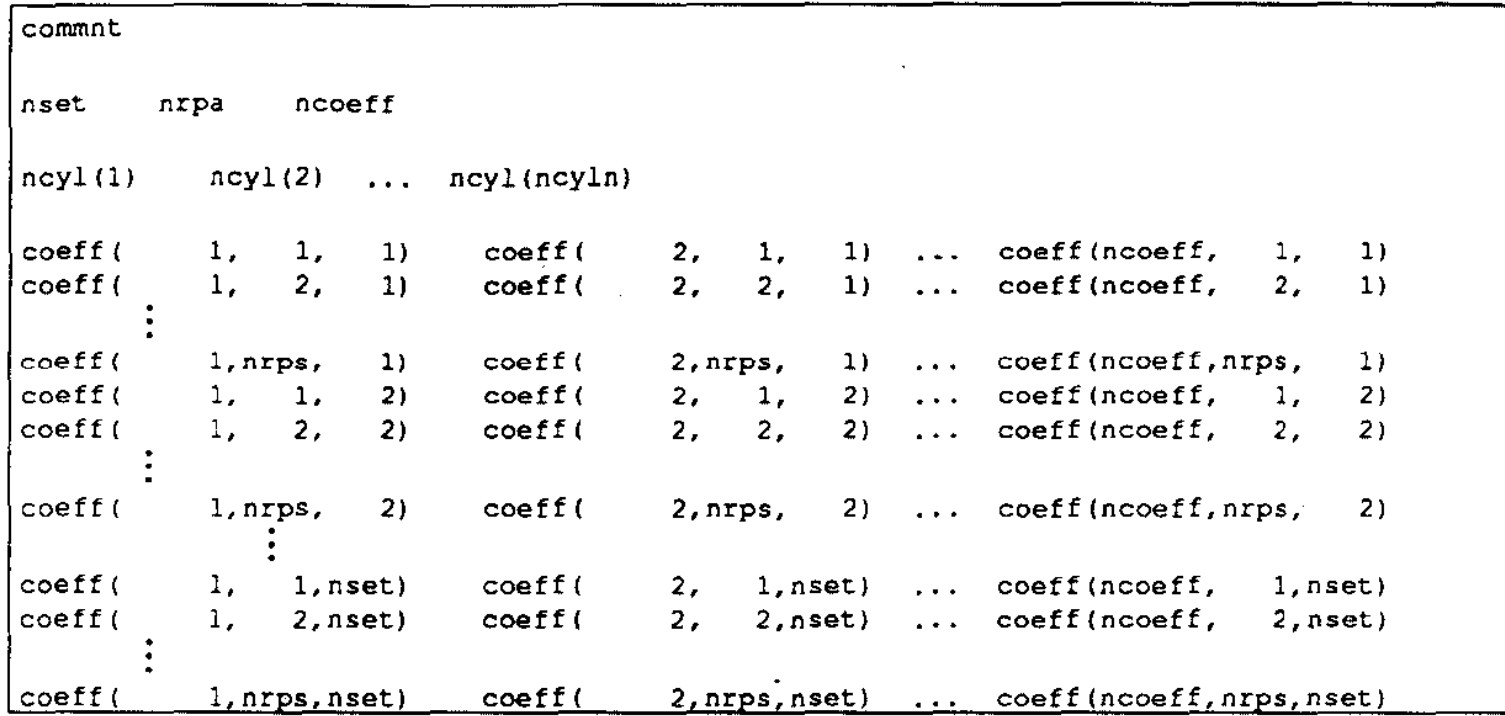

where

$$
\begin{aligned}
\text { commnt } & \equiv \text { Section label } \\
\text { nset } & \equiv \text { Number of sets of radial profiles } \\
\text { nrpa } & \equiv \text { Number of radial points in each set } \\
\text { ncoeff } & \equiv \text { Number of coefficients in each set }
\end{aligned}
$$

coeff $(n c, n p, n s) \equiv n c^{\text {th }}$ coefficient for radial power polynomial in exposure for point np and cylinder set ns

See section 3.2 of the FLOWTRAN-TF Software Design report for more information. 


\section{Section 34+(1- 1exp) +3 (nchn -1$)+3$ (ncyln -1$)$ \\ Moderated decay power - tube region power fractions}

Section $34+(1-1$ exp $)+3(n c h n-1)+3($ ncyln -1$)$ is read by subroutine INDPWR and takes on one of two forms

For iskip $=0$

commnt

iskip

For iskip $=1$

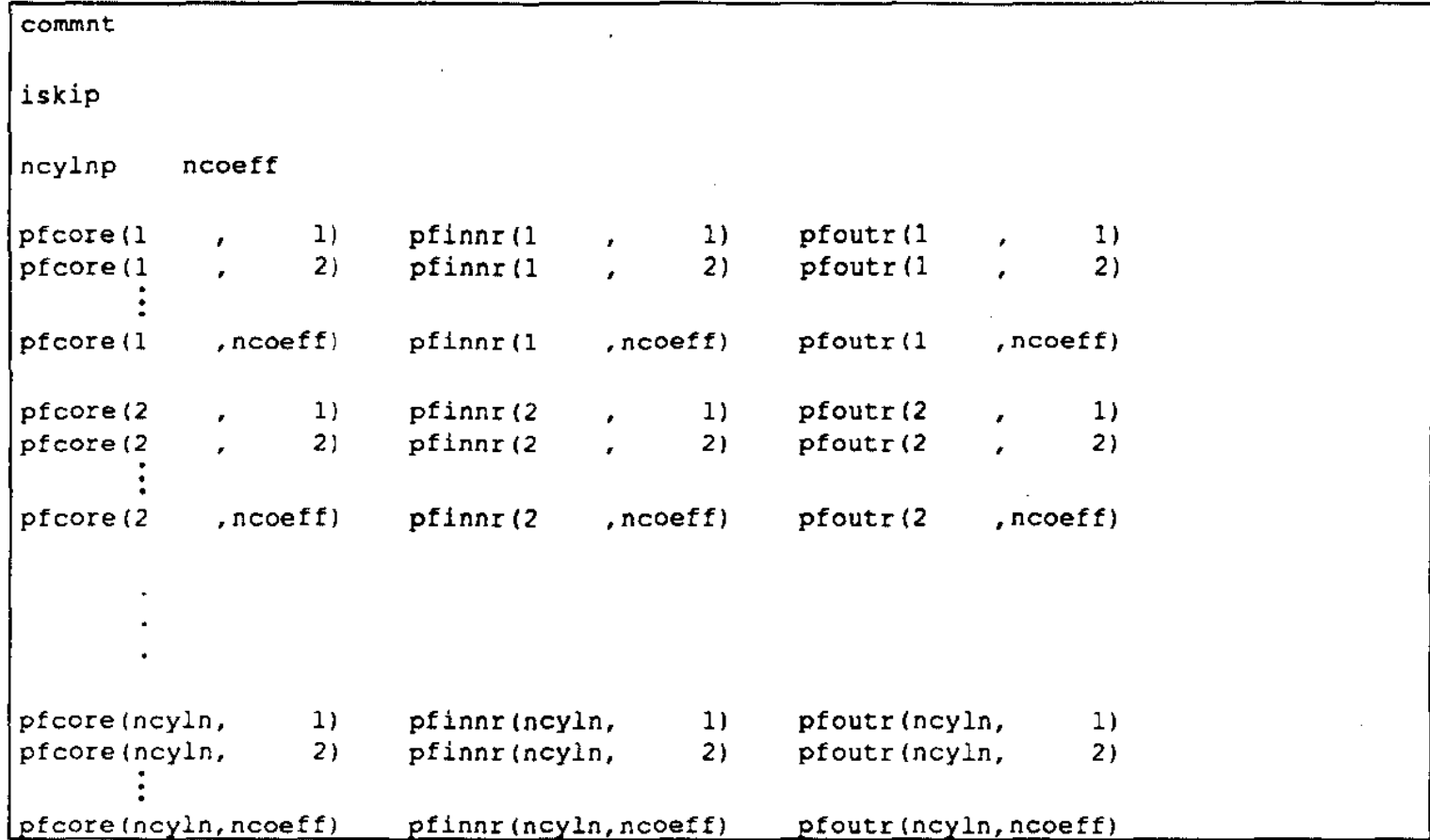

where

commnt $\equiv$ Section label

iskip $\equiv$ Moderated decay power flag. Options are 0 - use fission power shape data for moderated decay 1 - read and process moderated decay data

ncy lnp $\equiv$ Number of cylinders (must be same as ncy ln specified above)

ncoeff $\equiv$ Number of polynomial coefficients in each power fraction

pfcore $(i c y l n, n c f) \equiv n f^{\text {th }}$ coefficient for power fraction polynomial in exposure for core region of cylinder icyln 
pfinnr (icyln, ncf) $\equiv n^{\text {th }}$ coefficient for power fraction polynomial in exposure for inner clad region of cylinder icy in

pfoutr (icyln, ncf) $\equiv n$ nfth $^{\text {th }}$ coefficient for power fraction polynomial in exposure for outer clad region of cylinder icyln

See section 3.2 of the FLOWTRAN-TF Software Design report for more information.

Section $34+i s k i p+(1-i e x p)+3($ nchn -1$)+3($ ncyln -1$)$

Fission power - radial power shapes

Section $34+i s k i p+(1-i$ exp $)+3(n c h n-1)+3(n c y i n-1)$ is read by subroutine INDPWR only if iskip $=1$ above and takes the form

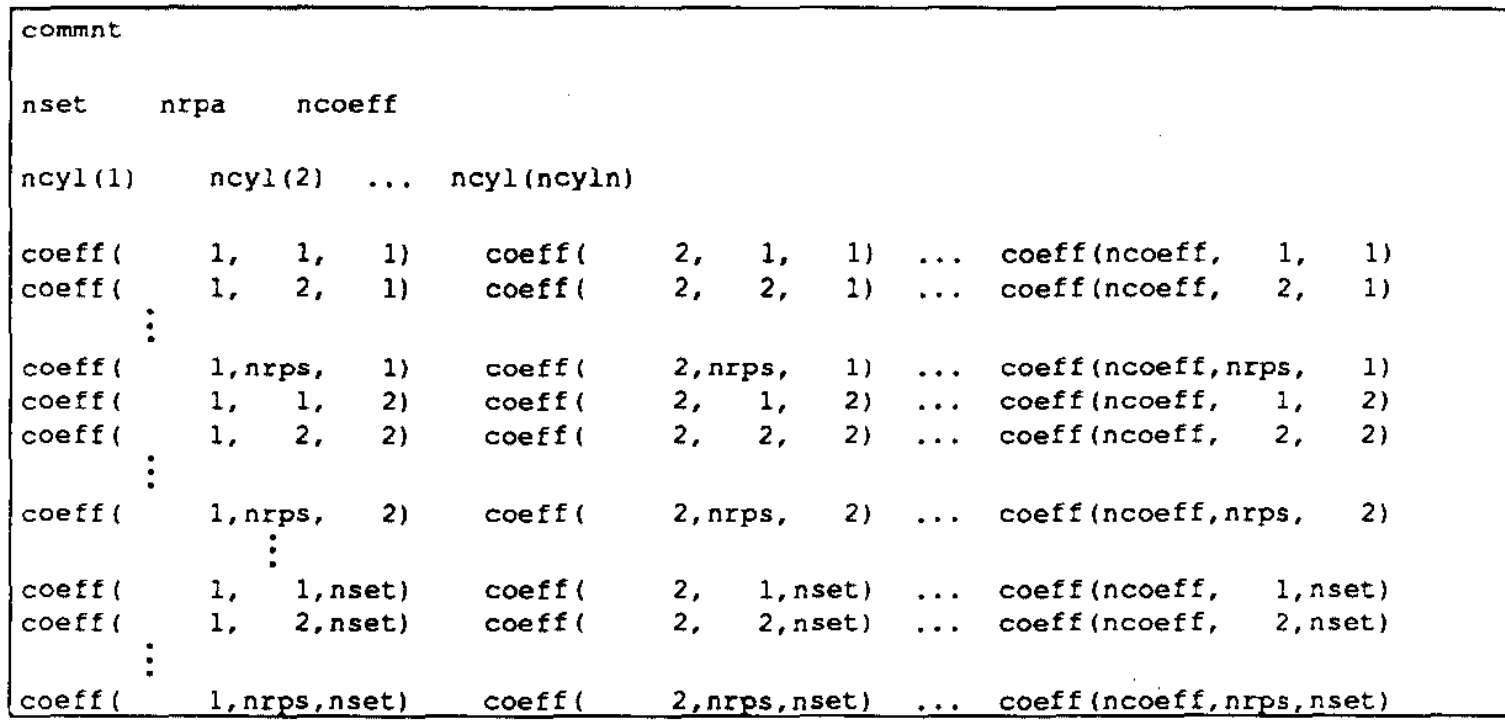

where

$$
\begin{aligned}
\text { commnt } & \equiv \text { Section label } \\
\text { nset } & \equiv \text { Number of sets of radial profiles } \\
\text { nrpa } & \equiv \text { Number of radial points in each set } \\
\text { ncoeff } & \equiv \text { Number of coefficients in each set }
\end{aligned}
$$

coeff $(n c, n p, n s) \equiv n c^{\text {th }}$ coefficient for radial power polynomial in exposure for point $\mathrm{np}$ and cylinder set ns

See section 3.2 of the FLOWTRAN-TF Software Design report for more information. 
Section $35+1$ sk1p $+(1-1$ exp $)+3($ nchn -1$)+3(n c y) n-1)$

Dry decay power - tube region power fractions

Section $35+1$ skip $+(1-1$ exp $)+3($ nchn -1$)+3($ ncyln -1$)$ is read by subroutine INDPWR and takes on one of two forms

For iskip $=0$ or 2

commnt

iskip

For iskip $=1$

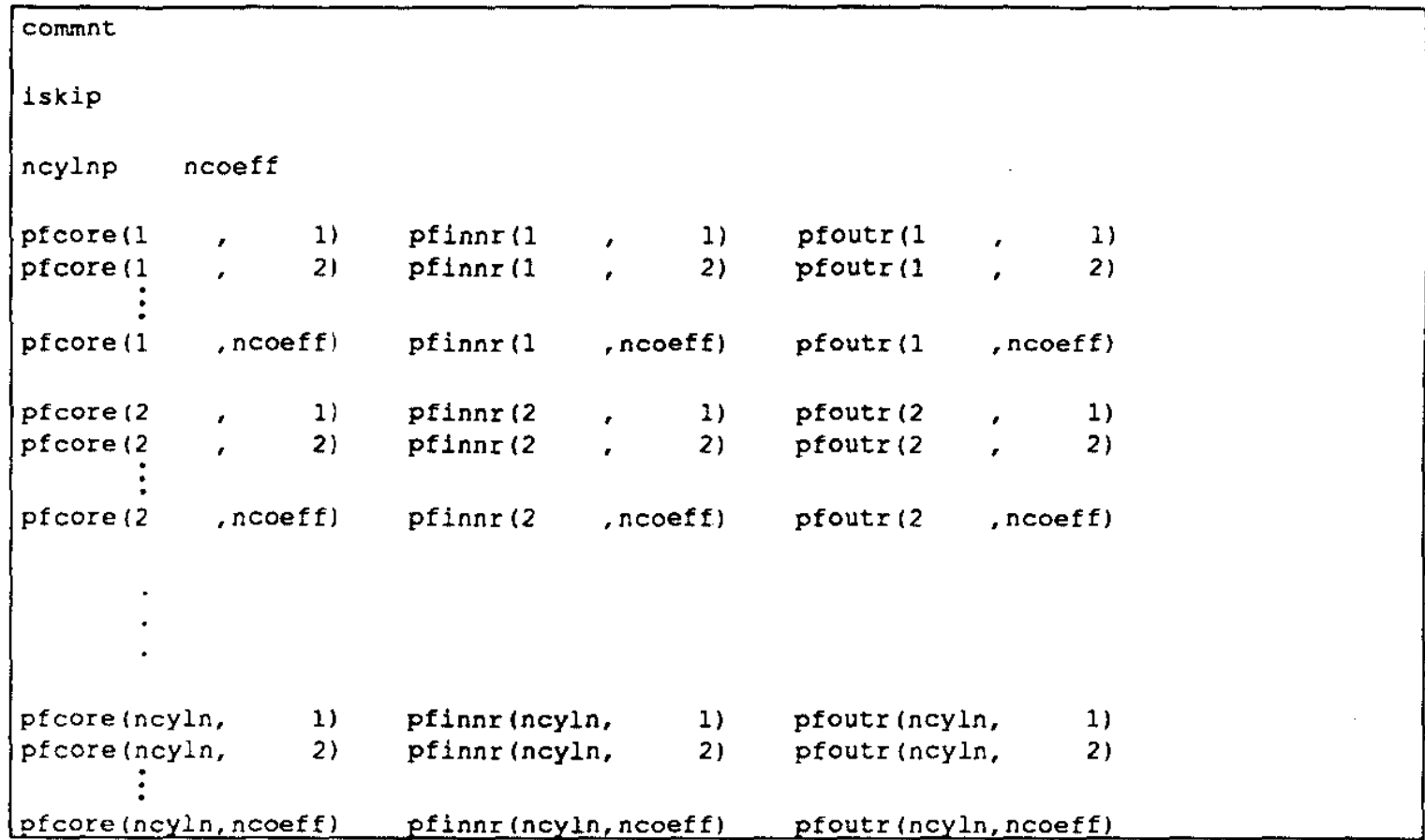

where

commnt $\equiv$ Section label

iskip $\equiv$ Moderated decay power flag. Options are

0 - use fission power shape data for dry decay

1 - read and process dry decay data

2 - use moderated decay data for dry decay

ncylnp $\equiv$ Number of cylinders (must be same as ncyln specified above)

ncoef $f \equiv$ Number of polynomial coefficients in each power fraction

pfcore (icyln, ncf) $\equiv$ ncf th coefficient for power fraction polynomial in exposure for core region of cylinder icy in 
pfinnr (icyln, ncf) $\equiv$ ncf th coefficient for power fraction polynomial in exposure for inner clad region of cylinder icy in

pfoutr (icyln, ncf) $\equiv$ ncf th $c 0$ fficient for power fraction polynomial in exposure for outer clad region of cylinder icy in

See section 3.2 of the FLOWTRAN-TF Software Design report for more information.

Section $35+i s k i p(d r y$, if $=1)+i$ skip (moderated $)+(1-i \exp )+3($ nchn -1$)+3($ ncyln -1$)$

Fission power - radial power shapes

Section $35+$ iskip (dry, if $=1)+i$ skip (moderated $)+(1-i$ exp $)+3($ nchn -1$)+3($ ncy 1 n -1$)$ is read by subroutine INDPWR only if $i s k i p=1$ above and takes the form

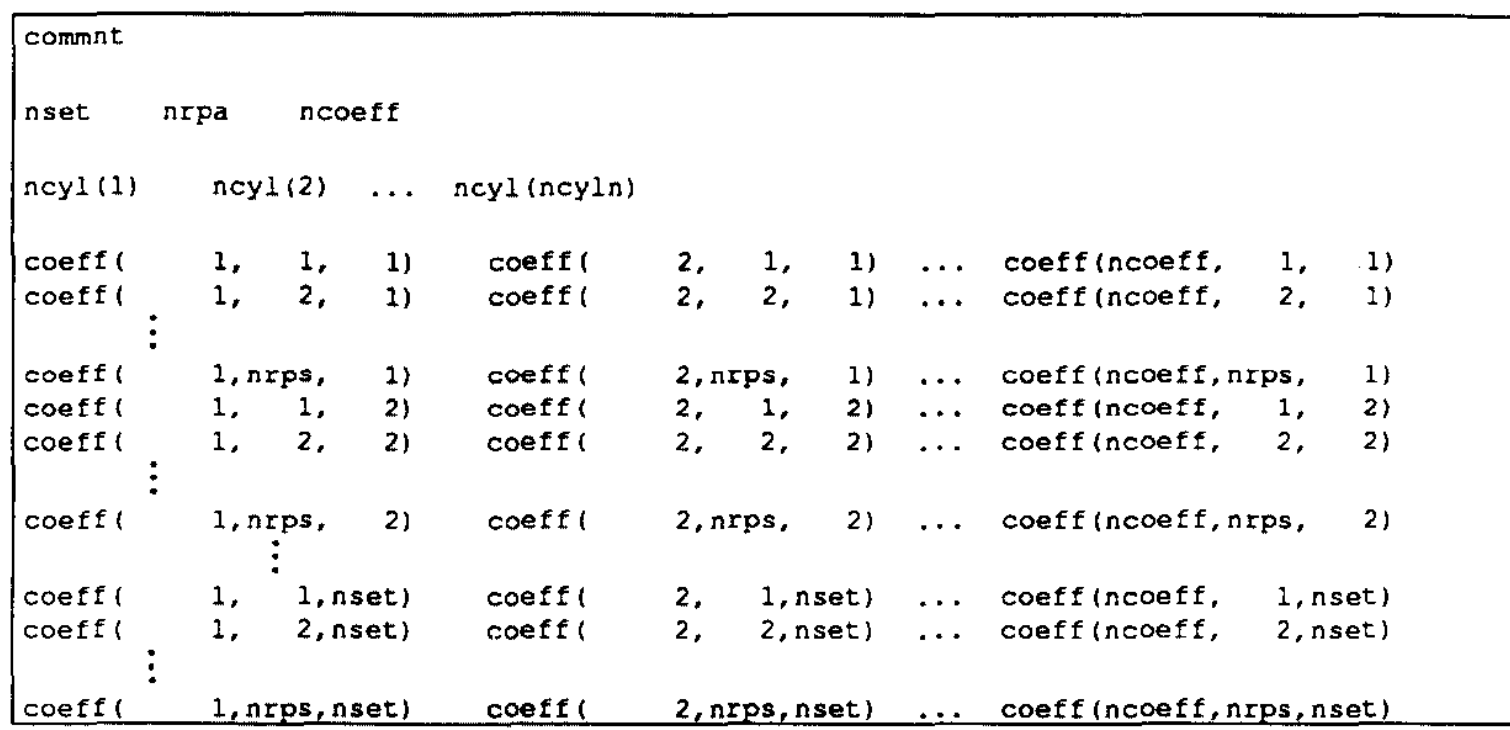

where

$$
\begin{aligned}
\text { commnt } & \equiv \text { Section label } \\
\text { nset } & \equiv \text { Number of sets of radial profiles } \\
\text { nrpa } & \equiv \text { Number of radial points in each set } \\
\text { ncoeff } & \equiv \text { Number of coefficients in each set }
\end{aligned}
$$

coeff $(n c, n p, n s) \equiv n c^{\text {th }}$ coefficient for radial power polynomial in exposure for point np and cylinder set ns

See section 3.2 of the FLOWTRAN-TF Software Design report for more information. 
Section $36+1 s k 1 p(d r y$, if $=1)+1$ skip (moderated $)+(1-1$ exp $)+3($ nchn -1$)+3$ (ncyln -1$)$

Azimuthal power shapes

Section $36+1$ skip $($ dry, if $=1)+1$ skip (moderated $)+(1-1$ exp $)+3($ nchn -1$)+3($ ncyln -1$)$ is read by subroutine INPOWR and takes the form

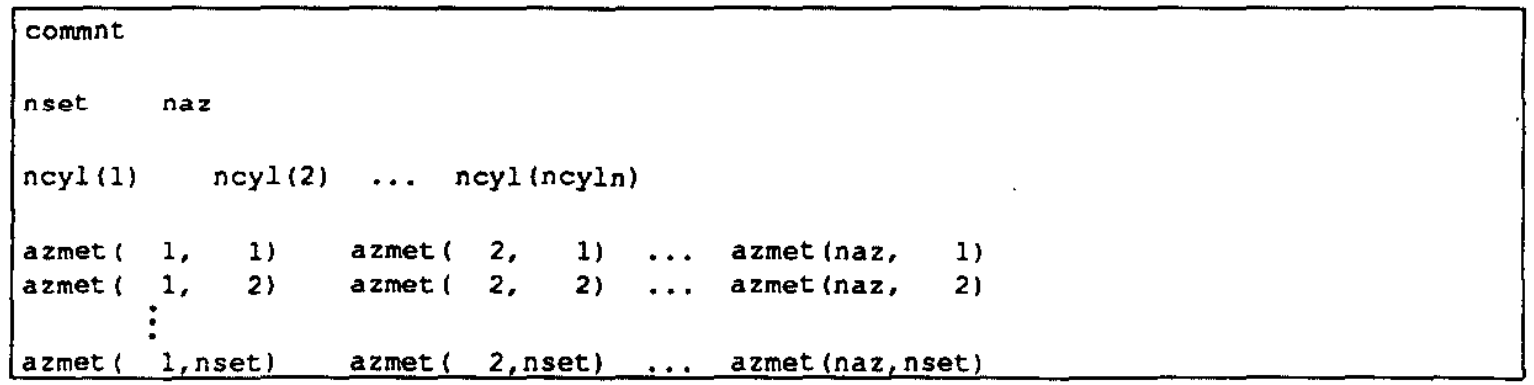

where

$$
\begin{aligned}
\text { commnt } & \equiv \text { Section label } \\
n s e t & \equiv \text { Number of sets of azimuthal profiles } \\
n a z & \equiv \text { Number of azimuthal points in each set (must equal na) } \\
n c y l(i c y l n) & \equiv \text { Azimuthal set assigned to cylinder icyln } \\
\text { azmet }(i a, n s) & \equiv \begin{array}{l}
\text { Azimuthal power shape for azimuthal position ia and azimuthal } \\
\text { profile set } n s
\end{array}
\end{aligned}
$$

See section 3.2 of the FLOWTRAN-TF Software Design report for more information.

Section $37+i s k i p(d r y$, if $=1)+i s k i p($ moderated $)+(1-i$ exp $)+3(n c h n-1)+3(n c y)-1 n$
Power profile spline pointers

Section $37+i \operatorname{skip}(d r y$, if $=1)+i \operatorname{skip}($ moderated $)+(1-i \exp )+3($ nchn -1$)+3($ ncyln -1$)$ is read by subroutine INPOWR and takes the form

ifissn imodh idryh iconh

where

$$
\begin{aligned}
\text { commnt } & \equiv \text { Section label } \\
\text { ifissn } & \equiv \text { Number of spline function for fission power transient } \\
\text { imodh } \equiv \text { Number of spline function for moderated decay power transient } & \\
\text { idryh } \equiv & \begin{array}{l}
\text { Number of spline function for dry decay power transient if } \\
\text { iexp }=0 \text { or experimental rig power transient if iexp }=1
\end{array}
\end{aligned}
$$


iconh $\equiv$ Number of spline function for conservative decay heat multiplier The conservative decay heat multiplier is not used when $i \exp =1$.

Section $38+$ iskip $($ dry, if $=1)+1$ skip (moderated $)+(1-1$ exp $)+3($ nchn -1$)+3($ ncyln -1$)$

Power profile spline pointers

Section $38+i$ skip $(d r y$, if $=1)+1$ skip (moderated $)+(1-i$ exp $)+3(n c h n-1)+3($ ncyln -1$)$ is read by subroutine INPOWR and takes the form

commnt

iaxlp(i)

timet (1) $\operatorname{tax} \operatorname{lp}(1)$ timet (1) timet (itime)

where

$$
\begin{aligned}
\text { commnt } & \equiv \text { Section label } \\
\text { iaxlp }(\text { itsec }) & \equiv \begin{array}{l}
\text { Number of spline function specifying axial power shape at at } \\
\text { time timet (itsec) }
\end{array} \\
\text { timet }(\text { itsec }) & \equiv \text { Time of iaxlp (itsec) }
\end{aligned}
$$

\section{Section $39+1$ skip $(d r y$, if $=1)+1$ sk 1 p(moderated $)+(1-1 \exp )+3($ nchn -1$)+3($ ncyln -1$)$ \\ Spline input comment}

Section $39+i \operatorname{skip}($ dry, if $=1)+i$ skip (moderated $)+(1-i \exp )+3($ nchn -1$)+3($ ncyln -1$)$ is read by subroutine INSPLN and takes the form

commnt

where

commnt $\equiv$ Section label (e.g. "SPLINE DATA INPUT") 


\section{Section $40+1$ skip $($ dry, if $=1)+1$ skip $($ moderated $)+(1-1$ exp $)+3($ nchn $-11+3$ (ncy $1 n-1)$ Spline data input}

Section $40+1$ skip $($ dry, if $=1)+1$ skip(moderated $)+(1-1$ exp $)+3(n c h n-1)+3($ ncy $1 n-1)$ is read by subroutine INSPLN and takes the form

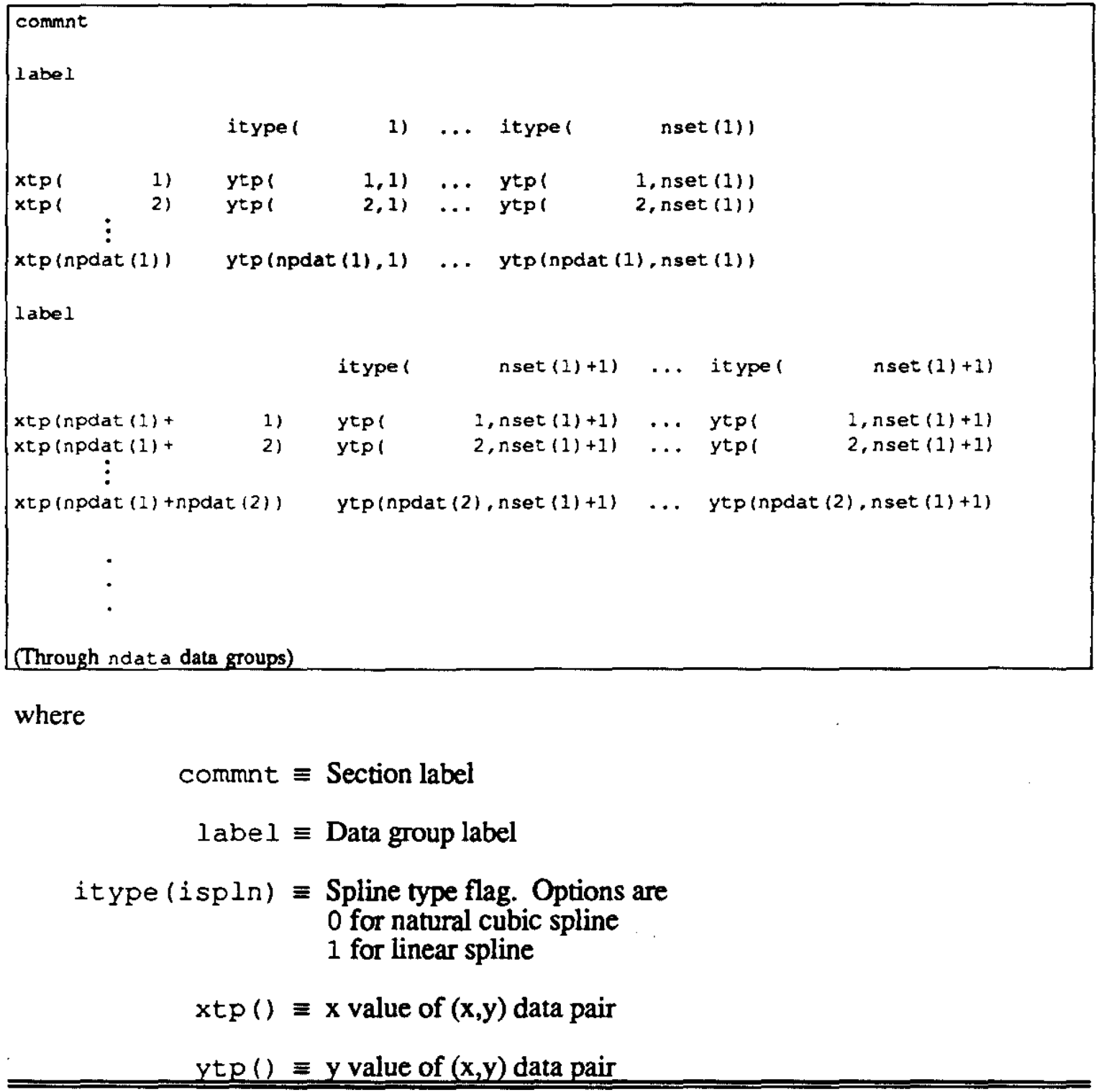




\section{Sample Input File}

The input file used to generate the VOID Rig benchmarking results for -1 psig plenum pressure, 12" tank level and $8 \mathrm{gpm}$ is listed below for the purpose of illustrating a typical FLOWTRAN-TF input file. The FLOWTRAN-TF Software Testing report describes the application in detail. The input file is saved as test_31_01_m08. in and read from unit number 5.

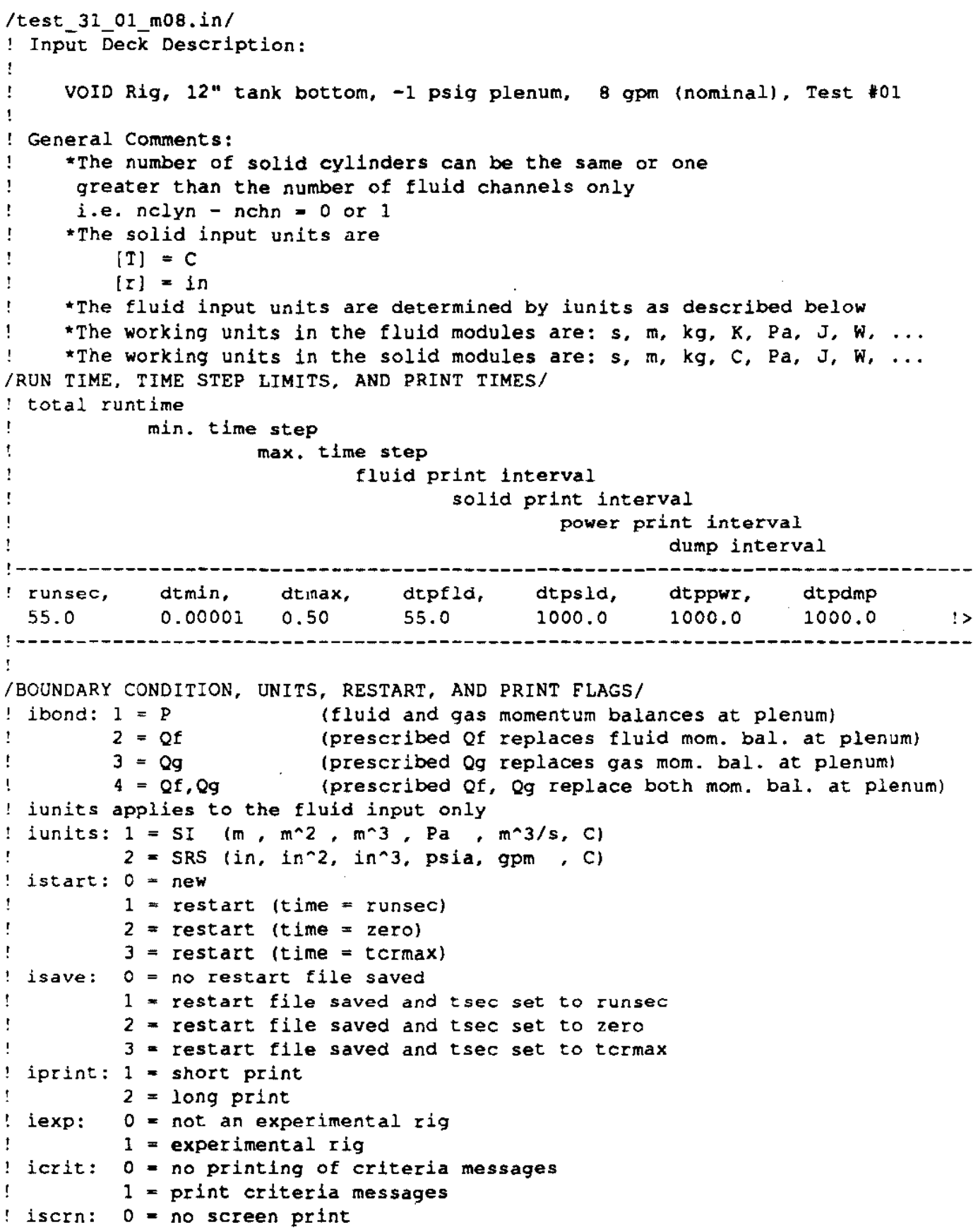




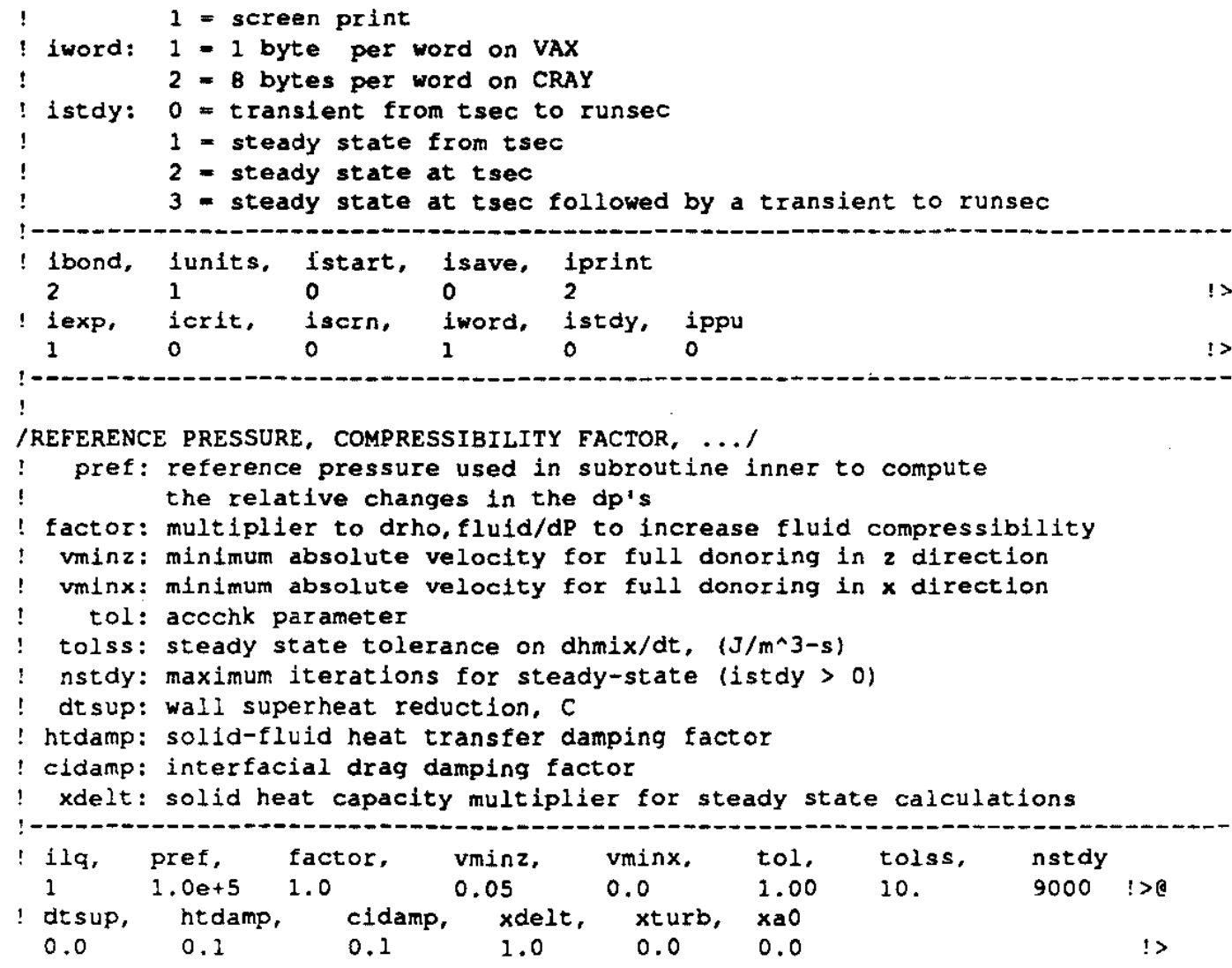

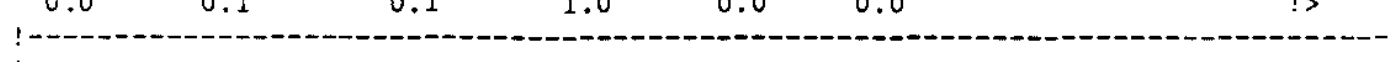

!

/BOILING CURVE AND INTERPHASE TRANSPORT OPTIONS/

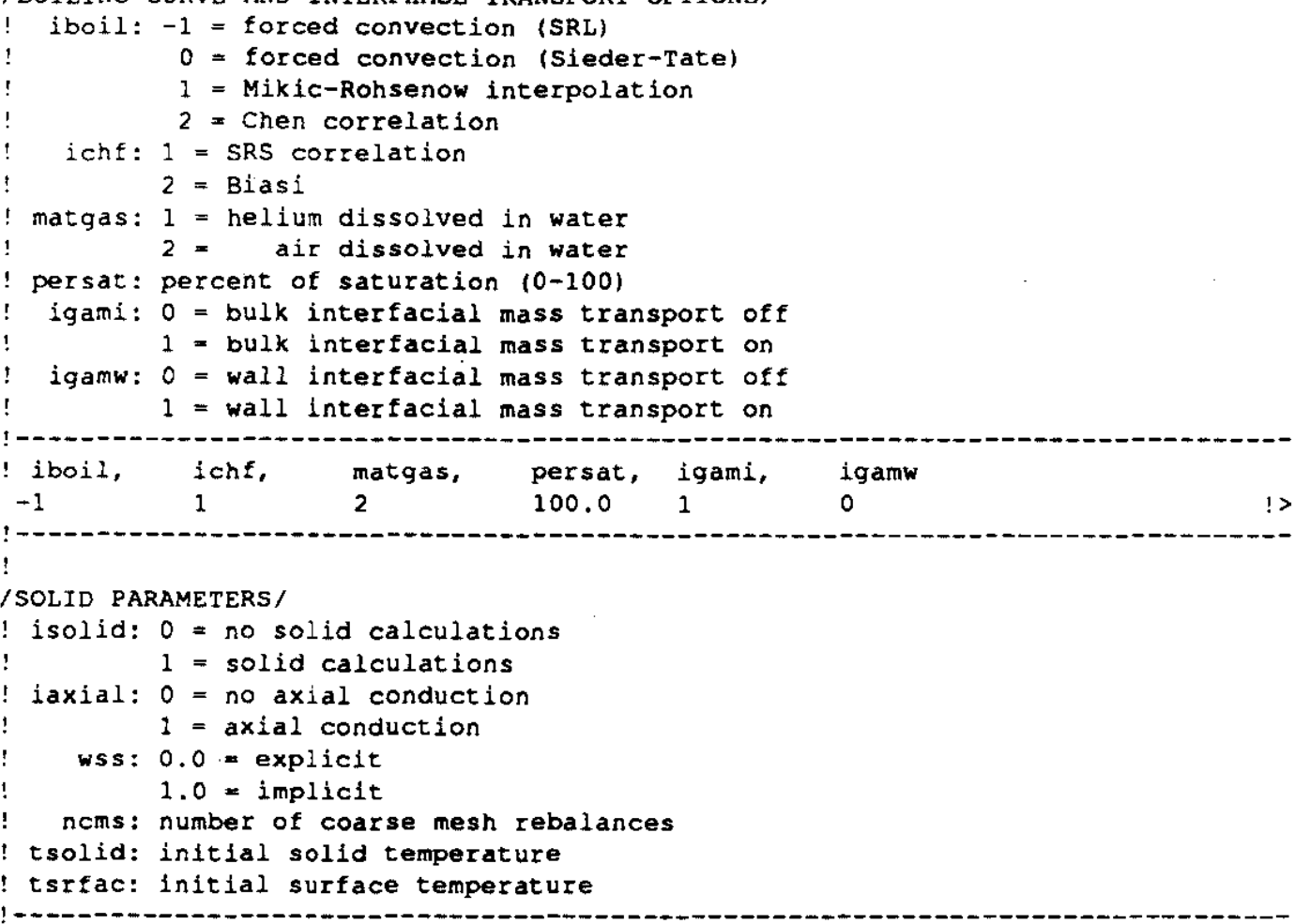




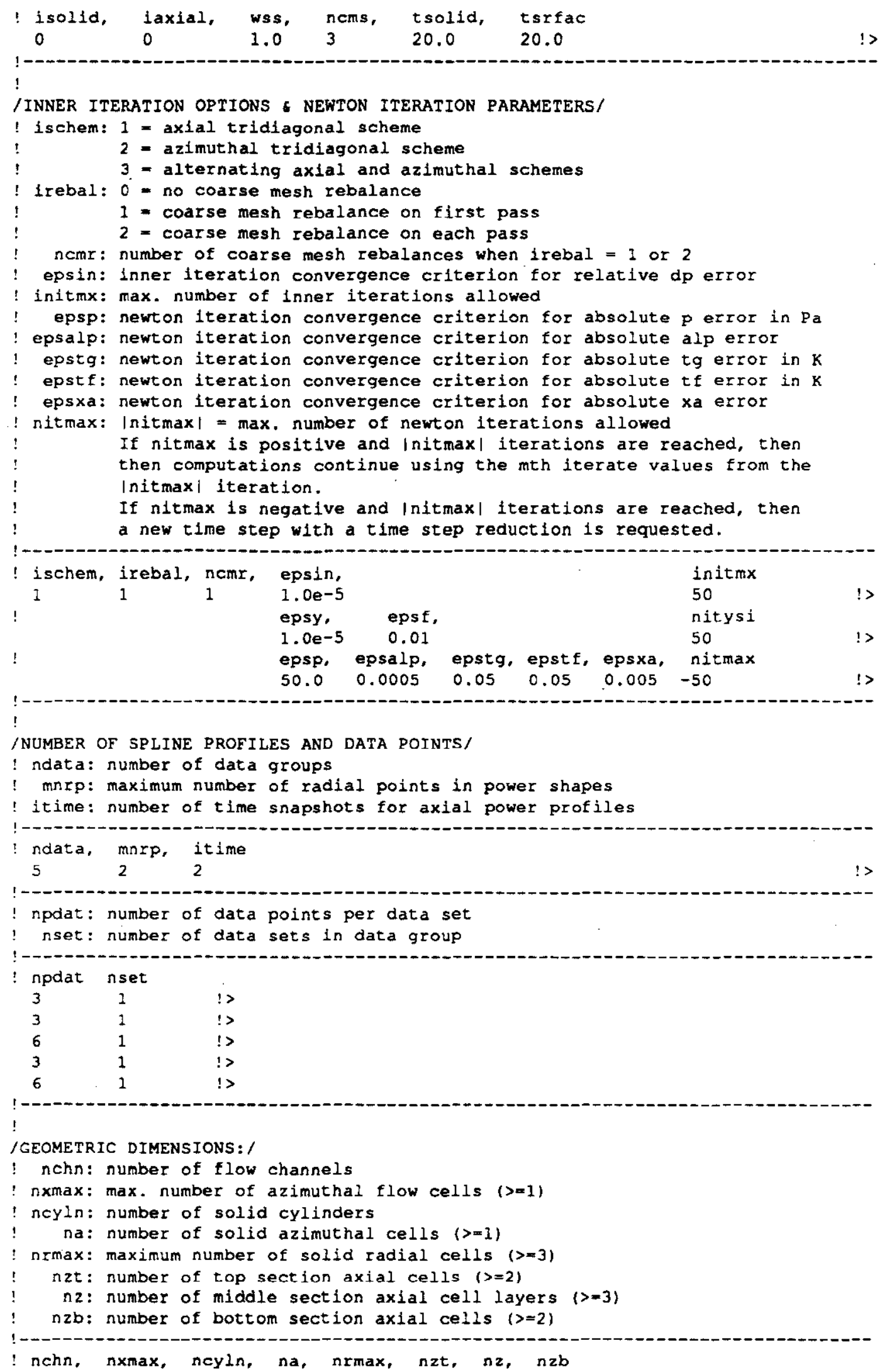




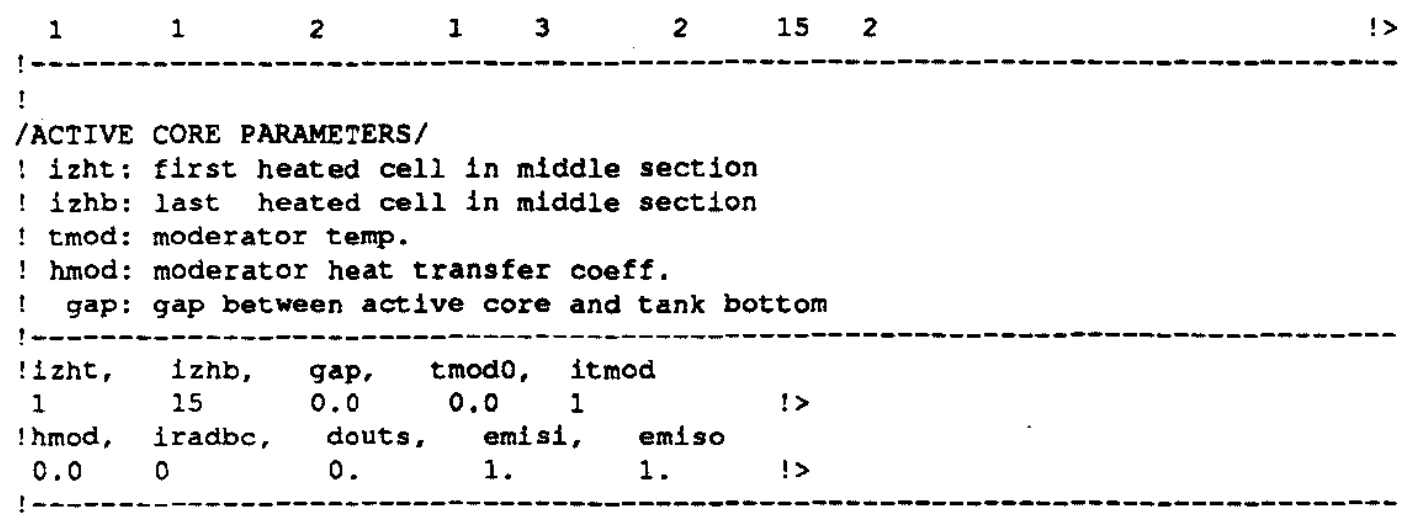

/POWER ITERATION INPUT/

! asypwr: assembly power in $\mathrm{kW}$

! maxpi: maximum number of power iterations

tolpow: tolerance on power limit

! ncrit: number of criterla used to check for power limit

! ---

! asypwr, maxpi, tolpow, nerit

$\begin{array}{lllll}0.0 & 1 & 0.005 & 4 & \text { ! }\end{array}$

!

SENSITIVITY VARIABLES INPOT SECTION

/SENSITIVITY PARAMETERS/

! cizfac: axial interfacial drag multiplying factor

cixfac: azimuthal interfacial drag MULTIPLYING FACTOR if cixfac < 0 applied as cix = cixfac*ciz azimuthal interfacial drag COEFFiCIENT if cixfac $>0$ USED ONLY IF nChn=3:

delpl: starts transition from adverse to favorable channel inlet void correlation

delp2: ends transition from adverse to favorable channel inlet void correlation

: xcofh, xreh, xcofl, xrel, xkmet, xcvmet

$\begin{array}{lllllll}1.0 & 1.0 & 1.0 & 1.0 & 1.0 & 1.0 & \text { ! }\end{array}$

: xhfi, xhgi, xkgi, xphi

$1.0 \quad 1.0 \quad 1.0 \quad 1.0$

! cizfac, cixfac, iribv

$1.0 \quad 1 . e 9 \quad 1$

! xfric, plnht, cipln, formhs, alphs

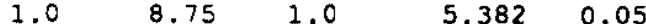

alb2, als2, ala2, expbs, expsa

! delp1, delp2, sigai, sigam, sigfi, sigfm, dalsub, thetao

$\begin{array}{lllllllll}0.0 & 200.0 & 0.0 & 0.0 & 0.0 & 0.0 & 0.0 & 0.0 & \text { !> }\end{array}$

!

FLUID GEOMETRY AND MOMENTUM CLOSURE INPUT SECTION

/TOP BOUNDARY CELL: PLENUM VOLUME AND AREA/

! volpl: plenum volume

! acpl: plenum mid-cell area 


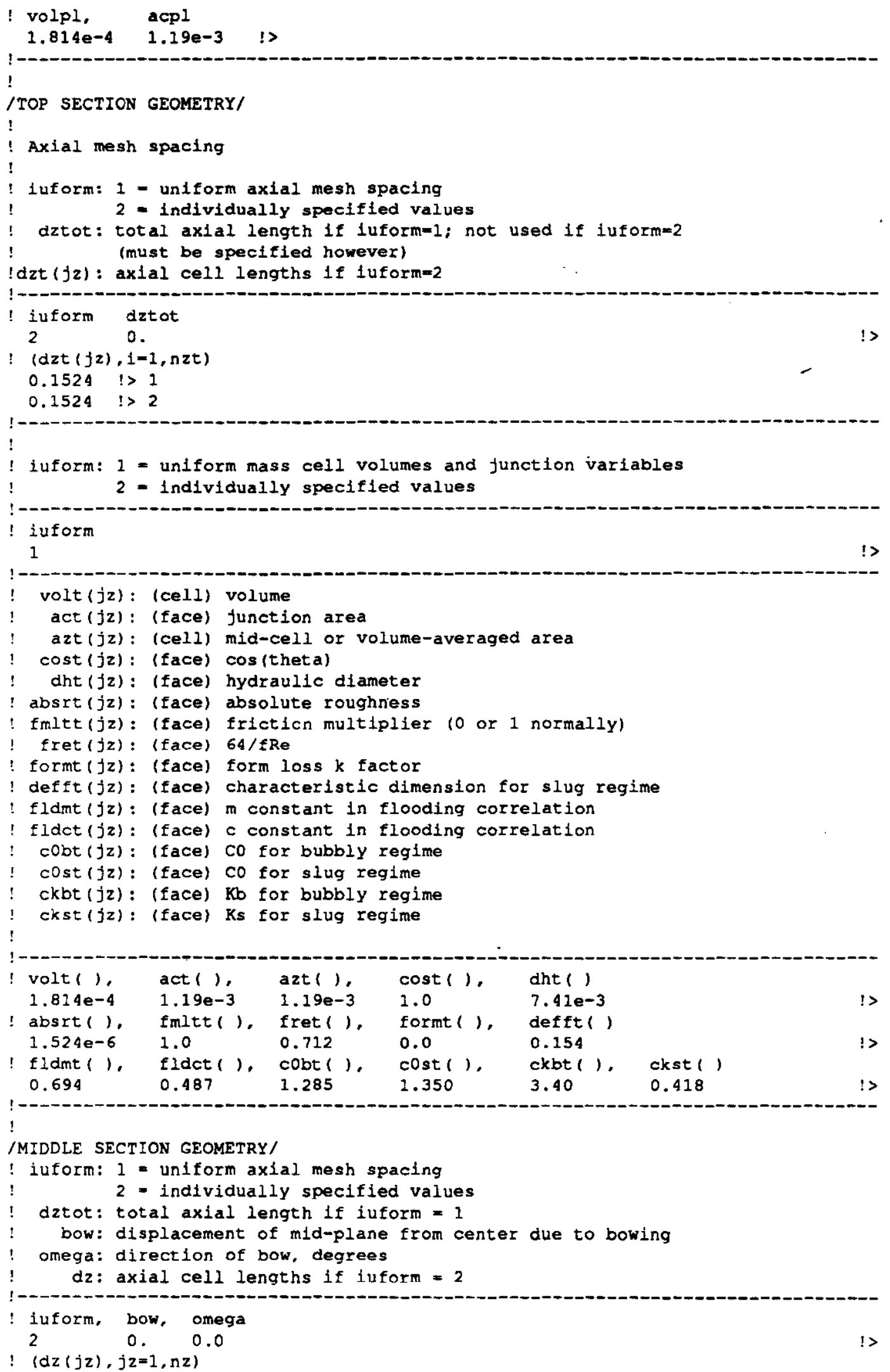




$0.1524 \quad !>1$
$0.2860 \quad \$ 13$ !> $2-14$
$0.1524 \quad !>15$
/CHANNEL $1 /$
$!$ nsub: number of subchannels
di: Inner diameter of channel
do: outer diameter of channel
$!$ nsub, di, $\quad 0.0940 \quad 0.1019$

! $1-0-0-1$

!

/CHANNEL 1 X GEOMETRY/

: Iuform: 2 = axlally and azimuthally uniform cell x-direction geometry

! $\quad 2$ = individually specified cell $x$-direction geometry

! other = Individually specified values

iuform

1

!>

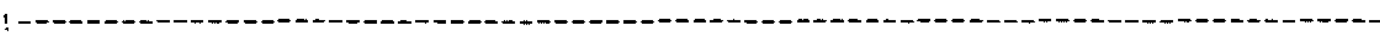

! acx $(j z, i x, i c)$ : (face) ENTER RIB CLEARANCE; CODE CONVERTS TO $x$-area

$\operatorname{axx}(j z, i x, i c):$ (face) CHANNEL CLEARANCE; CODE CONVERTS TO $x$-area

$\cos x(j z, i x, i c):$ (face) cos(theta) for $x$-direction

$d h x(j z, i x, i c):$ (face) hydraulic diameter in $x$-direction

abs $x \times(j z, i x, i c)$ : (face) absolute roughness

fmitx $(j z, i x, i c)$ : (face) friction multiplier ( 0 or 1 normally)

frex $(j z, i x, i c):$ (face) $64 / f R e$

formx $(j z, i x, i c):$ (face) form loss $k$ factor

! (jz loop inside ix loop)

: $\operatorname{acx}(), \quad \operatorname{axx}(), \quad \cos x(), \operatorname{dhx}()$

$1.0 \mathrm{e}-3 \quad 1.0 \mathrm{e}-3 \quad 0.0,1.0 \mathrm{e}-3$ i> (NOT USED BECAUSE CHN. IS 1D)

! $\operatorname{absix}(), f \operatorname{mltx}(), \operatorname{frex}(), \operatorname{formx}()$

$\begin{array}{lllll}1.524 \mathrm{e}-6 & 0.0 & 1.0 & 10.0 & 1>\end{array}$

/CHANNEL 12 GEOMETRY/

! iuform: 1 = axially and azimuthally uniform cell z-direction

! 2 = individually specified cell z-direction geometry

! other = individually specified values

iuform

$1 \quad$ ! $1>$

! iuform=1

! acz $(j z, i x, i c):$ (face) junction area

azz $(j z, 1 x, i c)$ : (cell) mid-cell area

$\cos z(j z, i x, i c):$ (face) cos(theta) for z-direction

dhz $(j z, i x, j c):$ (face) hydralic diameter in $z$-direction

absrz(jz,ix,ic): (face) absolute roughness

fmltz(jz,ix,ic): (face) friction multiplier (o or 1 normally)

frez(jz,ix,ic): (face) $64 / f \operatorname{Re}$

formz(jz,ix,ic): (face) form loss $k$ factor

deffz(jz,ix,ic): (face) characteristic dimension for slug regime

! fldmz(jz,ix,ic): (face) m constant in flooding correlation

! fldcz(jz,ix,ic): (face) c constant in flooding correlation

cObz $(j z, i x, i c):$ (face) co for bubbly regime

cosz $(j z, i x, i c)$ : (face) co for slug regime

ckbz(jz,ix,ic): (face) $\mathrm{kb}$ for bubbly regime

cksz(jz,ix,ic): (face) ks for slug regime

(jz loop inside ix loop)

! - - - - - - - - - - - -

( acz (), $\operatorname{azz}(1), \cos z(), \operatorname{dhz}()$

$1.19 \mathrm{e}-3 \quad 1.19 \mathrm{e}-3 \quad 1.0 \quad 7.41 \mathrm{e}-3$ 


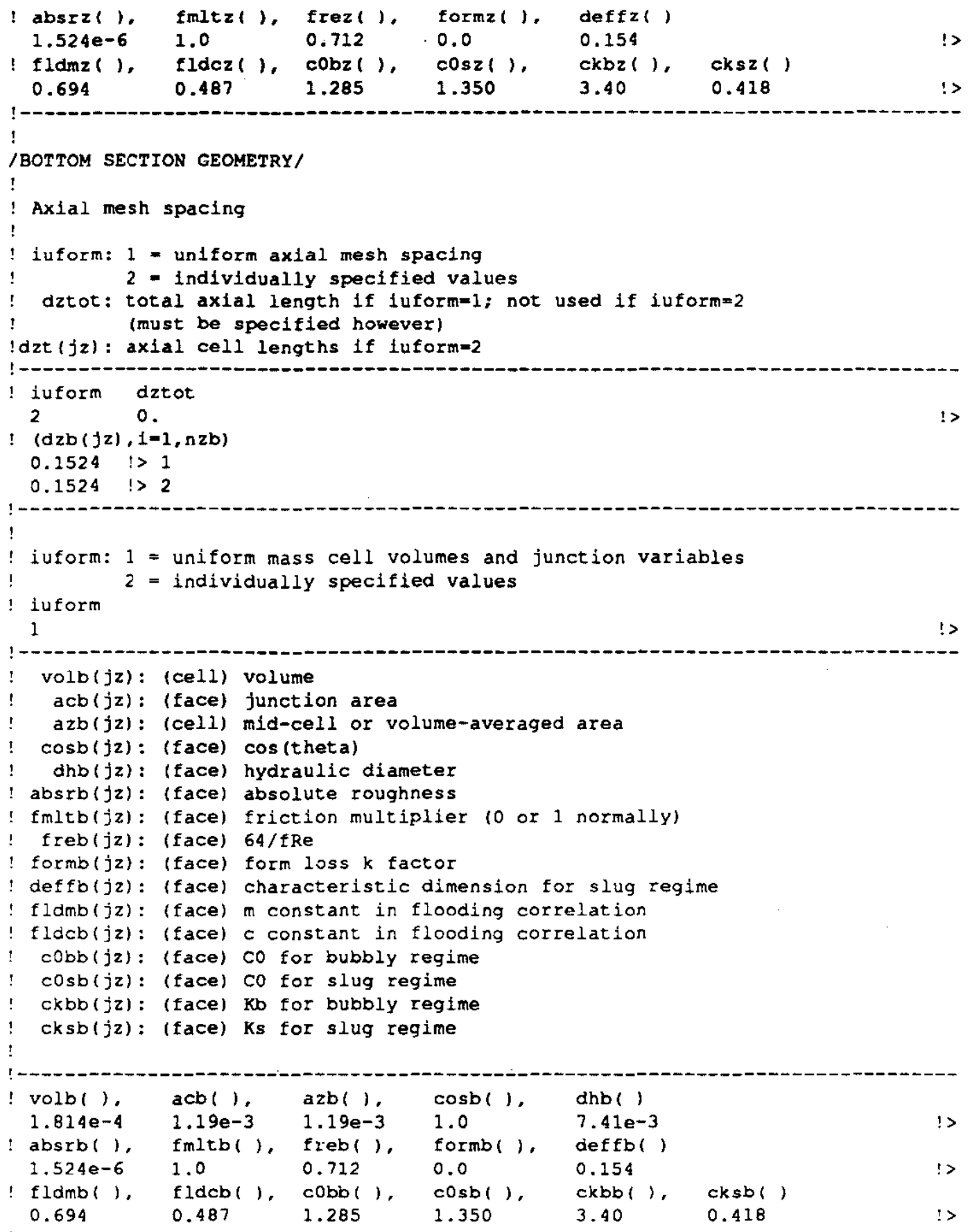

!

/BOTTOM BOUNDARY CELL: TANK BOTTOM VOLUME AND AREA/

! voltb: tank bottom volume

! actb: tank bottom mid-cell area

! $-\cdots$

! voltb, actb

$\begin{array}{lll}1.814 \mathrm{e}-4 \quad 1.19 \mathrm{e}-3 & \text { i> }\end{array}$

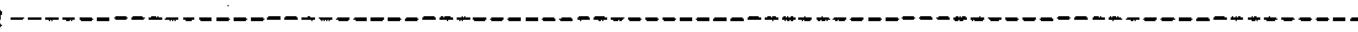

SOLID GEOMETRY INPUT SECTION 


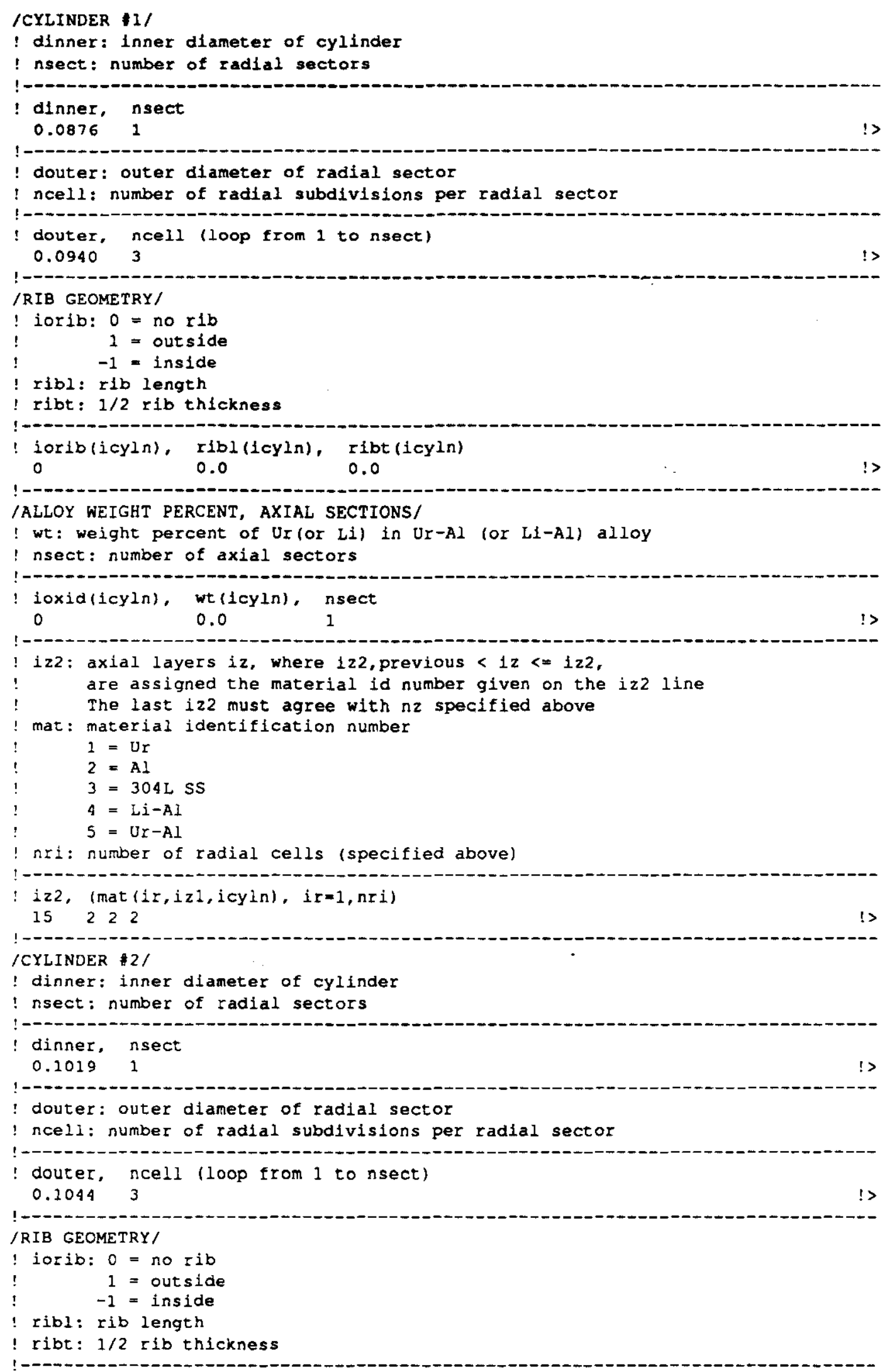




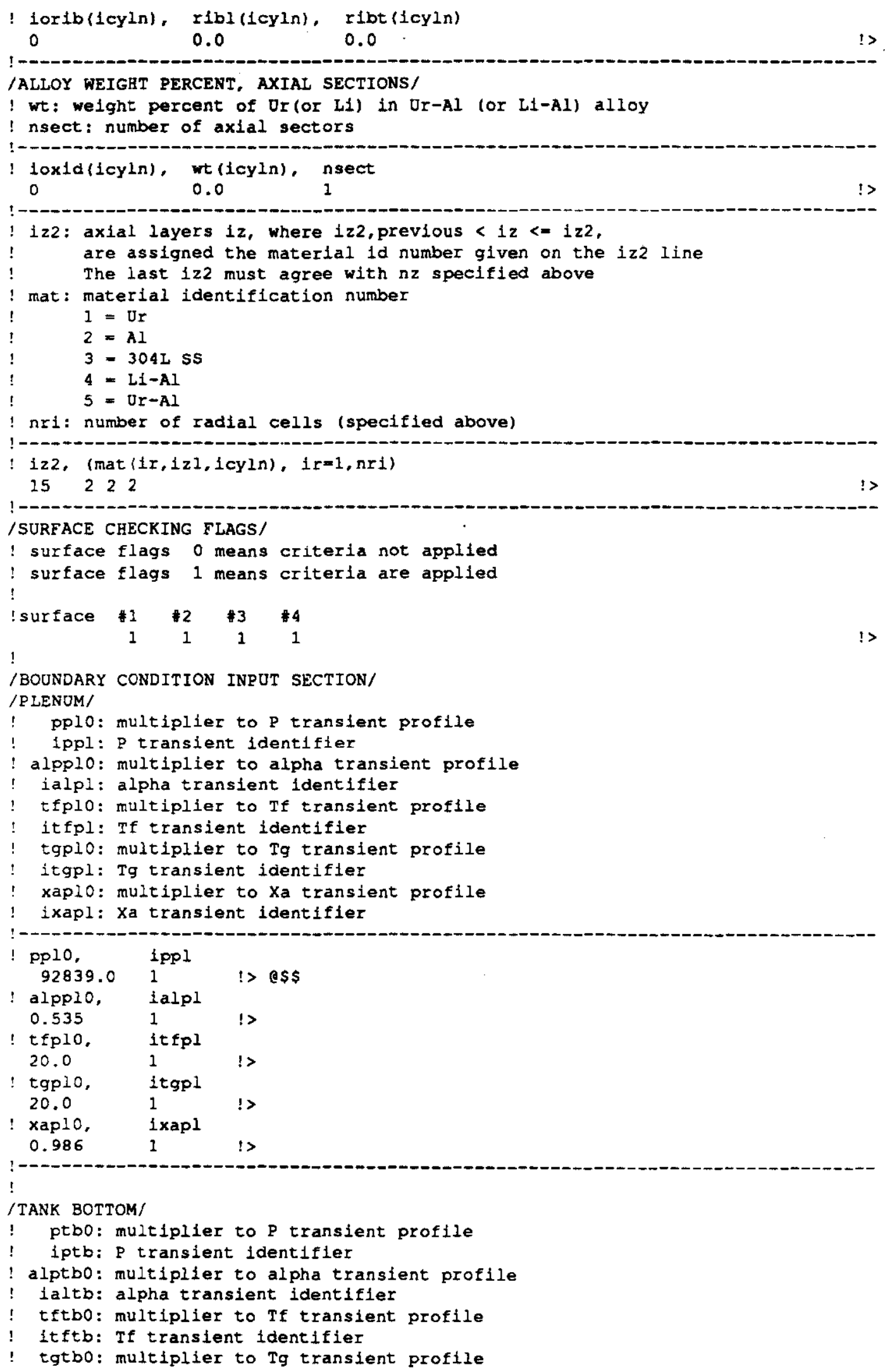




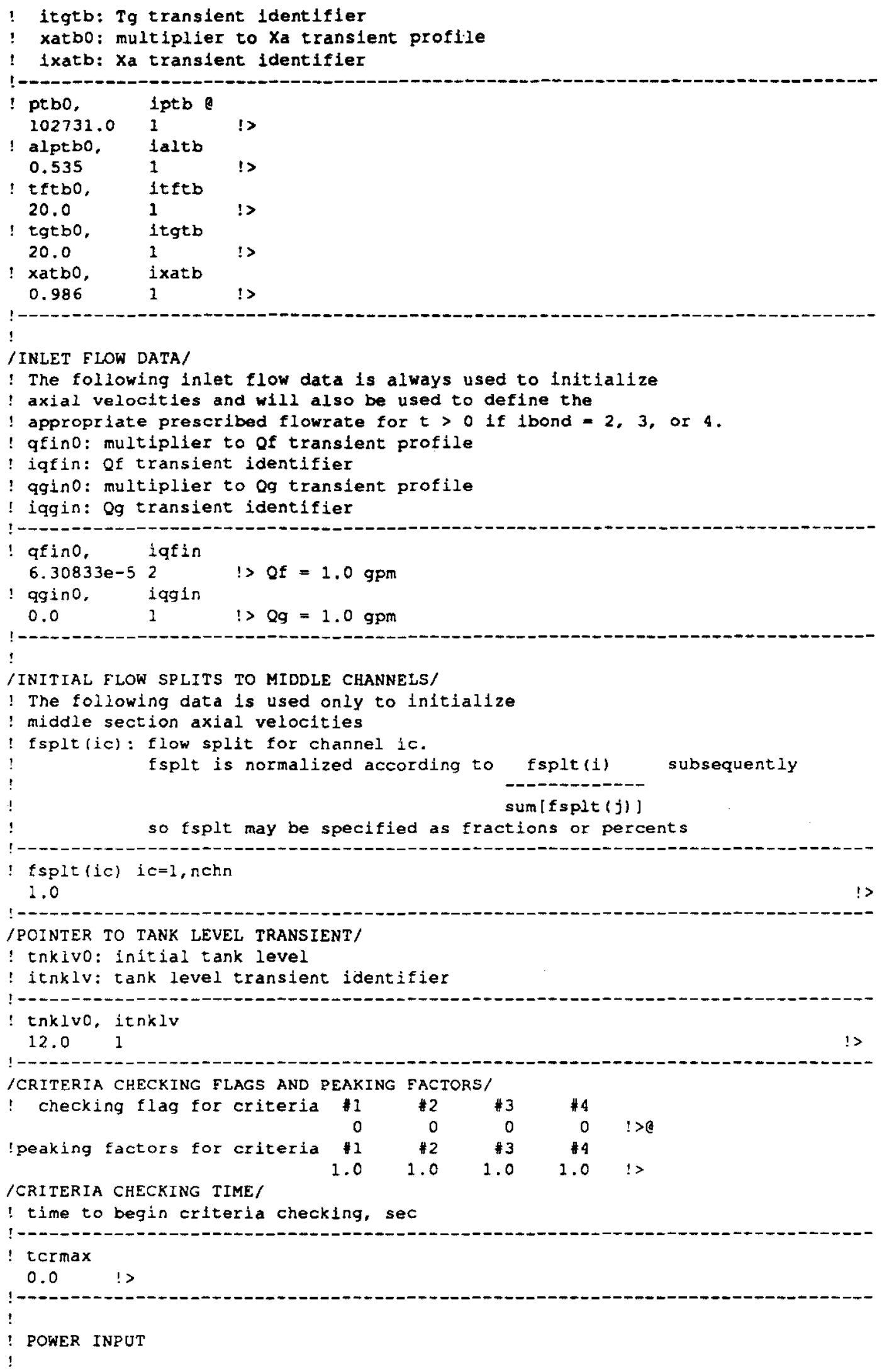




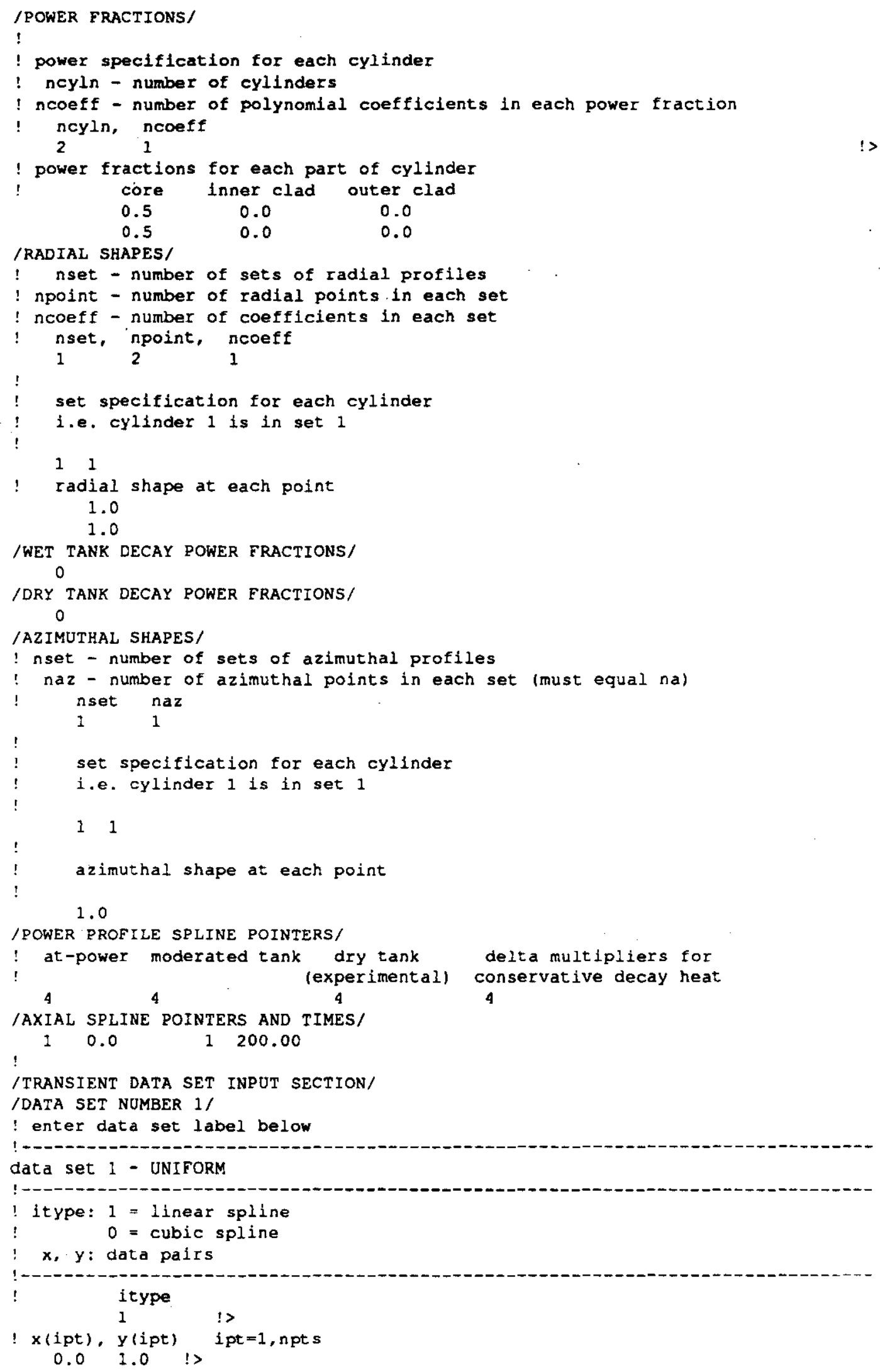




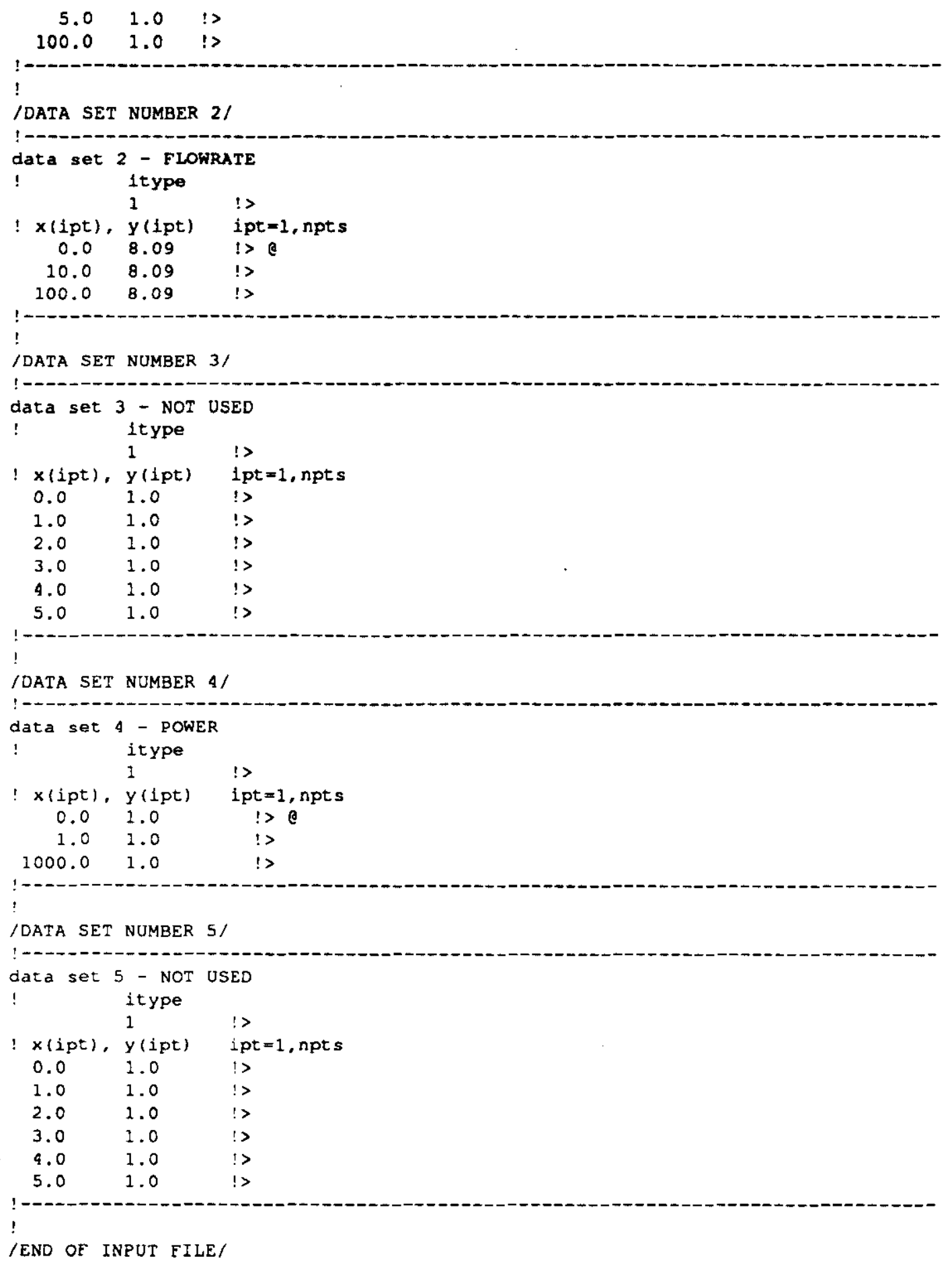




\section{Output Description}

The various output options and quantities printed for each option have been broadly discussed in the Input Specifications section. The Sample Output File section below effectively describes the output in detail. FLOWTRAN-TF output values are clearly identified with self-explanatory labels. Dimensional units are given. The user may consult the FLOWTRAN-TF v1.2 FORTRAN source code listing and/or code proprietor for additional clarification if necessary.

\section{Sample Output File}

The output files corresponding to the above input file are listed below for the purpose of illustrating typical FLOWTRAN-TF output. The following file saved as test_31_01_m08.out was written to unit number 11:
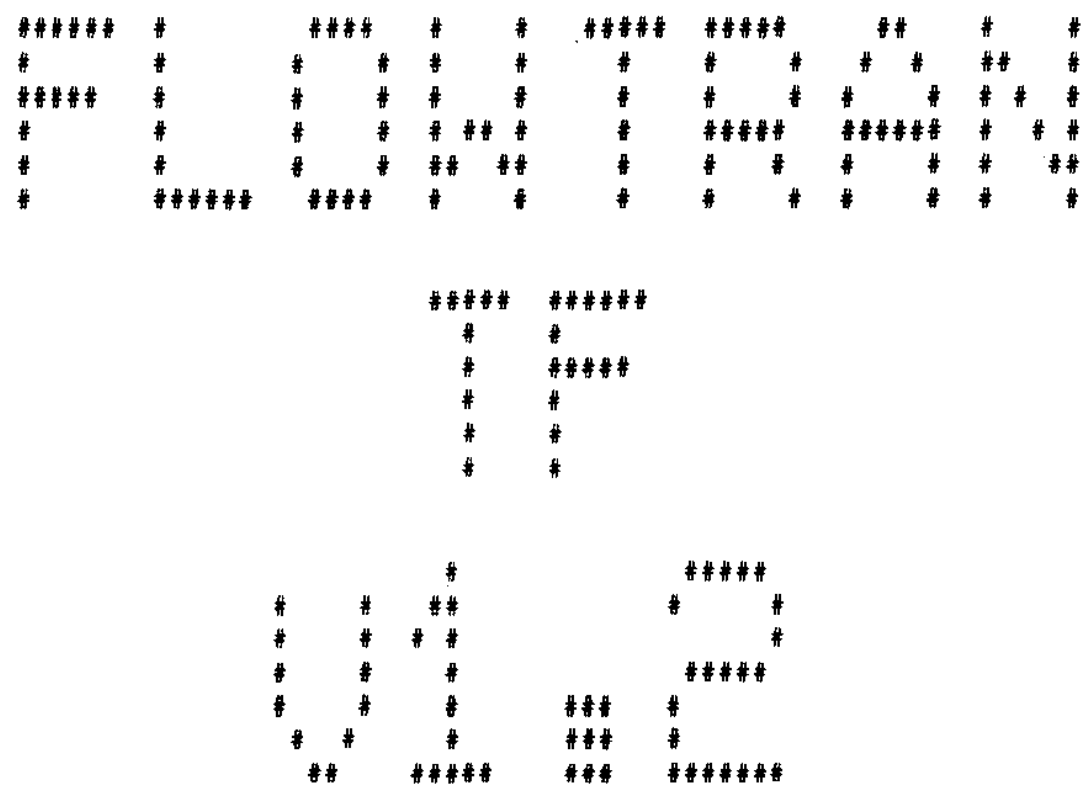

\footnotetext{
NES Code Management System, TP-92-049, Rev 0

IBM RISC System/6000, Model 530

AIX Version 3 for RISC system/6000, 03.01.0005.0012

IBM AIX XL FORTRAN Compiler, 02.02.0000.0000

Compiler options: -0 -qautodbl=dblpad

Loader options: -berok

Built 29-JAN-1993 by S.E. Aleman e $\times 52986$ at 773-11A

Status of Code - TESTING
} 


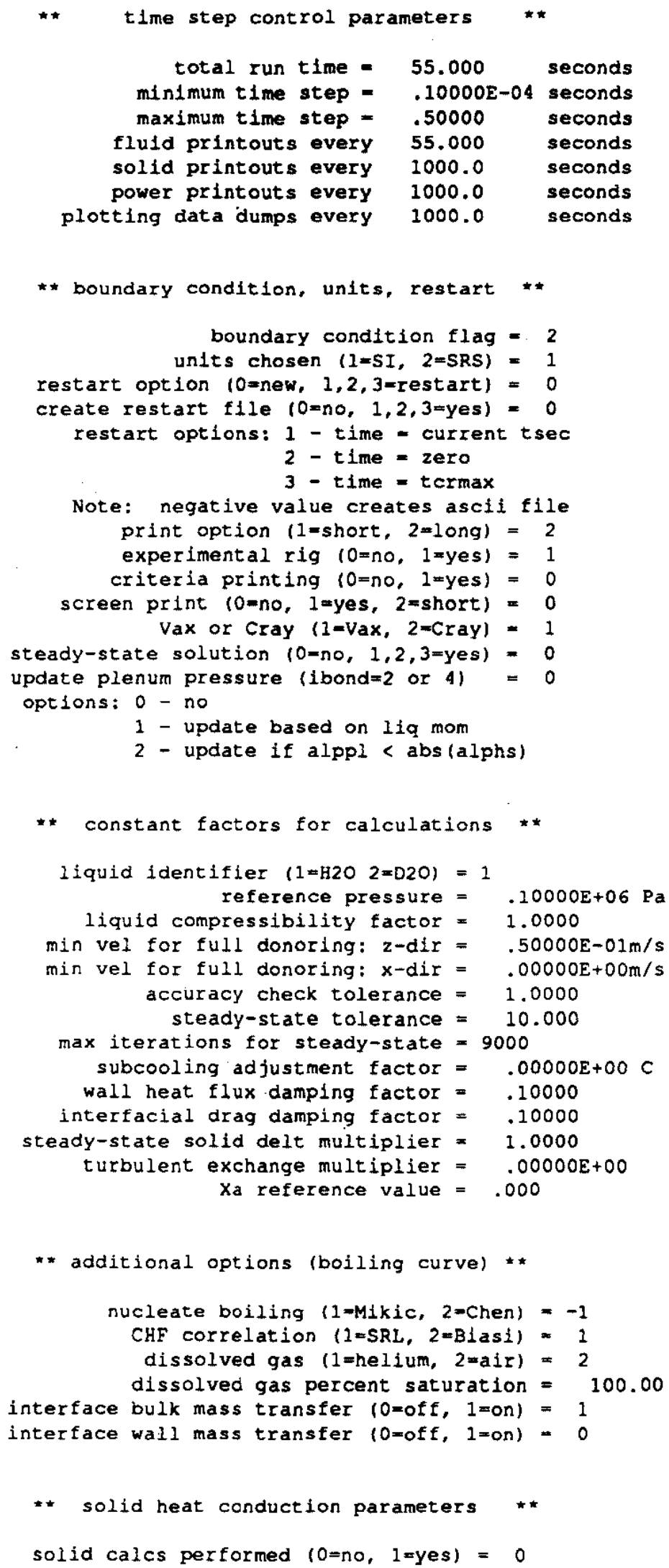


axial heat conduction $(0=$ no, 1 -yes $)=0$

1mplicit conduction $(0.0=$ no, 1.0 yes $)=1.0$

number of rebalance iterations $=3$

inttial solid temperature $=20.000 \mathrm{C}$

initial surface temperature $=20.000 \mathrm{C}$

* inner pressure solution parameters **

inner iteration calculaticn method $=1$

inner 1teration rebalance option $=1$

number of rebalance iterations $=1$

tolerance on inner iteration $=.10000 \mathrm{E}-04$

maximum number of inner iterations $=50$

* ysi iteration parameters **

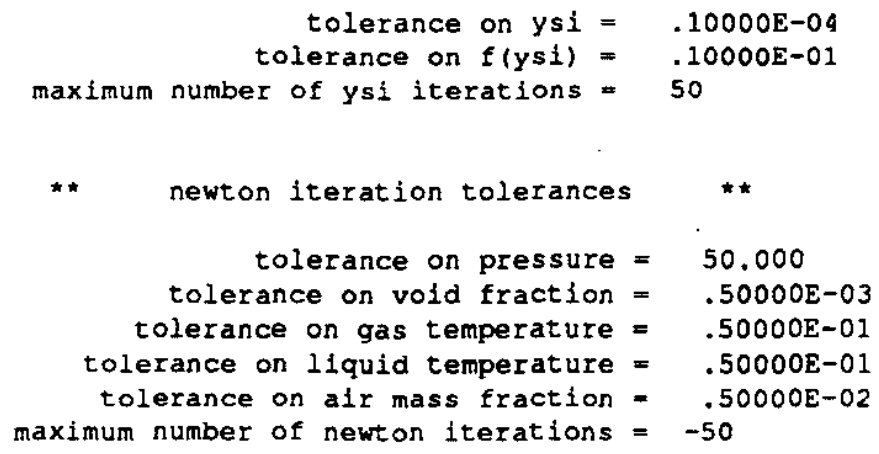




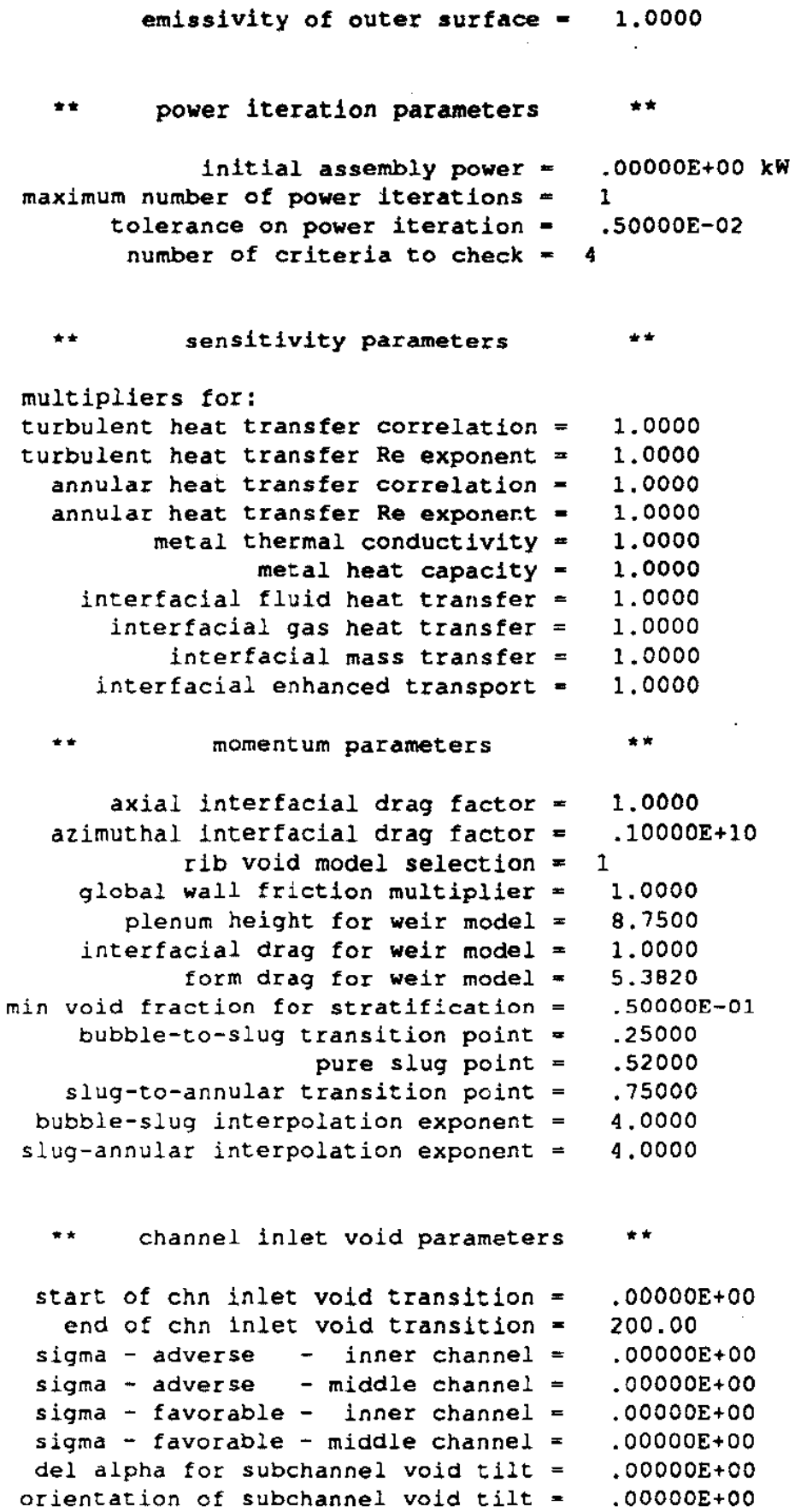

1 azimuthal cells are in channel 1

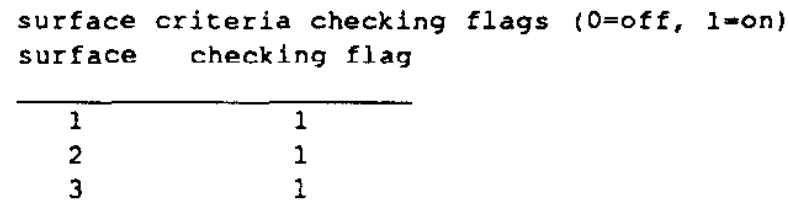


4

1

cylinder 1:

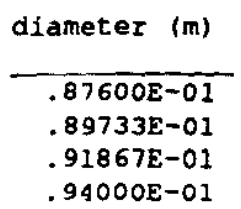

diameter (m)

.87600E-01

$.89733 E-01$

$.91867 \mathrm{E}-01$

$.94000 E-01$

material id array
222
$\begin{array}{lll}2 & 2 & 2\end{array}$
$\begin{array}{lll}2 & 2 & 2\end{array}$
$\begin{array}{lll}2 & 2 & 2\end{array}$
222
222
222
$\begin{array}{lll}2 & 2 & 2\end{array}$
$\begin{array}{lll}2 & 2 & 2\end{array}$
222
222
222
$\begin{array}{lll}2 & 2 & 2\end{array}$
$\begin{array}{lll}2 & 2 & 2\end{array}$
$\begin{array}{lll}2 & 2 & 2\end{array}$

cylinder $* 2:$ alloy weight percent $=.00000 \mathrm{E}+00$ rib orientation $=0$ rib length $(\mathrm{m})=.00000 \mathrm{E}+00$ rib half width $(\mathrm{m})=.00000 \mathrm{E}+00$

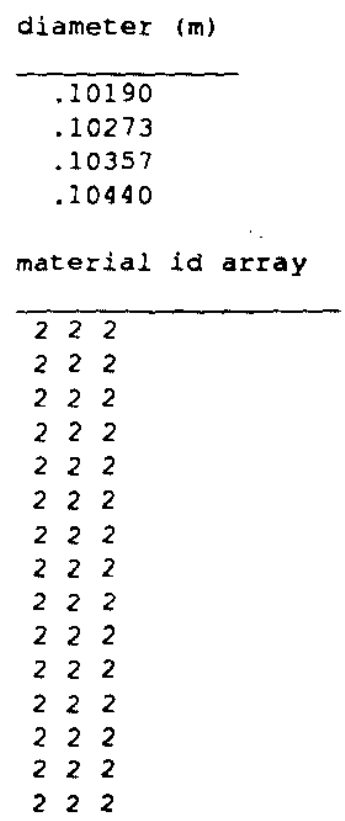


criteria checking flags and peaking factors

criteria checking flag peaking factor

$\begin{array}{lll}1 & 0 & 1.0000 \\ 2 & 0 & 1.0000 \\ 3 & 0 & 1.0000 \\ 4 & 0 & 1.0000\end{array}$

Time at which criteria checking begins $=.0 \mathrm{sec}$

1 input power data as read from unit 7

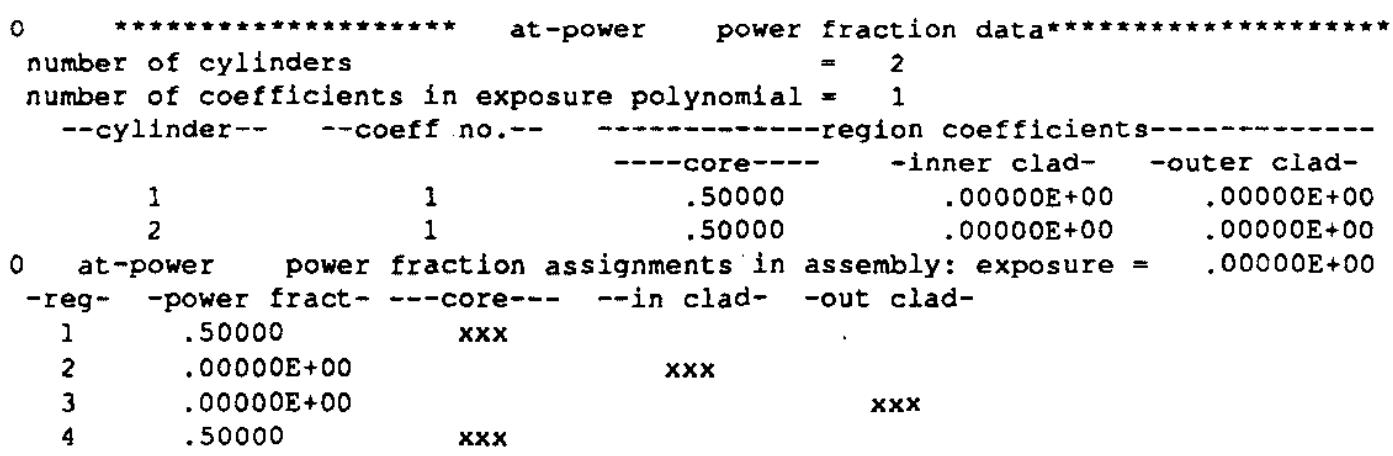
$.00000 \mathrm{E}+00$

$.00000 \mathrm{E}+00 \quad \mathbf{x x x}$

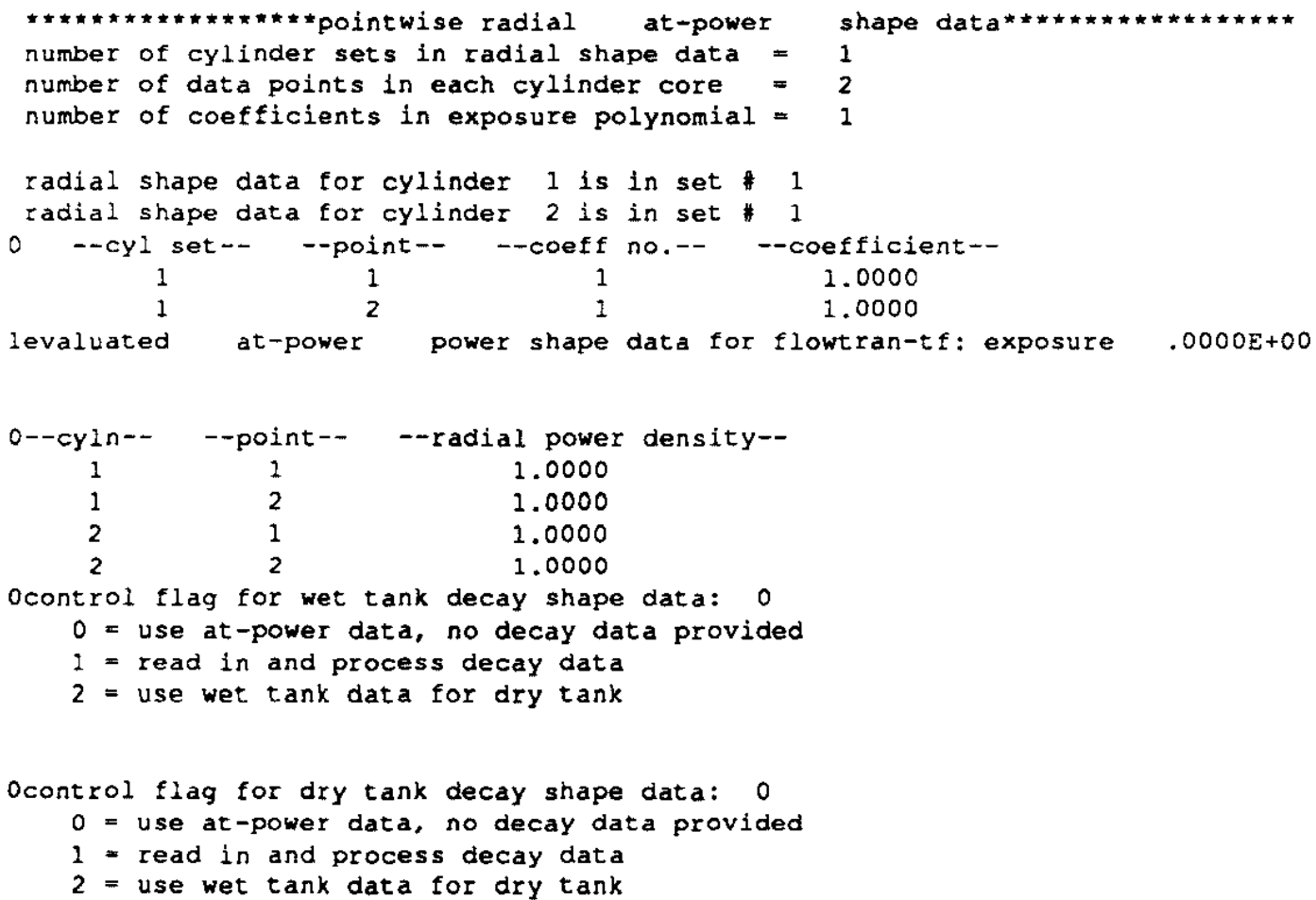



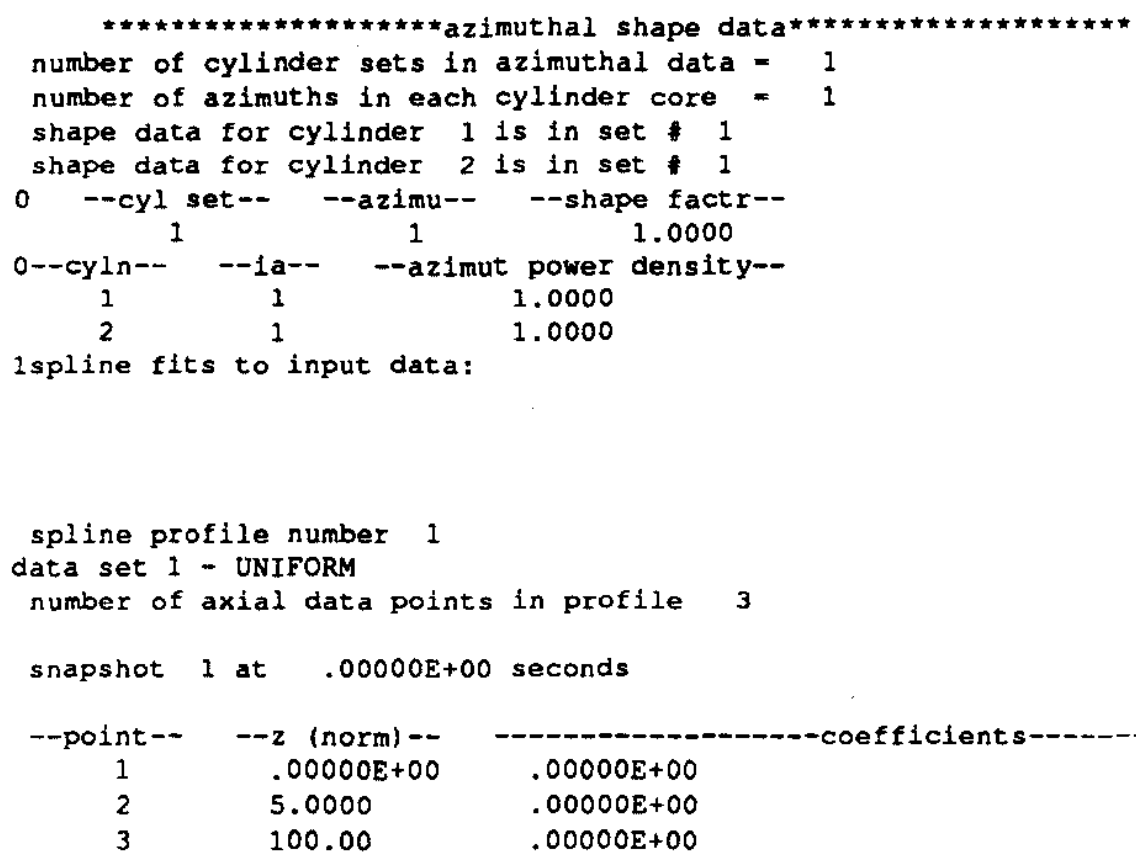

spline profile number 4 data set 4 - POWER

number of axial data points in profile 3

$\begin{array}{ccc}-p 0 i n t-- & --t i m e & .00000 \mathrm{E}+00 \\ 1 & .00000 \mathrm{E}+00 & .00000 \mathrm{E}+00 \\ 2 & 1.0000 & .00000 \mathrm{E}+00\end{array}$

spline profile number 5 data set 5 - NOT USED 


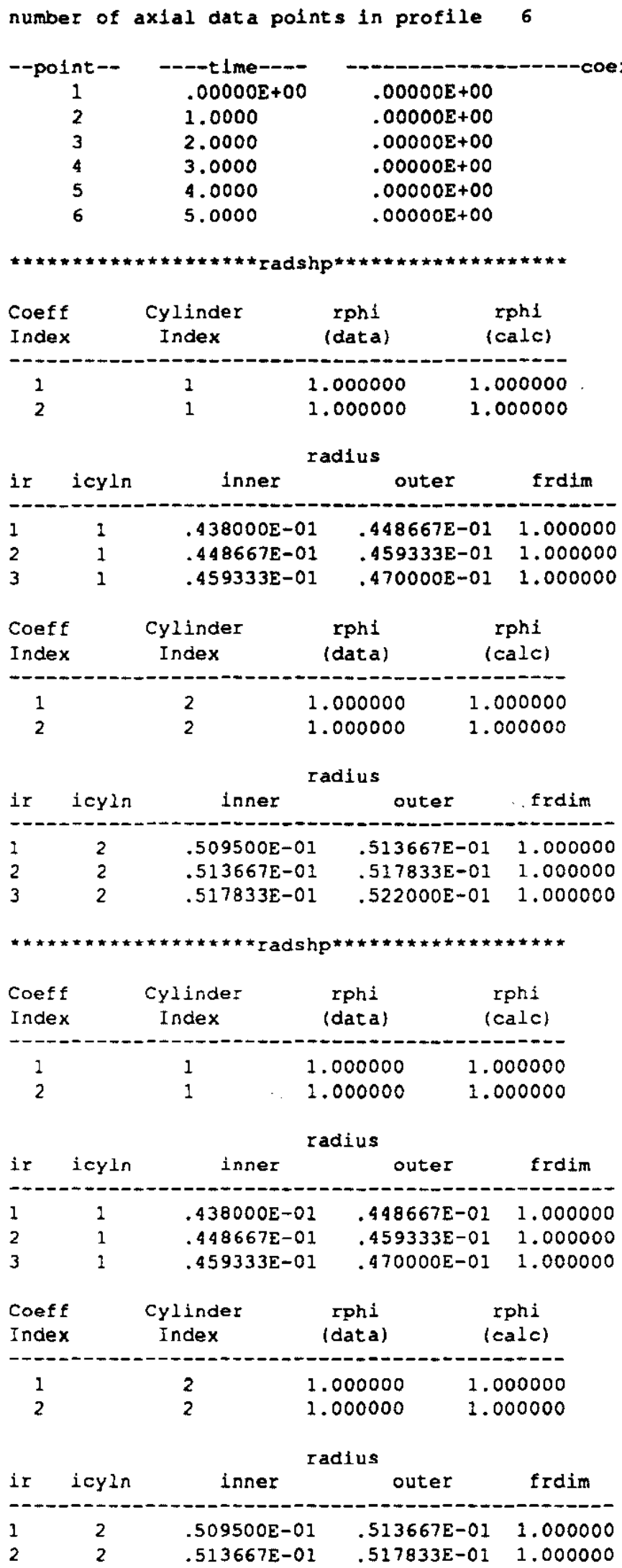




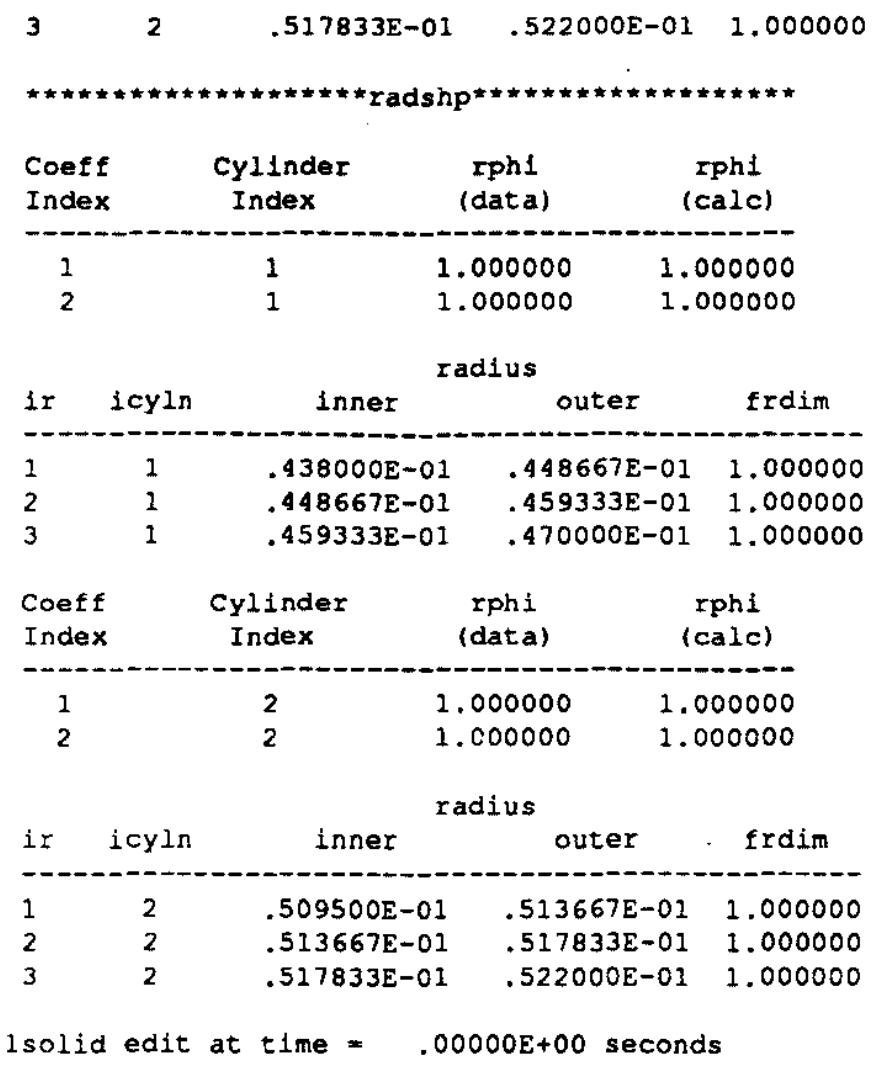

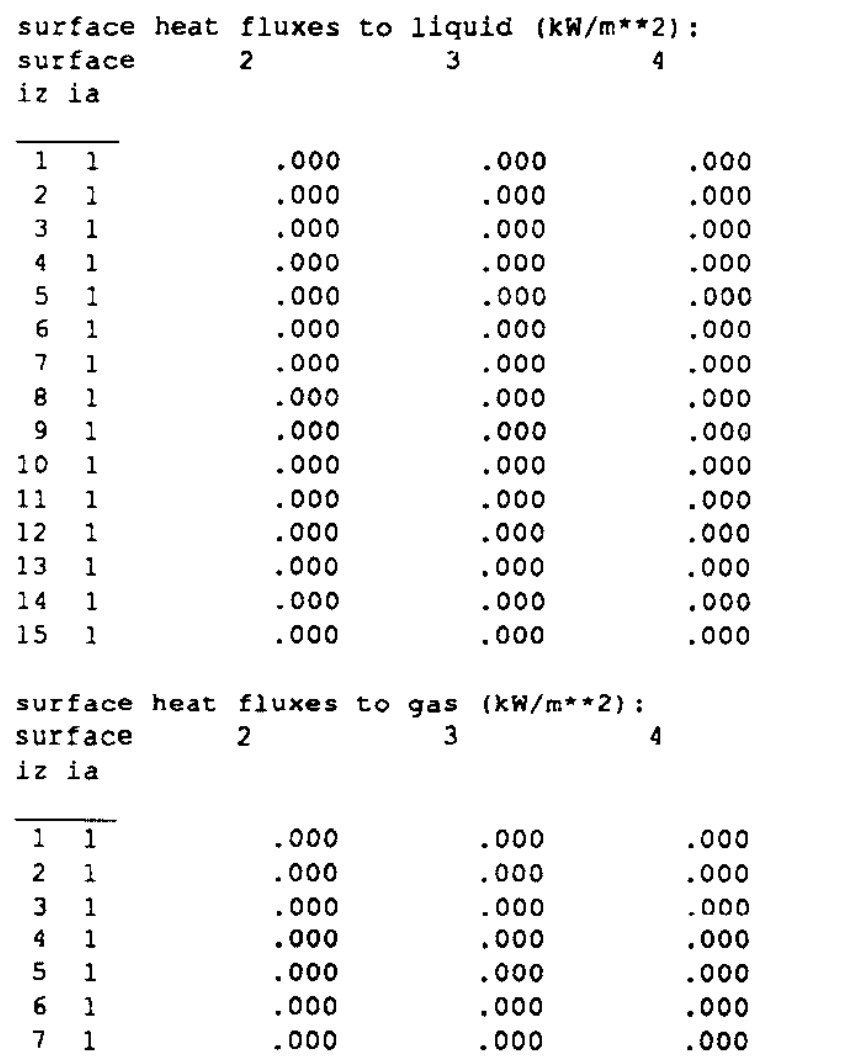




$\begin{array}{rrrrr}8 & 1 & .000 & .000 & .000 \\ 9 & 1 & .000 & .000 & .000 \\ 10 & 1 & .000 & .000 & .000 \\ 11 & 1 & .000 & .000 & .000 \\ 12 & 1 & .000 & .000 & .000 \\ 13 & 1 & .000 & .000 & .000 \\ 14 & 1 & .000 & .000 & .000 \\ 15 & 1 & .000 & .000 & .000\end{array}$

cylinder surface temperatures (C): $\begin{array}{llll}\text { surface } & 2 & 3 & 4\end{array}$

iz ia

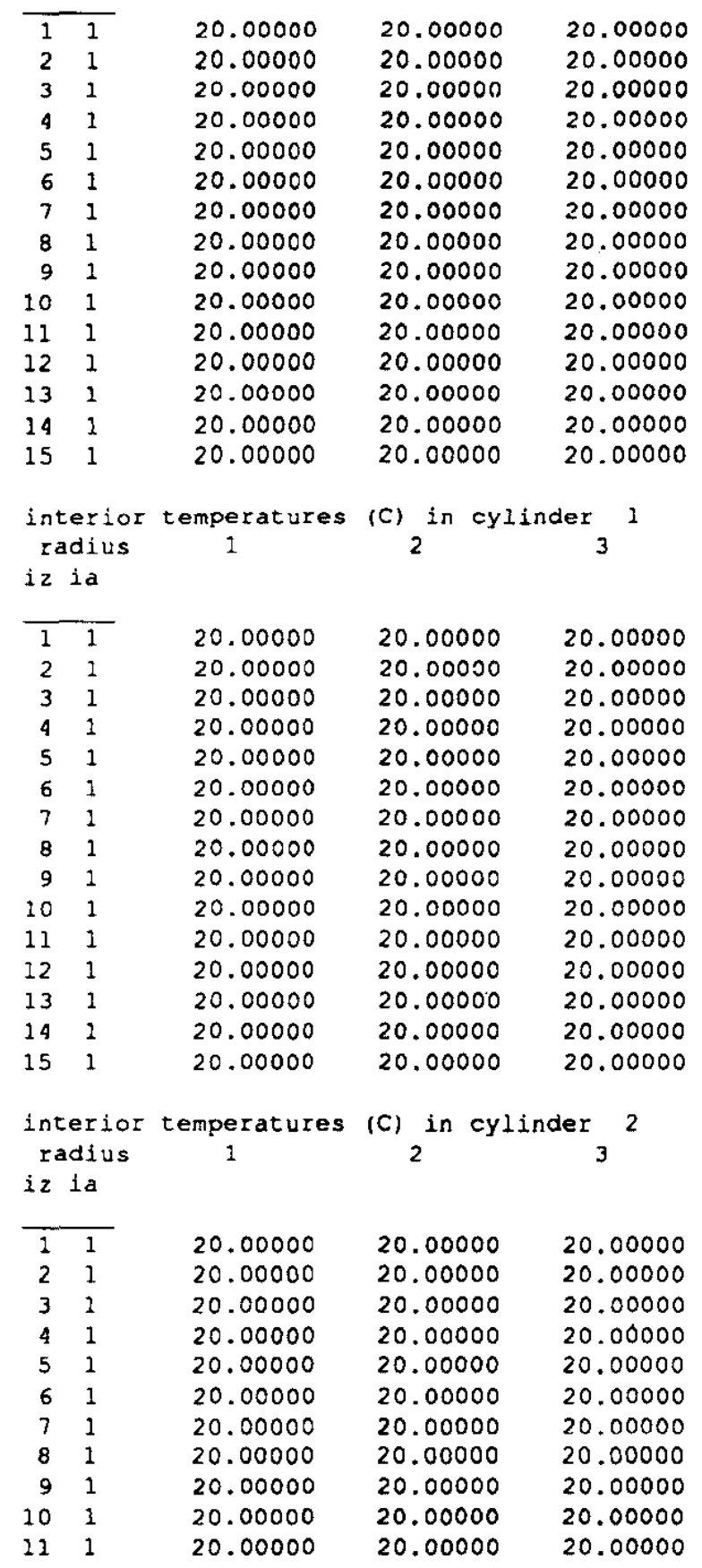




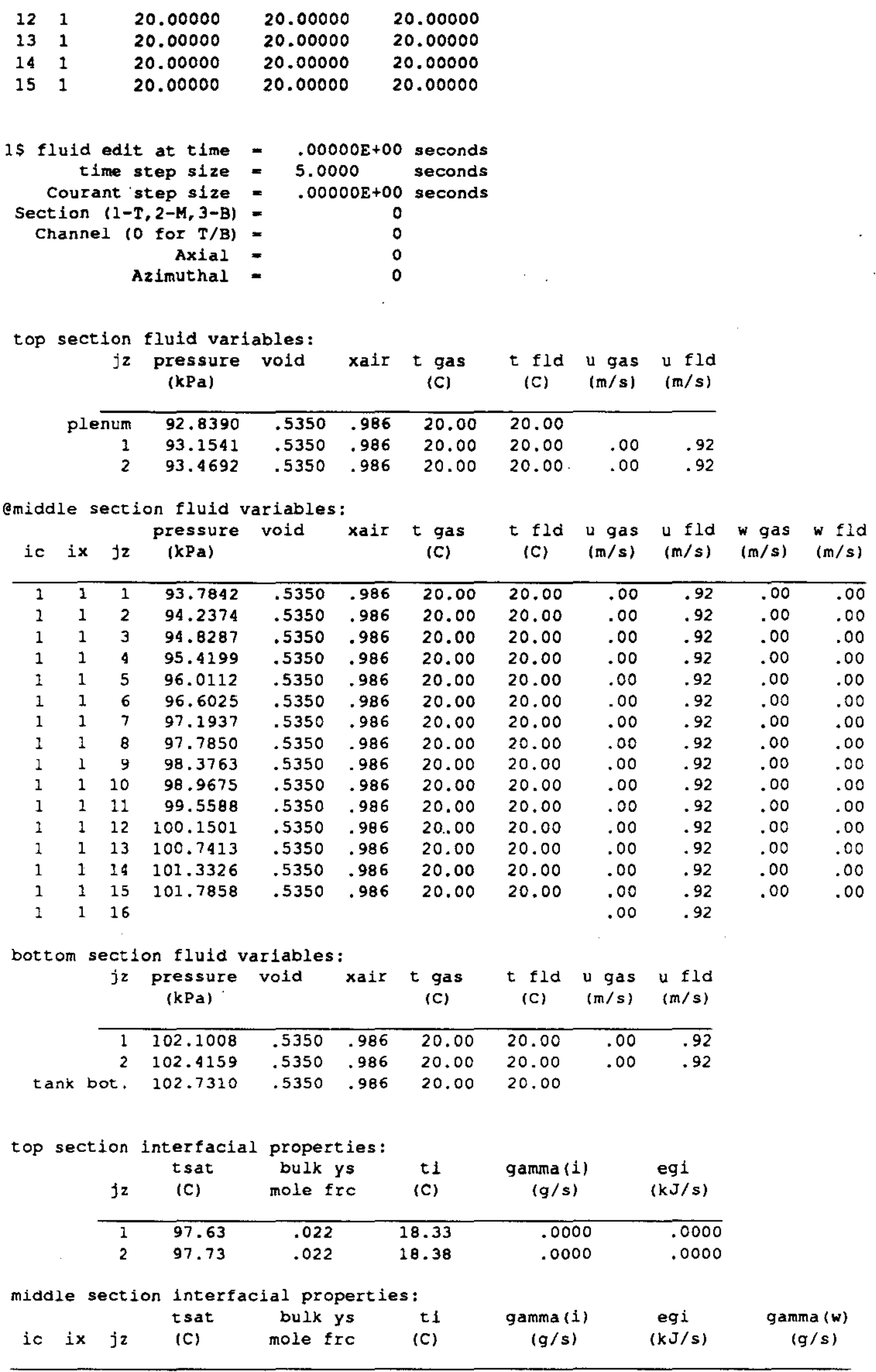




$\begin{array}{rr}97.82 & .022 \\ 97.95 & .022 \\ 98.13 & .022 \\ 98.30 & .022 \\ 98.48 & .022 \\ 98.65 & .022 \\ 98.82 & .022 \\ 98.99 & .022 \\ 99.16 & .022 \\ 99.33 & .022 \\ 99.50 & .022 \\ 99.66 & .022 \\ 99.83 & .022 \\ 100.00 & .022 \\ 100.12 & .022\end{array}$

18.44
18.51
18.61
18.71
18.81
18.91
19.01
19.10
19.20
19.30
19.39
19.49
19.58
19.68
19.75

$$
\begin{aligned}
& .0000 \\
& .0000 \\
& .0000 \\
& .0000 \\
& .0000 \\
& .0000 \\
& .0000 \\
& .0000 \\
& .0000 \\
& .0000 \\
& .0000 \\
& .0000 \\
& .0000 \\
& .0000 \\
& .0000
\end{aligned}
$$$$
\begin{aligned}
& .0000 \\
& .0000 \\
& .0000 \\
& .0000 \\
& .0000 \\
& .0000 \\
& .0000 \\
& .0000 \\
& .0000 \\
& .0000 \\
& .0000 \\
& .0000 \\
& .0000 \\
& .0000 \\
& .0000
\end{aligned}
$$

bottom section interfaclal properties:

\begin{tabular}{cccccc} 
jz & $\begin{array}{l}\text { tsat } \\
\text { (C) }\end{array}$ & $\begin{array}{c}\text { bulk ys } \\
\text { mole frc }\end{array}$ & $\begin{array}{c}\text { ti } \\
\text { (C) }\end{array}$ & $\begin{array}{c}\text { gamma(i) } \\
(\mathrm{g} / \mathrm{s})\end{array}$ & $\begin{array}{c}\mathrm{eg} i \\
(\mathrm{~kJ} / \mathrm{s})\end{array}$ \\
\hline 1 & 100.21 & .022 & 19.80 & .0000 & .0000 \\
2 & 100.30 & .022 & 19.85 & .0000 & .0000
\end{tabular}

top section densities and enthalpies:

\begin{tabular}{rrrrr}
$j z$ & $\begin{array}{c}\text { rho gas } \\
\left(\mathrm{kg} / \mathrm{m}^{\wedge} 3\right)\end{array}$ & $\begin{array}{c}\text { rho fld } \\
\left(\mathrm{kg} / \mathrm{m}^{\wedge} 3\right)\end{array}$ & $\begin{array}{c}\mathrm{h} \text { gas } \\
(\mathrm{kJ} / \mathrm{kg})\end{array}$ & $\begin{array}{c}\mathrm{h} \mathrm{fld} \\
(\mathrm{kJ} / \mathrm{kg})\end{array}$ \\
\hline 1 & & & & \\
\hline 2 & 1.09 & 997.84 & 324.566 & 83.216 \\
1.10 & 997.84 & 324.565 & 83.216 \\
& 1.10 & 997.84 & 324.565 & 83.216
\end{tabular}

middle section densities and enthalpies:

ic ix jz $\begin{array}{cccc}\text { rho gas rho fld } & \text { h gas } & \mathrm{h} f \mathrm{fld} \\ \left(\mathrm{kg} / \mathrm{m}^{\wedge} 3\right) & \left(\mathrm{kg} / \mathrm{m}^{\wedge} 3\right) & (\mathrm{kJ} / \mathrm{kg}) & (\mathrm{kJ} / \mathrm{kg})\end{array}$

$\begin{array}{rrrrrrr}1 & 1 & 1 & 1.11 & 997.84 & 324.564 & 83.216 \\ 1 & 1 & 2 & 1.11 & 997.84 & 324.564 & 83.216 \\ 1 & 1 & 3 & 1.12 & 997.84 & 324.563 & 83.216 \\ 1 & 1 & 4 & 1.12 & 997.84 & 324.562 & 83.216 \\ 1 & 1 & 5 & 1.13 & 997.84 & 324.561 & 83.216 \\ 1 & 1 & 6 & 1.14 & 997.84 & 324.560 & 83.216 \\ 1 & 1 & 7 & 1.15 & 997.84 & 324.559 & 83.216 \\ 1 & 1 & 8 & 1.15 & 997.84 & 324.558 & 83.216 \\ 1 & 1 & 9 & 1.16 & 997.84 & 324.557 & 83.216 \\ 1 & 1 & 10 & 1.17 & 997.84 & 324.556 & 83.216 \\ 1 & 1 & 11 & 1.17 & 997.84 & 324.556 & 83.216 \\ 1 & 1 & 12 & 1.18 & 997.84 & 324.555 & 83.216 \\ 1 & 1 & 13 & 1.19 & 997.84 & 324.554 & 83.216 \\ 1 & 1 & 14 & 1.19 & 997.84 & 324.553 & 83.216 \\ 1 & 1 & 15 & 1.20 & 997.84 & 324.552 & 83.216\end{array}$

\begin{tabular}{|c|c|c|c|c|c|}
\hline & $j z$ & $\begin{array}{l}\text { rho gas } \\
\left(\mathrm{kg} / \mathrm{m}^{\wedge} \mathrm{3}\right)\end{array}$ & $\begin{array}{l}\text { tho fld } \\
\left(\mathrm{kg} / \mathrm{m}^{\wedge} 3\right)\end{array}$ & $\begin{array}{c}\text { h gas } \\
(\mathrm{kJ} / \mathrm{kg})\end{array}$ & $\begin{array}{c}h \text { fld } \\
(k J / k g)\end{array}$ \\
\hline & 1 & 1.20 & 997.89 & 324.552 & 83.216 \\
\hline & 2 & 1.21 & 997.84 & 324.551 & 83.216 \\
\hline $\tan k$ & ot. & 1.21 & 997.84 & 324.551 & 83.216 \\
\hline
\end{tabular}

top section volumetric and mass flowrates: 


\begin{tabular}{ccccc}
$j z$ & $(1 / \mathrm{s})$ & $(1 / \mathrm{s})$ & $(\mathrm{g} / \mathrm{s})$ & $(\mathrm{kg} / \mathrm{s})$ \\
\hline 1 & .000 & .510 & .000 & .509 \\
2 & .000 & .510 & .000 & .509
\end{tabular}

middle section volumetric and mass flowrates: Qz gas Qz fld mz gas $\mathrm{mz}$ fld

\begin{tabular}{|c|c|c|c|c|c|c|c|c|c|c|}
\hline ic & ix & $j z$ & $\begin{array}{r}029 d s \\
(1 / s)\end{array}$ & $(1 / s)$ & $(g / s)$ & $(\mathrm{kg} / \mathrm{s})$ & $\begin{array}{r}\text { (1/s) } \\
(1 / s\end{array}$ & $(1 / s)$ & $(g / s)$ & $(\mathrm{kg} / \mathrm{s})$ \\
\hline 1 & 1 & 1 & .000 & .510 & .000 & .509 & .000 & .000 & .000 & .000 \\
\hline 1 & 1 & 2 & .000 & .510 & .000 & .509 & .000 & .000 & .000 & .000 \\
\hline 1 & 1 & 3 & .000 & .510 & .000 & .509 & .000 & .000 & .000 & .000 \\
\hline 1 & 1 & 4 & .000 & .510 & .000 & .509 & .000 & .000 & .000 & .000 \\
\hline 1 & 1 & 5 & .000 & .510 & .000 & .509 & .000 & .000 & .000 & .000 \\
\hline 1 & 1 & 6 & .000 & .510 & .000 & .509 & .000 & .000 & .000 & .000 \\
\hline 1 & 1 & 7 & .000 & .510 & .000 & .509 & .000 & .000 & .000 & .000 \\
\hline 1 & 1 & 8 & .000 & .510 & .000 & .509 & .000 & .000 & .000 & .000 \\
\hline 1 & 1 & 9 & .000 & .520 & .000 & .509 & .000 & .000 & .000 & .000 \\
\hline 1 & 1 & 10 & .000 & .510 & .000 & .509 & .000 & .000 & .000 & .000 \\
\hline I & 1 & 11 & .000 & .510 & .000 & .509 & .000 & .000 & .000 & .000 \\
\hline 1 & 1 & 22 & .000 & .510 & .000 & .509 & .000 & .000 & .000 & .000 \\
\hline 1 & 1 & 13 & .000 & .510 & .000 & .509 & .000 & .000 & .000 & .000 \\
\hline 1 & 1 & 14 & .000 & .510 & .000 & .509 & .000 & .000 & .000 & .000 \\
\hline 1 & 1 & 15 & .000 & .510 & .000 & .509 & .000 & .000 & .000 & .000 \\
\hline 1 & 1 & 16 & .000 & .510 & .000 & .509 & & & & \\
\hline
\end{tabular}

bottom section volumetric and mass flowrates:

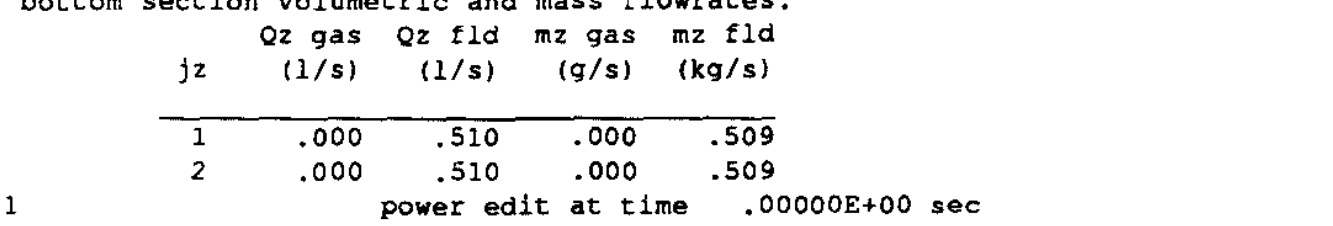

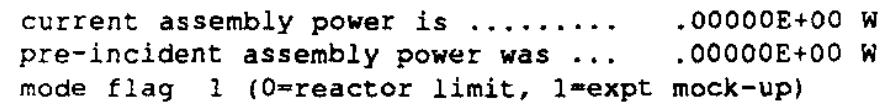

detailed power distributions

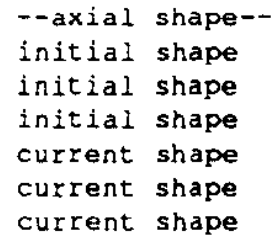

$\begin{array}{llllll}.66667 \mathrm{E}-01 & .66667 \mathrm{E}-01 & .66667 \mathrm{E}-01 & .66667 \mathrm{E}-01 & .66667 \mathrm{E}-01 \\ .66667 \mathrm{E}-01 & .66667 \mathrm{E}-01 & .66667 \mathrm{E}-01 & .66667 \mathrm{E}-01 & .66667 \mathrm{E}-01 \\ .66667 \mathrm{E}-01 & .66667 \mathrm{E}-01 & .66667 \mathrm{E}-01 & .66667 \mathrm{E}-01 & .66667 \mathrm{E}-01 \\ .66667 \mathrm{E}-01 & .66667 \mathrm{E}-01 & .66667 \mathrm{E}-01 & .66667 \mathrm{E}-01 & .66667 \mathrm{E}-01 \\ .66667 \mathrm{E}-01 & .66667 \mathrm{E}-01 & .66667 \mathrm{E}-01 & .66667 \mathrm{E}-01 & .66667 \mathrm{E}-01 \\ .66667 \mathrm{E}-01 & .66667 \mathrm{E}-01 & .66667 \mathrm{E}-01 & .66667 \mathrm{E}-01 & .66667 \mathrm{E}-01\end{array}$

power (W) deposited in metal

o for cylinder number 1

axial level number 1

--azimuth--

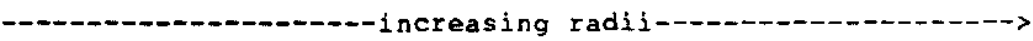
$.00000 \mathrm{E}+00 \quad .00000 \mathrm{E}+00 \quad .00000 \mathrm{E}+00$

axial level number 2

--azimuth--

axial level number 3

$$
1 \quad .00000 \mathrm{E}+00 \quad .00000 \mathrm{E}+00 \quad .00000 \mathrm{E}+00
$$

--azimuth--

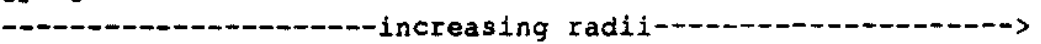
$.00000 \mathrm{E}+00 \quad .00000 \mathrm{E}+00 \quad .00000 \mathrm{E}+00$

axial level number 4 


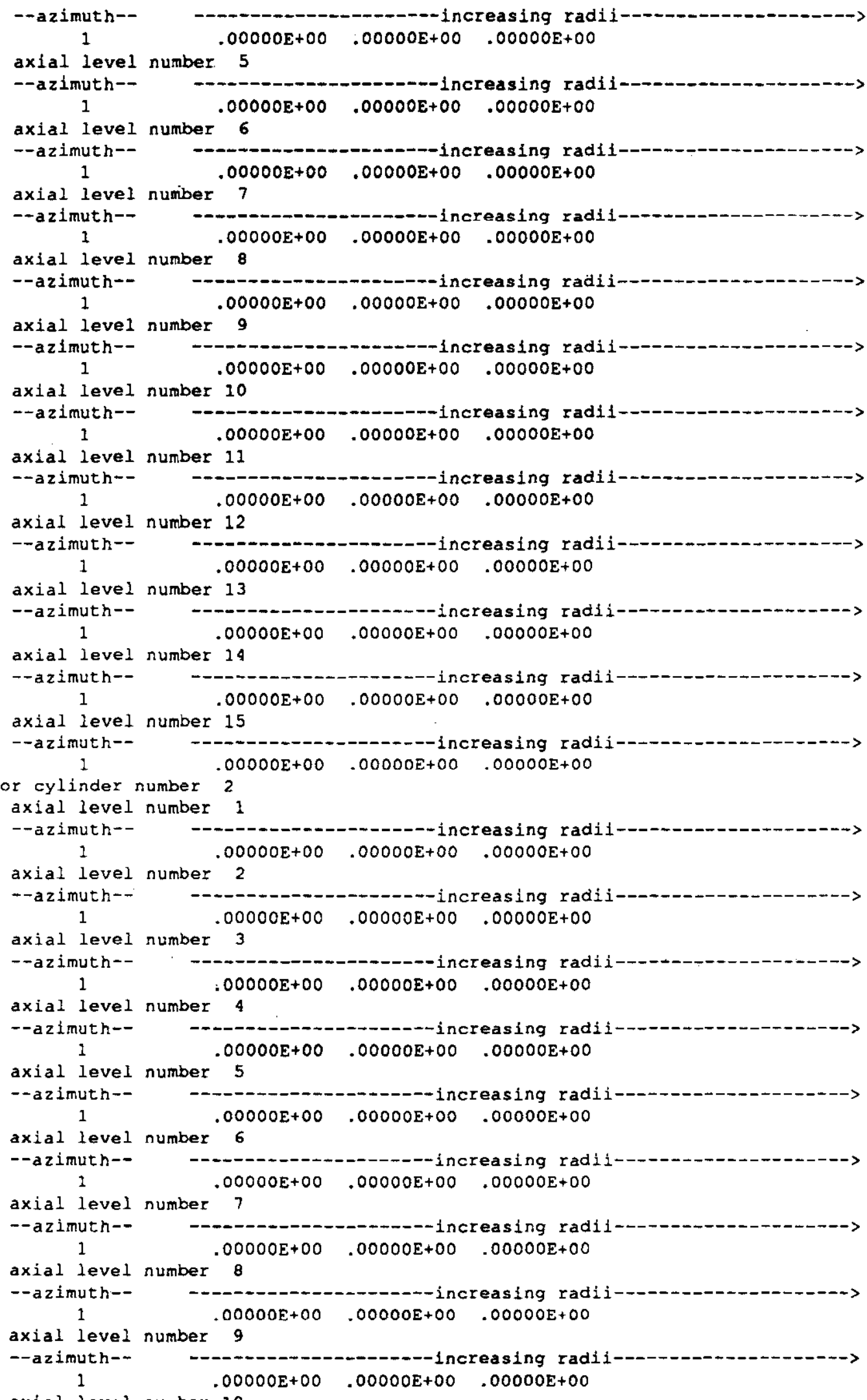

axial level number 10 


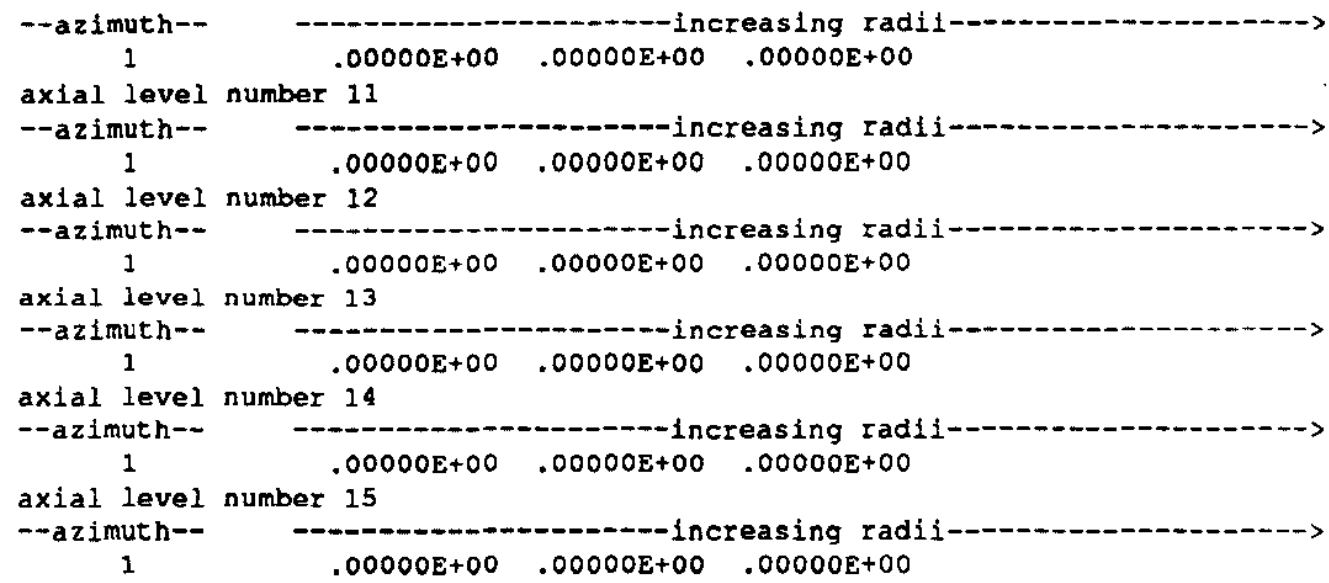

$\begin{array}{rlrl}\text { Is fluid edit at time } & =55.116 & \text { seconds } \\ \text { time step size } & =.14188 & \text { seconds } \\ \text { Courant step size } & =.14188 & \text { seconds } \\ \text { Section (1-T,2-M,3-B) } & = & & 1 \\ \text { Channel (O for T/B) } & = & 0 \\ \text { Axial } & = & & 2 \\ \text { Azimuthal } & = & \end{array}$

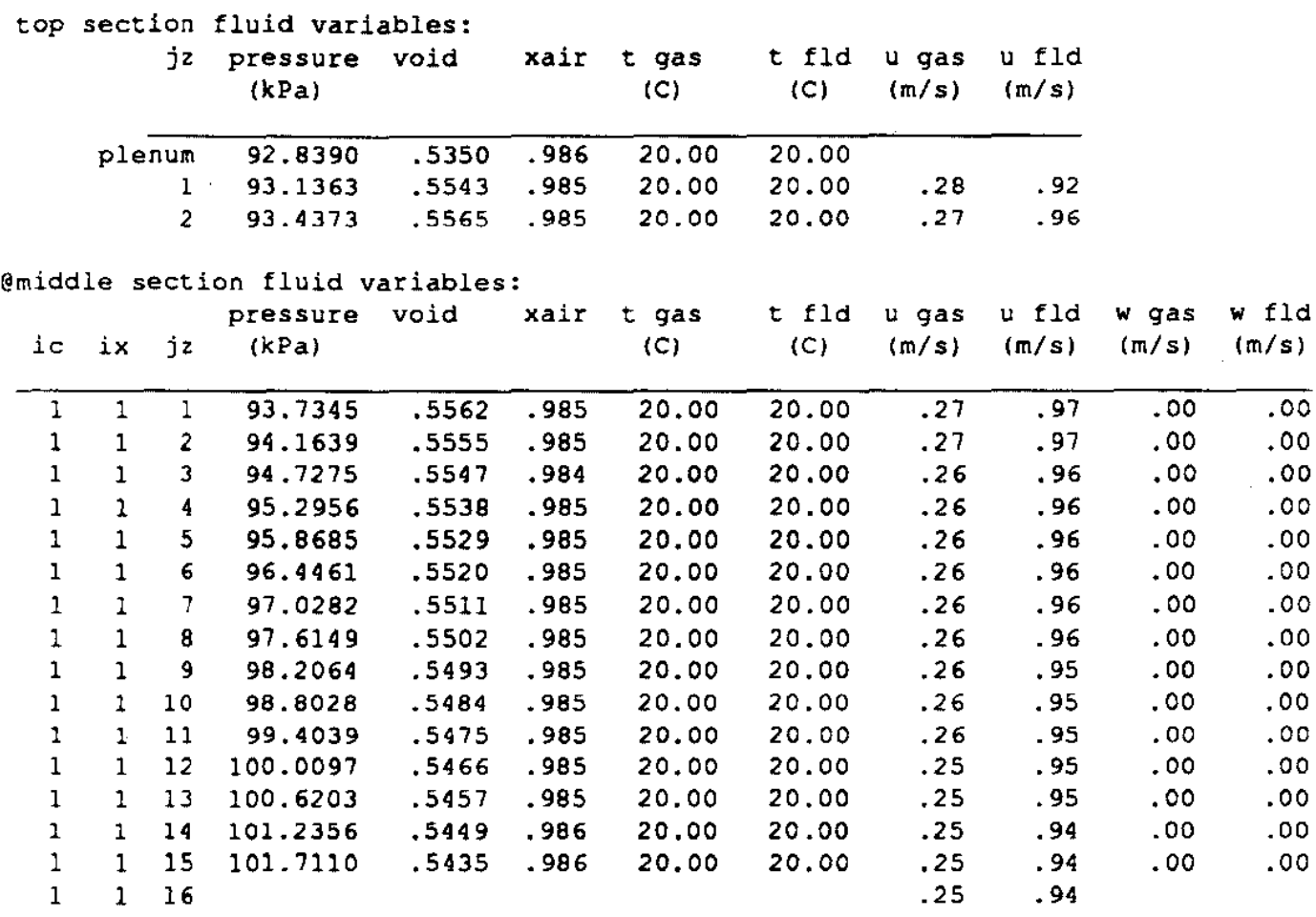

bottom section fluid variables: $j z$ pressure void xair $t$ gas $t$ fld u gas u fld (KPa) (C) (C) $(\mathrm{m} / \mathrm{s})(\mathrm{m} / \mathrm{s})$

\begin{tabular}{rrrrrrrr}
\hline 1 & 102.0455 & .5419 & .986 & 20.00 & 20.00 & .25 & .94 \\
2 & 102.3847 & .5393 & .986 & 20.00 & 20.00 & .25 & .93 \\
tank bot. & 102.7310 & .5350 & .986 & 20.00 & 20.00 & &
\end{tabular}




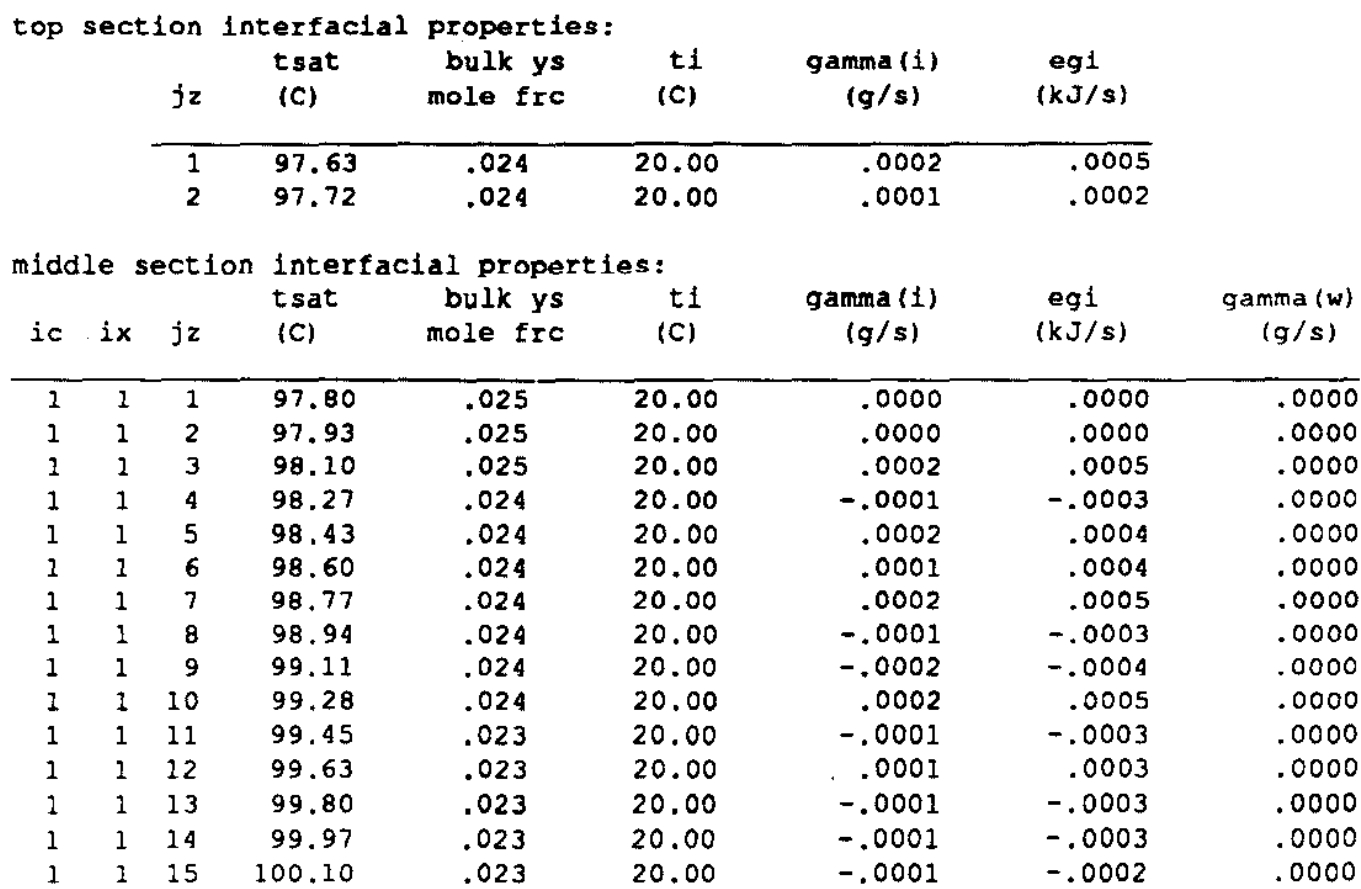

bottom section interfacial properties:

\begin{tabular}{llcccc}
$j z$ & $\begin{array}{c}\text { tsat } \\
\text { (C) }\end{array}$ & $\begin{array}{c}\text { bulk ys } \\
\text { mole frc }\end{array}$ & $\begin{array}{c}\text { ti } \\
\text { (C) }\end{array}$ & $\begin{array}{c}\text { gamma(i) } \\
(\mathrm{g} / \mathrm{s})\end{array}$ & $\begin{array}{c}\mathrm{egi} \\
(\mathrm{kJ} / \mathrm{s})\end{array}$ \\
\hline 1 & 100.20 & .023 & 20.00 & .0001 & .0002 \\
2 & 100.29 & .023 & 20.00 & -.0001 & -.0001
\end{tabular}

top section densities and enthalpies:

\begin{tabular}{rrrrr}
$j z$ & $\begin{array}{c}\text { rho gas } \\
\left(\mathrm{kg} / \mathrm{m}^{\wedge} 3\right)\end{array}$ & $\begin{array}{c}\text { rho fld } \\
\left(\mathrm{kg} / \mathrm{m}^{\wedge} 3\right)\end{array}$ & $\begin{array}{c}\mathrm{h} \text { gas } \\
(\mathrm{kJ} / \mathrm{kg})\end{array}$ & $\begin{array}{c}\mathrm{h} f \mathrm{fld} \\
(\mathrm{kJ} / \mathrm{kg})\end{array}$ \\
\hline 1 & 1.09 & 997.84 & 324.566 & 83.216 \\
2 & 1.10 & 997.84 & 326.808 & 83.215 \\
plenum & 1.20 & 997.84 & 327.529 & 83.215
\end{tabular}

middle section densities and enthalpies:

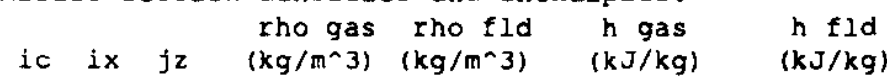

\begin{tabular}{lllllll}
\hline 1 & 1 & 1 & 1.10 & 997.84 & 327.744 & 83.215 \\
1 & 1 & 2 & 1.11 & 997.84 & 327.679 & 83.215 \\
1 & 1 & 3 & 1.12 & 997.84 & 327.957 & 83.214 \\
1 & 1 & 4 & 1.12 & 997.84 & 327.567 & 83.215 \\
1 & 1 & 5 & 1.13 & 997.84 & 327.544 & 83.214 \\
1 & 1 & 6 & 1.14 & 997.84 & 327.285 & 83.215 \\
1 & 1 & 7 & 1.14 & 997.84 & 327.163 & 83.215 \\
1 & 1 & 8 & 1.15 & 997.84 & 326.699 & 83.215 \\
1 & 1 & 9 & 1.16 & 997.84 & 326.584 & 83.215 \\
1 & 1 & 10 & 1.16 & 997.84 & 326.538 & 83.215 \\
1 & 1 & 11 & 1.17 & 997.84 & 326.108 & 83.215 \\
1 & 1 & 12 & 1.18 & 997.84 & 326.020 & 83.215 \\
1 & 1 & 13 & 1.19 & 997.84 & 325.749 & 83.215 \\
1 & 1 & 14 & 1.19 & 997.84 & 325.510 & 83.216
\end{tabular}


$1 \quad 1 \quad 15 \quad 1.20 \quad 997.84 \quad 325.418 \quad 83.216$

\begin{tabular}{|c|c|c|c|c|c|}
\hline & $j z$ & $\begin{array}{l}\text { rho gas } \\
\left(\mathrm{kg} / \mathrm{m}^{\wedge} 3\right)\end{array}$ & $\begin{array}{l}\text { rho fld } \\
\left(\mathrm{kg} / \mathrm{m}^{\wedge} 3\right)\end{array}$ & $\begin{array}{c}\text { h gas } \\
\text { (kJ/kg) }\end{array}$ & $\begin{array}{c}h \text { fld } \\
(\mathrm{kJ} / \mathrm{kg})\end{array}$ \\
\hline & 1 & 1.20 & 997.84 & 325.450 & 83.215 \\
\hline & 2 & 1.21 & 997.84 & 325.113 & 83.216 \\
\hline $\operatorname{tank}$ & bot. & 1.21 & 997.84 & 324.551 & 83.216 \\
\hline
\end{tabular}

top section volumetric and mass flowrates:

\begin{tabular}{ccccc}
$j z$ & $\begin{array}{r}Q z \text { gas } \\
(1 / \mathrm{s})\end{array}$ & $\begin{array}{r}Q z \text { fld } \\
(1 / \mathrm{s})\end{array}$ & $\begin{array}{r}\mathrm{mz} \text { gas } \\
(\mathrm{g} / \mathrm{s})\end{array}$ & $\begin{array}{c}\mathrm{mz} \text { fld } \\
(\mathrm{kg} / \mathrm{s})\end{array}$ \\
\hline 1 & .177 & .510 & .194 & .509 \\
2 & .177 & .510 & .194 & .509
\end{tabular}

middle section volumetric and mass flowrates:

$Q z$ gas $Q z$ fld $m z$ gas mz fld Qx gas $Q x$ fld $m x$ gas $m x$ fld

ic ix jz $(1 / \mathrm{s}) \quad(1 / \mathrm{s}) \quad(\mathrm{g} / \mathrm{s})(\mathrm{kg} / \mathrm{s}) \quad(1 / \mathrm{s}) \quad(1 / \mathrm{s}) \quad(\mathrm{g} / \mathrm{s})(\mathrm{kg} / \mathrm{s})$

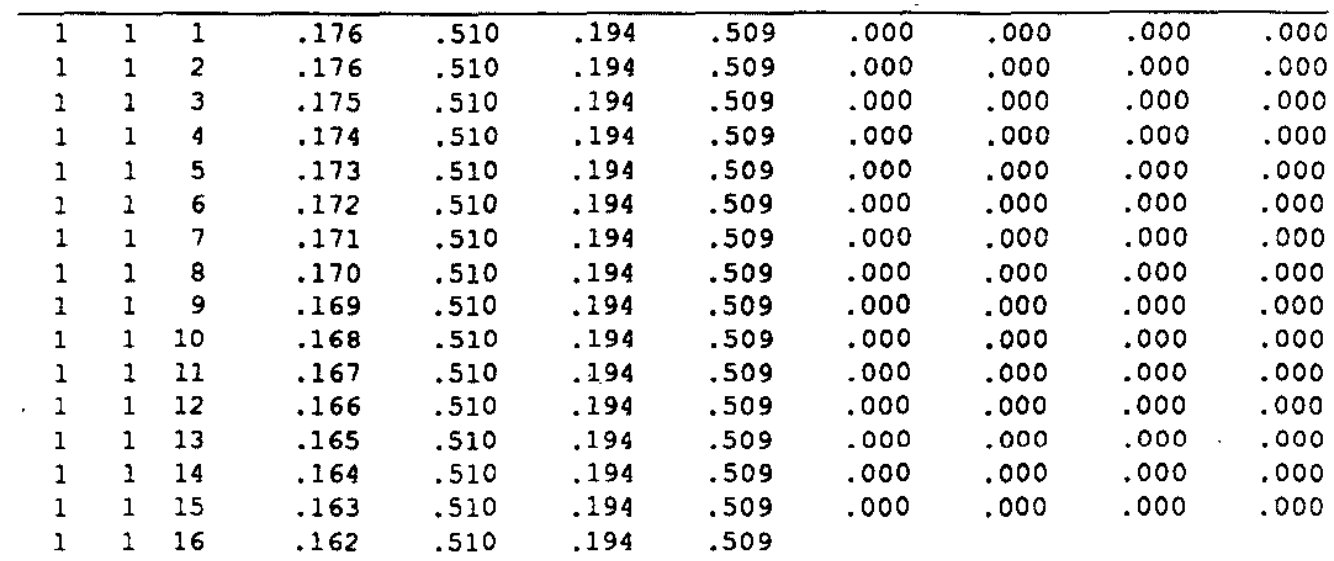

bottom section volumetric and mass flowrates:

\begin{tabular}{|c|c|c|c|c|}
\hline$j z$ & $\begin{array}{r}\text { Qz gas } \\
(1 / \mathrm{s})\end{array}$ & $\begin{array}{c}Q z \text { fld } \\
(1 / s)\end{array}$ & $\begin{array}{r}m z \text { gas } \\
(g / s)\end{array}$ & $\begin{array}{c}\mathrm{mz} \text { fld } \\
(\mathrm{kg} / \mathrm{s})\end{array}$ \\
\hline 1 & .161 & .510 & .194 & .50 \\
\hline 2 & .161 & .510 & .194 & .5099 \\
\hline
\end{tabular}

initial power is zero - a nonzero initial power must be used to calculate power iterations 
The following file saved as test_31_01_m08. out2 was written to unit number 20:

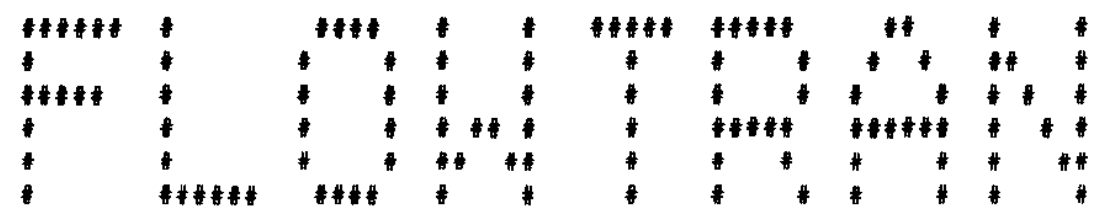
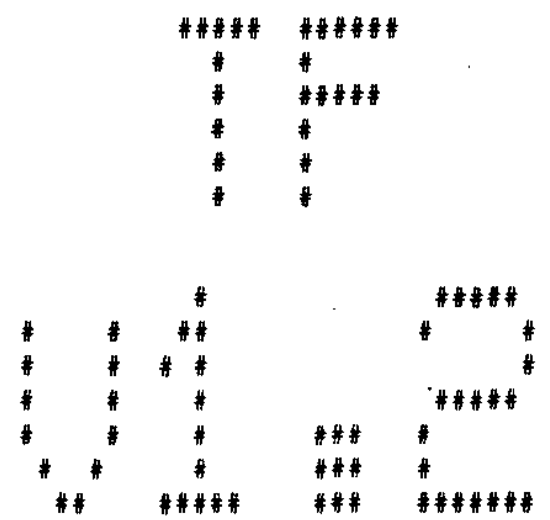

NES Code Management System, TP-92-049, Rev 0

IBM RISC System/6000, Model 530

AIX Version 3 for RISC system/6000, 03.01.0005.0012

IBM AIX XL FORTRAN Compiler, 02.02.0000.0000

Compiler options: -0 -qautodbl=dblpad

Loader options: -berok

Built 29-JAN-1993 by S.E.Aleman e x52986 at 773-11A

Status of Code - TESTING

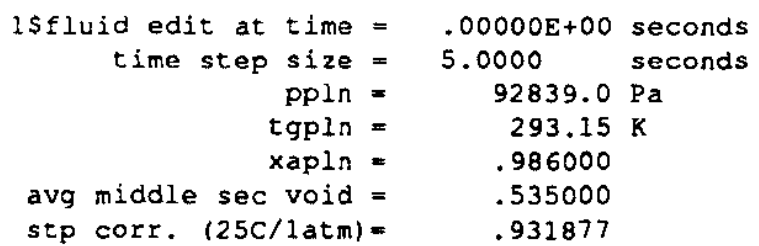

\begin{tabular}{ccccccc}
$j z$ & $j f$ & $j g$ & $j$ & $Q g$ & $Q g$ & \\
$(\mathrm{~m} / \mathrm{s})$ & $(\mathrm{m} / \mathrm{s})$ & $(\mathrm{m} / \mathrm{s})$ & $(\mathrm{cfm})$ & $\begin{array}{c}\text { Qf } \\
(\mathrm{gPm})\end{array}$ & $\begin{array}{c}\text { Qf } \\
(\mathrm{gpm})\end{array}$ \\
\hline 1 & .429 & .000 & .429 & .00000 & .00000 & 8.08911 \\
2 & .429 & .000 & .429 & .00000 & .00000 & 8.08911
\end{tabular}

middle section superficial velocities:

\begin{tabular}{ccccccccc} 
ic $i x ~ j z$ & $\begin{array}{c}j f \\
(\mathrm{~m} / \mathrm{s})\end{array}$ & $\begin{array}{c}j g \\
(\mathrm{~m} / \mathrm{s})\end{array}$ & $\begin{array}{c}j \\
(\mathrm{~m} / \mathrm{s})\end{array}$ & $\begin{array}{c}\text { Qg } \\
(\mathrm{cfm})\end{array}$ & $\begin{array}{c}\text { Qg } \\
(\mathrm{gpm})\end{array}$ & $\begin{array}{c}Q f \\
(\mathrm{gpm})\end{array}$ \\
\hline 1 & 1 & 1 & .429 & .000 & .429 & .00000 & .00000 & 8.08911 \\
1 & 1 & 2 & .429 & .000 & .429 & .00000 & .00000 & 8.08911 \\
1 & 1 & 3 & .429 & .000 & .429 & .00000 & .00000 & 8.08911
\end{tabular}




$\begin{array}{lllllllll}1 & 1 & 4 & .429 & .000 & .429 & .00000 & .00000 & 8.08911 \\ 1 & 1 & 5 & .429 & .000 & .429 & .00000 & .00000 & 8.08911 \\ 1 & 1 & 6 & .429 & .000 & .429 & .00000 & .00000 & 8.08911 \\ 1 & 1 & 7 & .429 & .000 & .429 & .00000 & .00000 & 8.08911 \\ 1 & 1 & 8 & .429 & .000 & .429 & .00000 & .00000 & 8.08911 \\ 1 & 1 & 9 & .429 & .000 & .429 & .00000 & .00000 & 8.08911 \\ 1 & 1 & 10 & .429 & .000 & .429 & .00000 & .00000 & 8.08911 \\ 1 & 1 & 11 & .429 & .000 & .429 & .00000 & .00000 & 8.08911 \\ 1 & 1 & 12 & .429 & .000 & .429 & .00000 & .00000 & 8.08911 \\ 1 & 1 & 13 & .429 & .000 & .429 & .00000 & .00000 & 8.08911 \\ 1 & 1 & 14 & .429 & .000 & .429 & .00000 & .00000 & 8.08911 \\ 1 & 1 & 15 & .429 & .000 & .429 & .00000 & .00000 & 8.08911 \\ 1 & 1 & 16 & .429 & .000 & .429 & .00000 & .00000 & 8.08911\end{array}$

bottom section superficial velocities:

\begin{tabular}{|c|c|c|c|c|c|c|}
\hline$j z$ & $\begin{array}{l}j f \\
(m / s)\end{array}$ & $\underset{(m / s)}{j g}$ & $\underset{(m / s)}{j}$ & $\begin{array}{l}Q 9 \\
(\mathrm{cfm})\end{array}$ & $\begin{array}{l}Q \mathrm{~g} \\
(\mathrm{gpm})\end{array}$ & $\begin{array}{l}\text { Qf } \\
(g \mathrm{pm})\end{array}$ \\
\hline 1 & .429 & .000 & .429 & .00000 & .00000 & 8911 \\
\hline 2 & .429 & .000 & .429 & .00000 & .00000 & 8.08911 \\
\hline
\end{tabular}

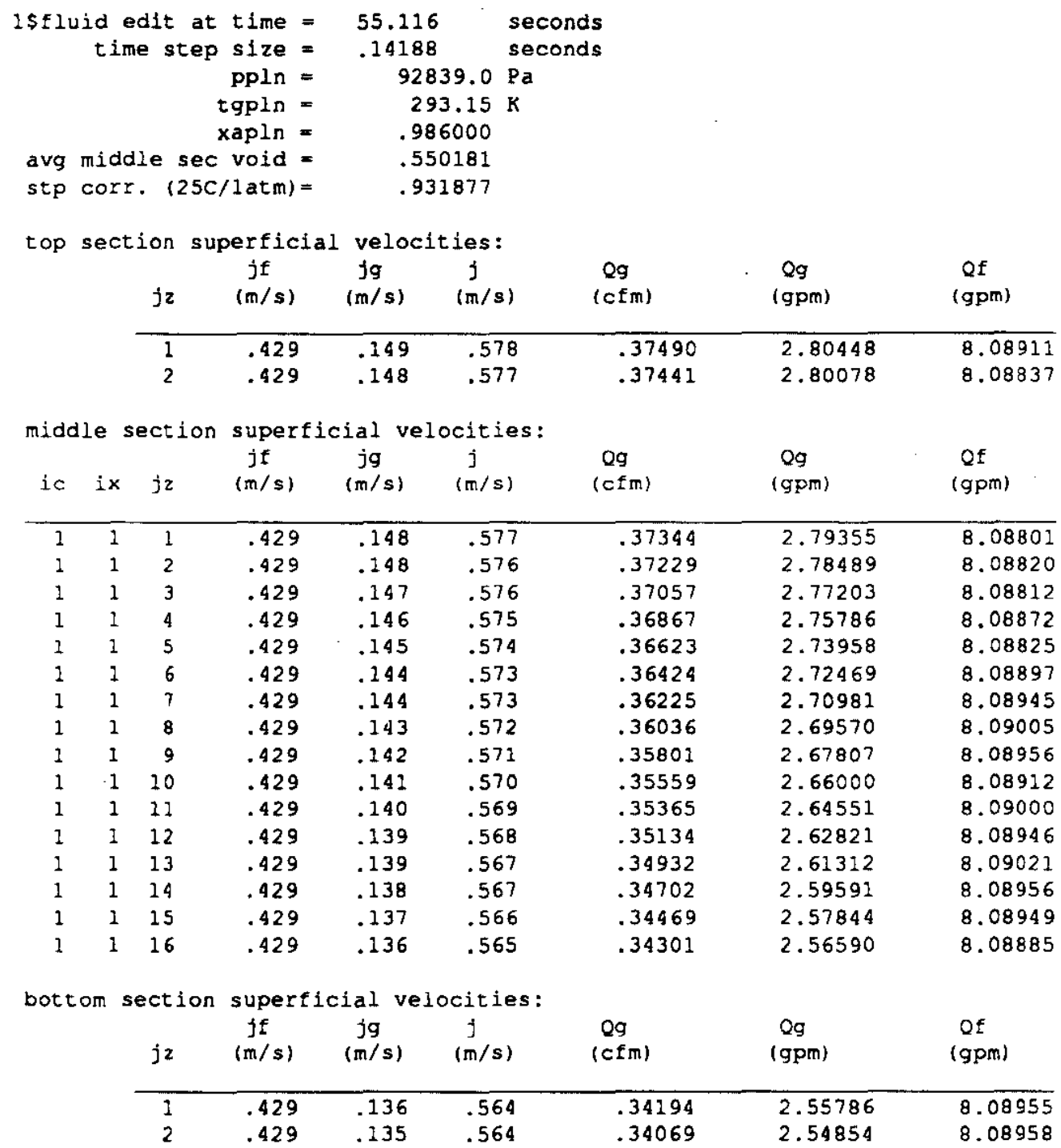


Savannah River Technology Center

S. E. Aleman, 773-11A

F. Beranek, 773-A

R. E. Cooper, 773-11A

D. A. Crowley, 773-11A

R. A. Dimenna, 773-11A

G. P. Flach, 773-11A
A. J. Garrett, 773-A
L. L. Hamm, 773-11A
A. L. Kielpinski, 773-11A
L. D. Koffman, 773-11A
S. Y. Lee, 773-11A
M. A. Shadday, 773-11A

CSA, c/o 773-11A

CDG File (2), 773-11A

Records (2), 773-52A

Savannah River Site

P. S. Shieh, 703-41A

F. G. Smith, 704-1T

T. M. Tran, 703-41A 